


\section{EXPECTING THE UNEXPECTED}

REDEFINING THE HOME TO ADAPT TO THE LIFETIME REQUIREMENTS OF ITS OCCUPANTS

SARAH GROOM

2017 



\section{EXPECTING THE UNEXPECTED}

REDEFINING THE HOME TO ADAPT TO THE LIFETIME REQUIREMENTS OF ITS OCCUPANTS

SARAH GROOM

A 120-point thesis submitted to the Victoria University of Wellington in partial fulfilment of the requirements for the degree of Master of Architecture (Professional).

Victoria University of Wellington, School of Architecture. 

What happens when the home expects the unexpected?

Since the beginning of the current housing price rise in 2012, homeownership in New Zealand has become increasingly difficult. The desire to enter the property market has been impeded by the unsuitability of current housing stock that no longer meets the needs of the modern household.

While it is widely accepted by economists, yet denied by politicians, New Zealand is amid a housing crisis. The government is addressing the issue by introducing a means to allow housing to be produced more quickly. This new housing is expected to mitigate the issues surrounding a shortage of land and population increase, by developing a large proportion of new developments in the classification of medium density housing.

With a shortfall of 10,000 houses per annum, the current situation presents an opportunity to reassess how medium density housing $(\mathrm{MDH})$ is configured in New Zealand. To break the cycle of housing stock rendering itself unsuitable in the future, this thesis aims to investigate how housing could be designed to allow for change over time.

All age groups stand to benefit from a home that is carefully planned and considers their lifetime needs. An established design framework enables the prefabricated modular system to adapt, reflecting the lifetime requirements of its occupants.

The outcome is an innovative, alternate design solution that considers the wellbeing of occupants through a lifetime design approach, offering adaptability and efficient production through prefabrication.

A home that expects the unexpected. 

To my Supervisor Morten,

Thank you for your guidance and support throughout this year.

To my Mum and Dad, and sisters Aimee and Kaitlin, Thank you for always selflessly supporting and encouraging me to help get me where I am today. I am truly grateful for all that you have done.

To my Partner Ben,

Thank you for your endless support throughout the past five years at University and beyond.

To all my friends and family,

Thank you for your encouragement and the good times.

And to my classmates and friends of 2016,

We did it. 



\section{TABLE OF CONTENTS}

01 INTRODUCTION

02 SITE ANALYSIS

03 LITERATURE REVIEW

04. PROJECT REVIEW

05 PRELIMARY DESIGN

39

06 DEVELOPED DESIGN

63

07 CONCLUSION + CRITICAL REFLECTION

85

Abstract

Acknowledgements

Table of Contents
Works Cited

89

Appendices

95

List of Figures

105 



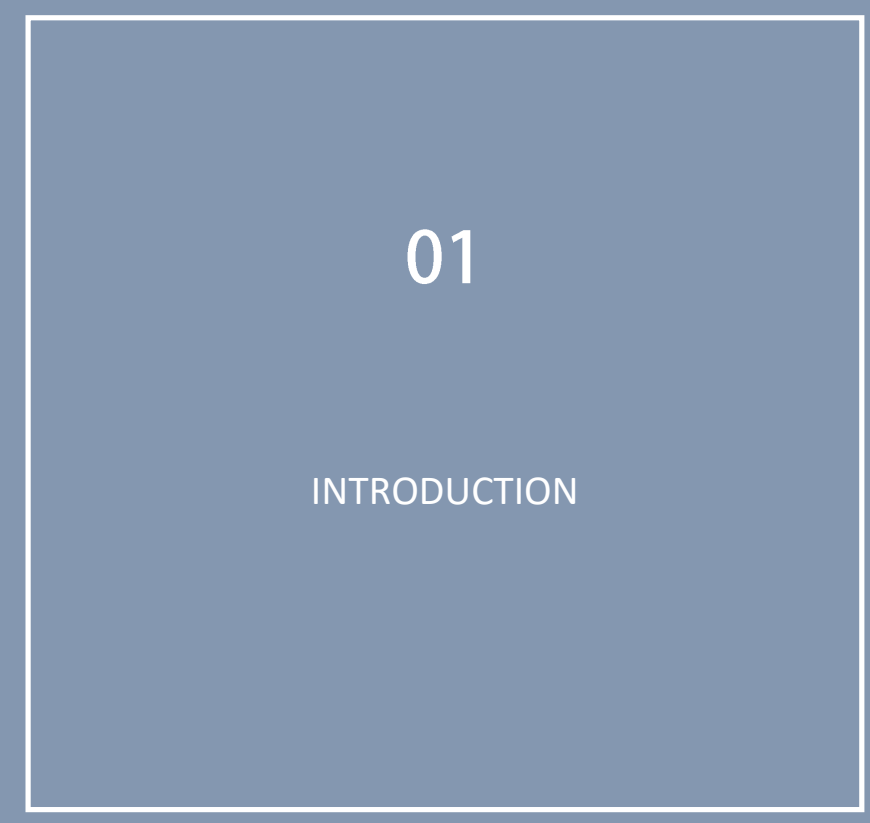





\section{INTRODUCTION | PROBLEM}

1. 0

While it is widely accepted by economists that New Zealand is amid a housing crisis, the government refuses to accept that the housing situation has reached crisis point. The severe housing shortage has seen an unprecedented rise in house prices in all areas of the market.

Despite government efforts to increase housing supply by increasing the rate at which housing is be produced, it is estimated that New Zealand is facing a shortfall of 10,000 dwellings per annum. (Bassett and Malpass i) Land shortages have fuelled the crisis, calling for a demand to intensify residential living through medium density housing.

Current housing stock, typically designed for the nuclear family of the 1950s, is struggling to meet the needs of the evolving household dynamic. The need for change comes as new findings confirm Gen-Y demographics are swaying from past norms; where they are opting to have children later, fewer children in total and masses of debt amounting from loans delaying owning a home all together. (MacPherson)

Increased life expectancy is contributing to the size of the elderly population. It has been estimated that the population of New
Zealanders aged over 65 years will have increased by $166 \%$ to reach 1.15 million by 2050. (Bulleyment 5)

With such varying demand in the housing market, an adaptable, universally accessible design will stand to benefit people of all age groups. Creating housing that is appropriate for different age groups and abilities, means creating housing that is adaptable over time.

This design-led research is motivated by the question; how can the home be redefined to adapt to the changing needs of its occupants?

\section{AIMS + OBJECTIVES}

1. 1

The aim of this thesis is to explore an adaptable home designed to meet the lifetime needs of its occupants.

To achieve adaptability of the home, prefabrication of modular units allows for a universal design with standardised openings. These specifically located openings, windows or doors create potential to expand or contract the home as circumstances change in the future.

Prefabrication of standardised façade panels also facilitates the aim of an adaptable home, allowing the addition of units to be possible without waste or extensive onsite construction. 
This research proposes an alternative housing solution that considers the occupants' wellbeing over their lifetime. A universal design will also ensure the wellbeing of occupants over time, with provisions in place if an occupant were to become wheelchair bound.

Wellbeing can be improved by ensuring a high level of residential amenity within a medium density context that aims to create a community environment. Recently published results of the Dunedin Longitudinal Study in the documentary 'Why Am I?', suggests that "Ioneliness, stress and isolation in early life are directly correlated to deteriorated health in later life. Not only are these factors detrimental to the mental health and wellbeing of people, but to their physical health as well. (McNeill)

If an adaptable housing typology could seek to integrate people into a community over their lifetime to establish a sense of belonging, it could be possible to reduce the effect of ill health in later life. The benefits of this could be vital to relieving strain on public facilities and aged care in the future as the population of elderly is set to boom by 2050 .

Designed to accommodate the changing needs of the household dynamic, this possible housing solution is understood to be a potential solution to the issues that have been identified. The design is not intended to be a housing solution capable of meeting the needs of everyone, rather those who are facing some of the issues outlined.

The thesis aims to arrive at a possible solution that will intensify suburbs efficiently through medium density housing. Producing housing through prefabricated modular units offers an accelerated delivery approach and establishes an infrastructure for universal design to allow for adaptability over a lifetime. 


\section{THESIS STRUCTURE}

1.3

This design-led thesis is structured sequentially to illustrate the iterative nature in which this research has been conducted.

Chapter One provides an overview of the thesis, outlining the motives for the research and the subsequent research questions, aims, and objectives. This chapter also situates the research within the discipline and addresses the methods used to validate the purpose of the research.

Chapter Two provides a critical site analysis of the selected context in Karori, Wellington. The site at 300-318 Karori Road is selected for its suitability to address the site-specific problems of the research. This chapter outlines the physical characteristics of the site including topography, solar exposure, access and other environmental conditions that are to be addressed by the design experiments.

Chapter Three establishes a theoretical framework to address and resolve the issues of ageing in place, wellbeing through residential amenity and prefabrication as a vehicle to produce an adaptable home. The design experiments are then assessed against the resulting framework to further the research and produce new findings within a medium density context.

Chapter Four investigates the following key design precedents that represent design approaches to resolve the issue of adaptable housing. Considerate of wellbeing through public amenity, all three case studies have utilized prefabricated modular designs, giving weight to the benefits of this construction method. The findings are assessed on their relevance to the scope of the research, with the key findings used to establish a strategic set of design principles to inform the design experiments.

Chapter Five tests the theoretical and design studies through a series of design experiments. The Preliminary Design chapter is structured through iterative testing, where each iteration is assessed against the aims and objectives to build upon one another and incorporate the relevant findings from the literature and case study reviews to arrive at a design solution.

Chapter six integrates all previously successful design experiments into a cohesive design outcome that represents a solution to the research question, 'how can the home be 
redefined to adapt to the changing needs of its occupants?' The aims and objectives of the investigation are also met by the developed design in this chapter before concluding by appraising the strengths and weaknesses of the developed design experiment.

Chapter Seven reflects on the outcome and findings of the thesis, concluding with a critical reflection on the design in relation to the scope of the research. The constraints and limitations of the findings are also assessed to understand how this study may advance further in future if extended beyond the original scope. 


\section{APPROACH}

1.4

This thesis has been driven by design-led research. The relevance of theoretical research and case study findings have been assessed and translated through hand-sketching and digital and physical modelling. Design through physical modelling has added dimension and form to the design that is highly valuable to realising a solution at the human scale.

Design experiments are critically evaluated against the research question, aims and objectives at each stage of the development process to arrive at a culmination in the preliminary and developed design.

The validity of sources has been assessed on the theorists' credentials and contributions to the discipline. The culmination of theoretical research in the literature review in the areas of prefabrication, ageing in place and wellbeing through residential amenity have each been influenced by a leading theorist.

Leading theorists who have entwined adaptability and flexibility with prefabrication are Tatjana Schneider and Jeremy Till. The award-winning collaboration of the two British Professors and academics has led to the works "Flexible housing: opportunities and limits" and "Flexible housing: the means to the end". Both articles have been presented the RIBA Presidents Award for Outstanding Research, giving weight to the opinions and findings that have been influential in positioning the thesis.

Dr Judith Davey, former Director of the New Zealand Institute for Research on Ageing (NZiRA) from 2002 to early 2007, informs research surrounding ageing in place. The article "Ageing in place: the views of older homeowners on maintenance, renovation and adaptation" for the Social Policy Journal of New Zealand 27 (2006) provides the framework for understanding the needs of elderly in a universal, lifetime design for the home. This also ensures wellbeing in later life and is easily merged with the framework that has arisen from the text, "Housing as if People Mattered" by Clare Cooper Marcus.

Clare Cooper Marcus is a Professor Emerita at the University of California, Berkley. Internationally recognized for her research on the social and psychological implications of design, particularly urban open space, affordable housing, outdoor space in healthcare, and environments for children and the elderly.

Marcus addresses a set of design guidelines aimed to improve the residential amenity of housing. This is a highly influential text that forms the basis of the framework for wellbeing in a residential setting. This literature is furthered throughout this thesis to implement the findings within an adaptable, medium density housing environment. 
The resulting framework is built upon to engage new ways of solving issues such as the fundamental of residential amenity (eg. privacy, light, natural ventilation and outdoor space), adaptability using prefabrication and ageing in place in a medium density context. These guidelines form the framework that design experiments will be evaluated against.

The following methodology diagram in figure 1.4.1, illustrates the iterative process this thesis has followed to arrive at the design outcomes. 


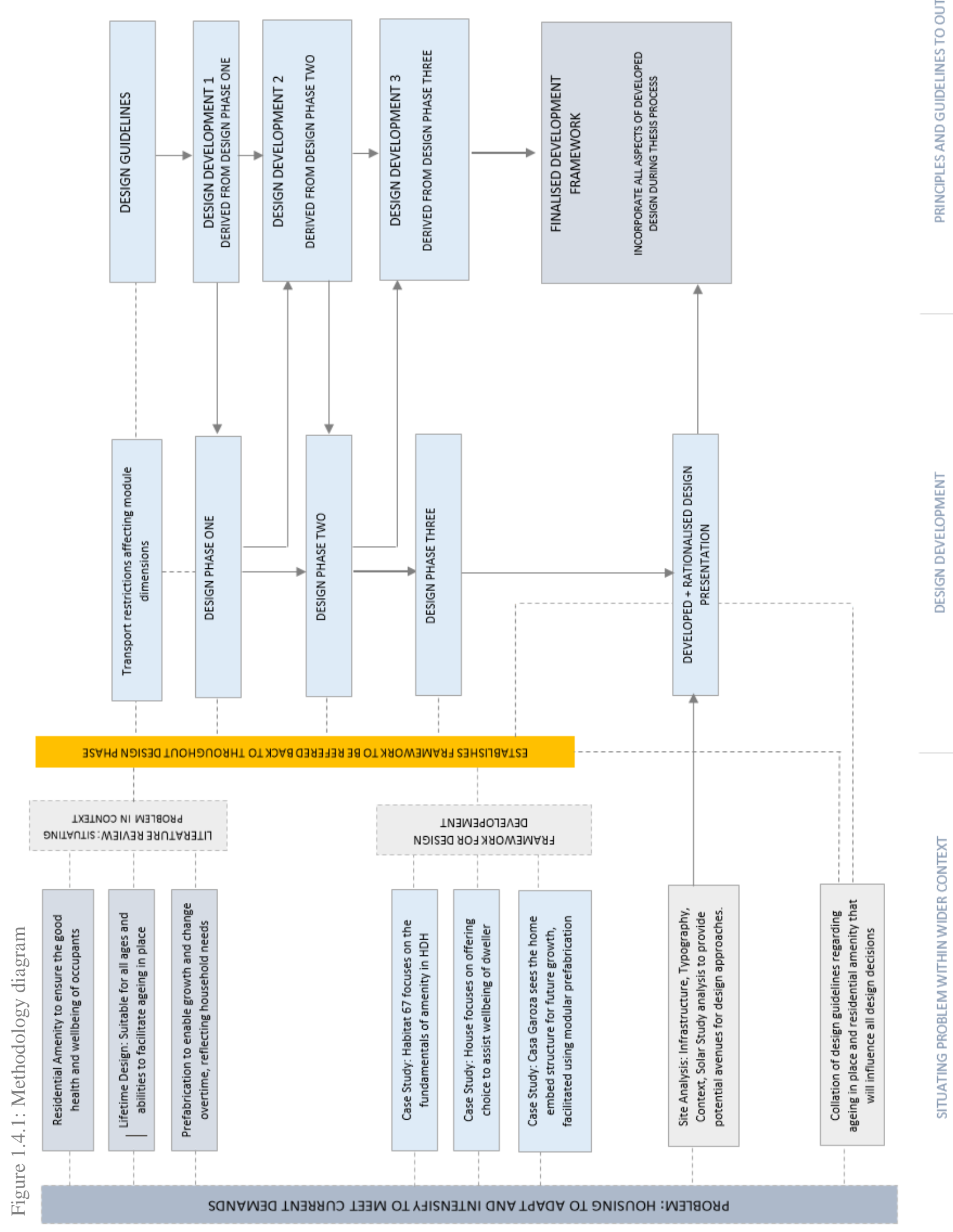




\section{SCOPE/ LIMITATIONS}

1.5

This research does not propose to solve the adaptable home to a level of resolution that would be required to take the design through to construction. Rather, it aims to tackle the tectonic, social and environmental issues of a universal, lifetime design that considers the wellbeing of its occupants.

The scope of the design is limited to resolving issues surrounding the tectonics of the home adapting over time, such as the meeting of an additional module with an existing module. To resolve this issue, a removable façade panel has been created and the material composition understood to complete the exterior of the home with provisions to expand in the future.

Ageing in place is also addressed through adaptability of the home offered by the prefabricated construction of the home. Panelised infill allows the owners to separate the upper floors from the ground floor for a change of ownership or multigenerational living. Adaptability is approached by embedding the ability to change and grow into the design. Standardisation of the modules carries the potential for future growth or minor changes to facilitate ageing in place.
Wellbeing addressed in terms of theoretical and case study findings surrounding the fundamentals of residential amenity as opposed to statistics based assessment. Costing of the design is not included within the scope of the research. However, affordability is briefly addressed in terms of the choices for change offered by the adaptable home. For example, unlined walls exposing the crosslaminated timber (CLT) construction can reduce costs of the initial build. Similarly, provisions made through standardisation of openings and removable façade panels can decrease the cost of possible future expansion.

This project does not create new methods of construction. Rather, the design utilizes previously discovered methods of prefabrication which have already been developed and proven to be efficient in New Zealand construction. The modular prefabrication of the home allows a high level of flexibility in the layout of the home after the initial construction is completed, to see the home adapt to needs as they change in the future. 


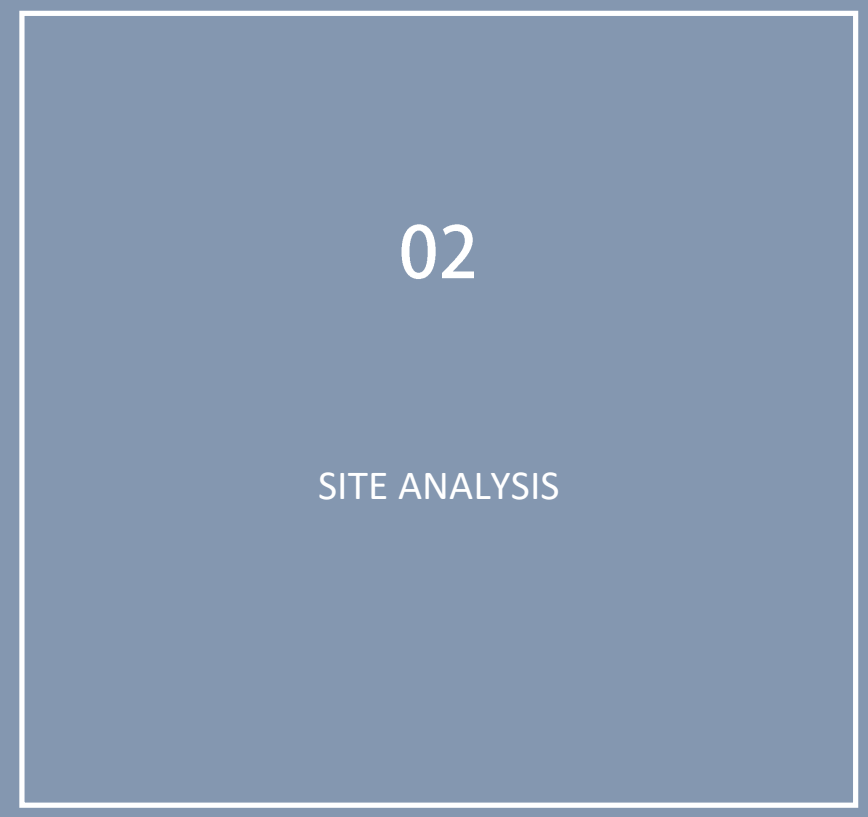


SITE ANALYSIS

2.0

INTRODUCTION | 2.1

Wellington City is continuing to experience population growth resulting an estimated 21,400 additional good quality homes required by the year 2043. Wellingtonians' changing needs and preferences, such as aging in place, lower maintenance properties and smaller households can be met by medium density housing.

The suburb of Karori has been identified by the Wellington City Council (WCC) as a commercially viable option for developers to produce targeted medium density housing $(\mathrm{MDH})$ at an affordable price. The introduction of $\mathrm{MDH}$ is expected to meet immediate demands and cope with the expected population boom of people aged over 55 . (Wellington City Council)

The selected zone for future $\mathrm{MDH}$ developments within the suburb of Karori has been limited to an area identified as the MDRA zone, as outlined in figure 2.1.3, by the Wellington City Council.

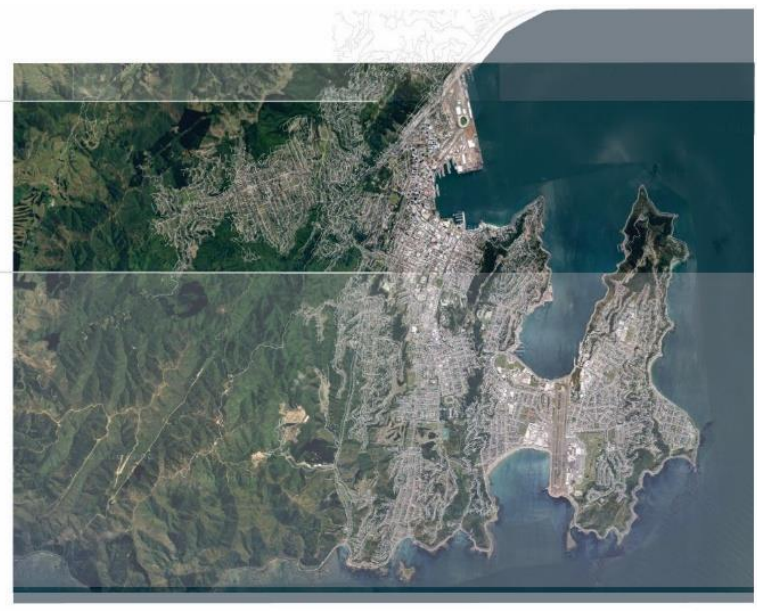

Figure 2.1.1: Map of Wellington City.

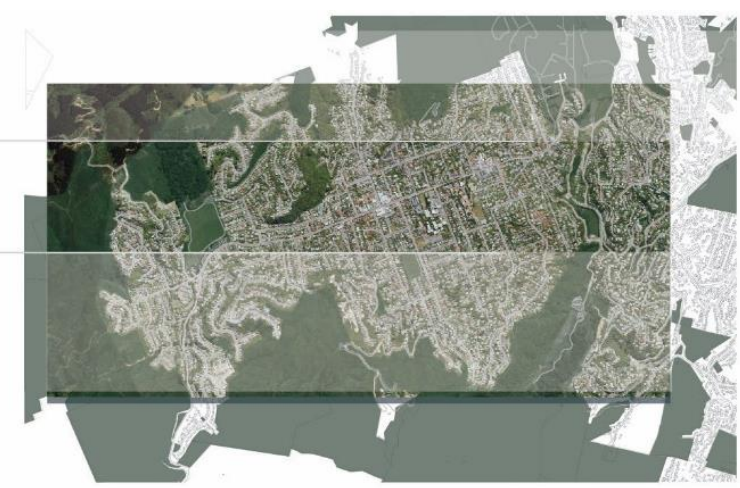

Figure 2.1.2: Map of Karori suburb.

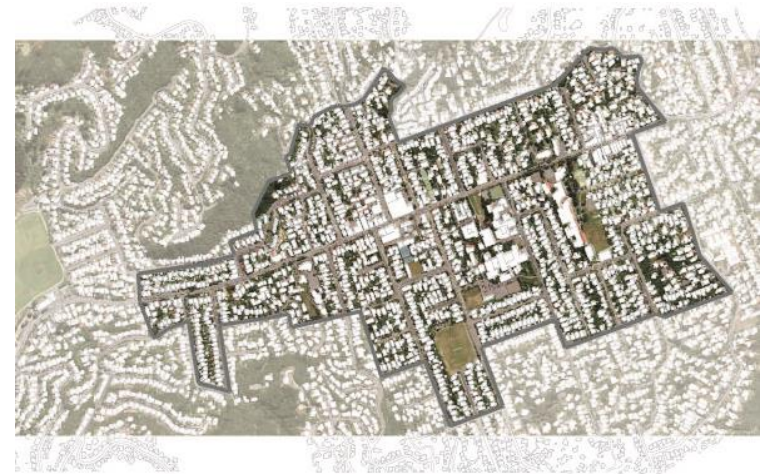

Figure 2.1.3: Map of Karori Road: MDRA selected Zone.

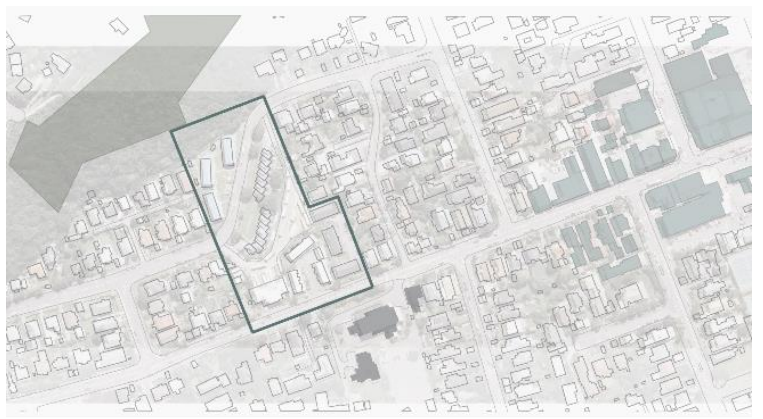

Figure 2.1.4: Map of selected site, 300-318 Karori Road. 
The selected site, shown in figure 2.1.4, is currently home to the Karori Bus Terminal and poorly designed low-medium density flats as pictured in the figure series 2.2.1 below. The segregated environment created by the mixeduse site will be redeveloped to intensify through $\mathrm{MDH}$ and create a positive environment that considers the needs of all age groups.
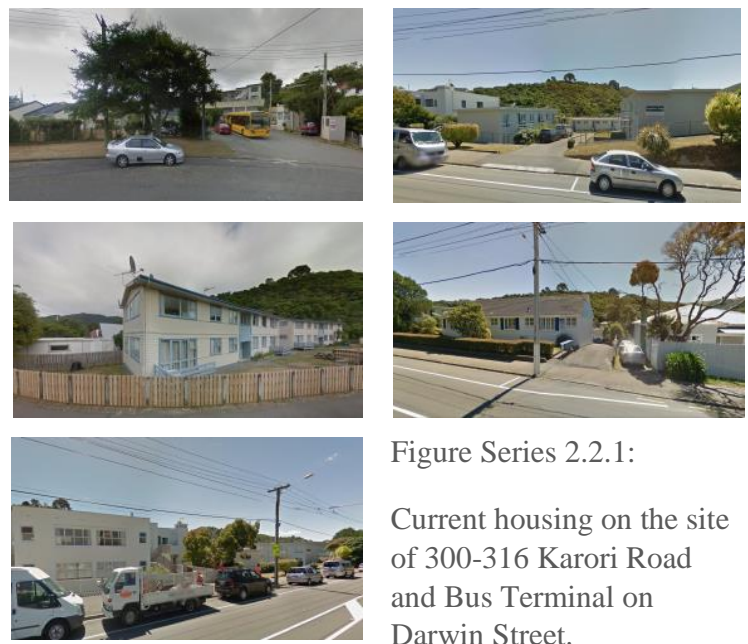

Figure Series 2.2.1:

Current housing on the site of 300-316 Karori Road and Bus Terminal on Darwin Street.

The community of Karori has been consulted at all stages of the MDH proposal and invited to submit feedback in response to the proposal. The draft district plan change received 216 submissions with $34 \%$ in opposition due to concerns including of loss of existing character.

Other feedback requested any new housing to be of high quality, preferred two storey dwellings over three, close to the town centre and public transport routes. (Wellington City Council)

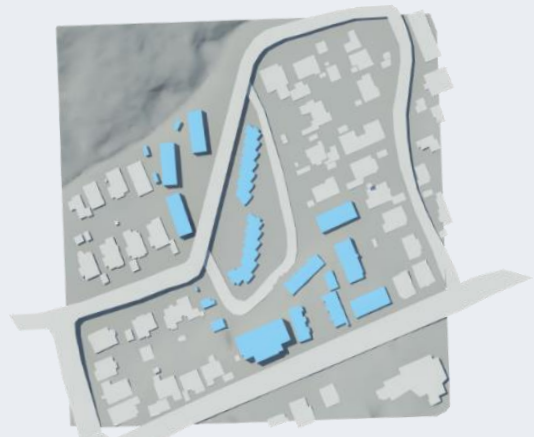

SUMMER SOLSTICE
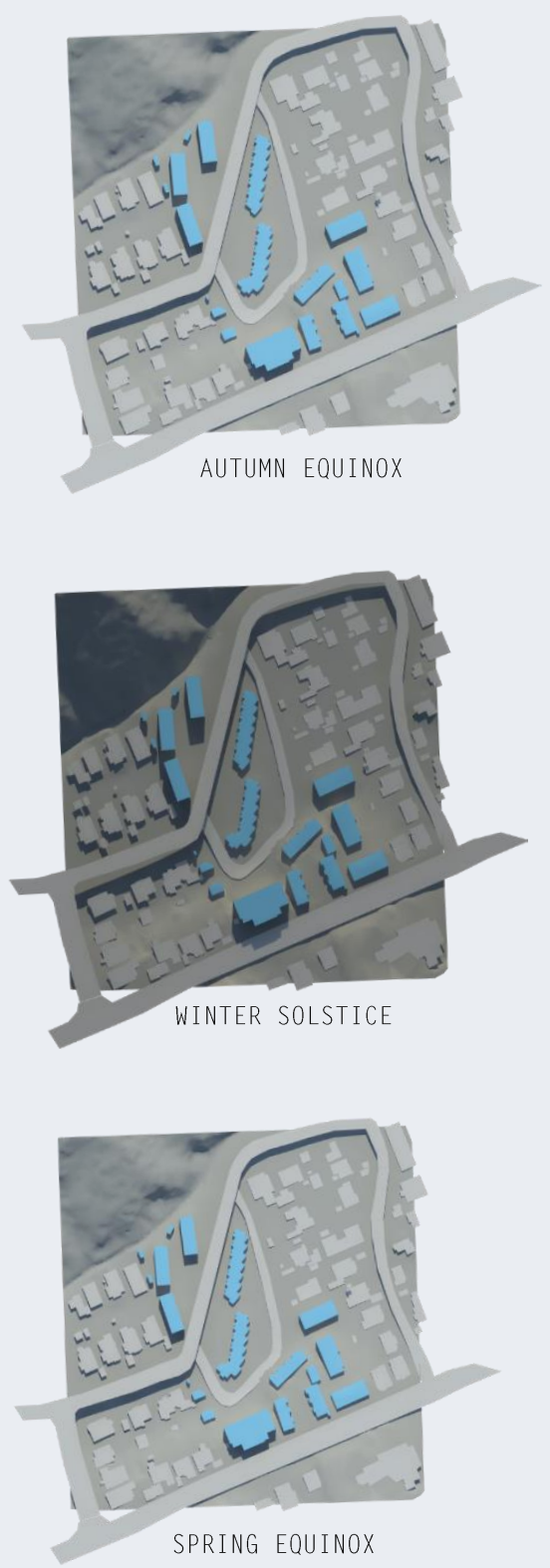

Figure Series 2.2.2:

Solar studies of the existing site throughout the year. Taken on the Summer solstice, Autumn equinox, Winter solstice, Spring equinox. 
Located on Karori Road, the context is ideal for addressing the research question and aims of this research; to explore an adaptable home designed to meet the lifetime needs of its occupants, due to its proximity to public amenities.

The three issues addressed by the aims and objectives to provide an adaptable solution to meet the lifetime requirements include:

- prefabrication to allow for adaptability,

- wellbeing of residents considered through residential amenity and

- a universal design that assists ageing in place.

The site is within five minutes walking distance of the town centre as indicated in figure 2.3.2, which has a variety of supermarkets, shops, healthcare, educational and public facilities benefiting all age groups. The existing infrastructure assists the aim to achieve a lifetime appropriate housing development considerate of wellbeing. Good access to public transport networks ensure connection to the wider community and city to mitigate isolation.
It has been found that loneliness has a detrimental effect on both the physical and mental health in later life, which in turn strains the already limited public care facilities. (McNeill) Good access to community facilities including schools, libraries, parks, doctors and shops, makes this location ideal for young families and elderly alike. Meeting their needs not only within the home, but also the community.

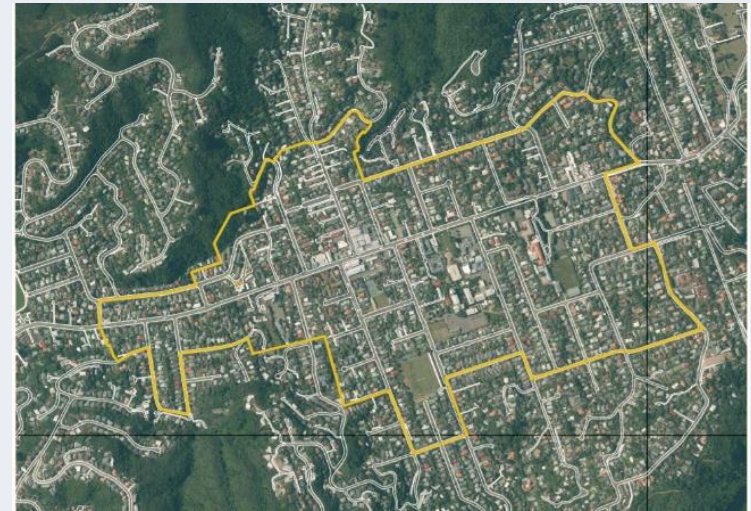

Figure 2.3.1: Map of MDRA zone. Identifies the most suitable zone for MDH developments to be introduced. Source: (Wraight + Associates Limited)

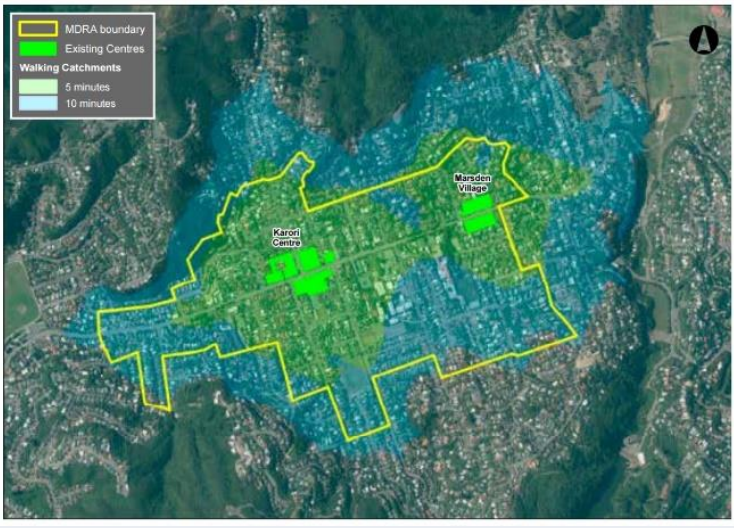

Figure 2.3.2: Map of MDRA zone justifying its suitability in terms of public amenity. Map indicates that the selected site is within five minutes walking distance to the town centre. Source: (Wraight + Associates Limited) 
The environmental factors of the site are largely dictated by the topography, which if not correctly addressed, would adversely affect the wellbeing of residents. Solar access, orientation and access for the ageing population all rely on the gradient of the site. As the gradient of the site increases, it becomes less accessible for the elderly and wheelchair users. This directly influences the form of the home to be internally level or have the appropriate provisions in place should someone become wheelchair bound. It is essential that the topography is addressed in conjunction with the aim of a lifetime appropriate home and the intention to have a positive impact on wellbeing.

The proposed development lies south of a hill of Department of Conservation protected greenery as inidcated in the solar studies of figures 2.3.4 and 2.3.5. While this provides a refreshing outlook, it is also detrimental to the health of current residents as the lack of sun encourages the growth of mould and mildew.

Careful consideration is given when creating a new masterplan of the site. Orientation to the sun is vital for ensure the good health and wellbeing of residents as well as reducing the ongoing costs of the home, employing passive heating and ventilation systems.

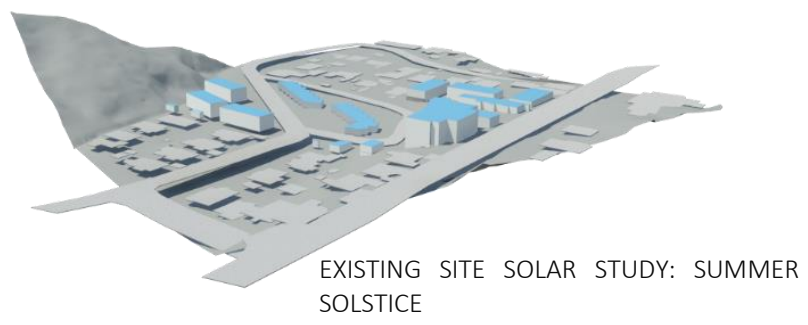

Figure 2.3.4: Perspective render of existing site to highlight solar access during the summer solstice.

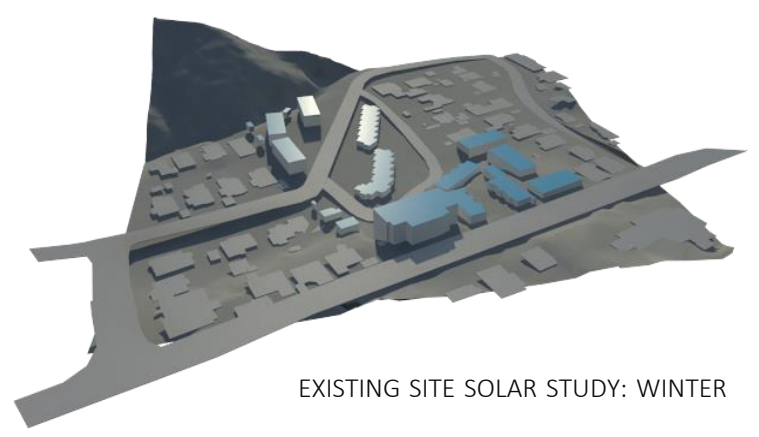

Figure 2.3.5 Perspective render of existing site to highlight solar access during the winter solstice to evaluate the most efficient layout and orientation of homes. 
The proposed MDH development is located is within the boundary of the urban centre. The character of this area remains relatively undefined with community, educational, recreational buildings and other public amenities. On the fringes of the town centre, some larger public amenity buildings such as churches and schools are scattered throughout low density housing.

The building heights, grain, age and character are inconsistent within this zone, highlighting its suitability for $\mathrm{MDH}$. The site is located with the zone for MDRA proposed housing by The Karori Character Assessment Report produced by Wraight + Associates Ltd for the Wellington City Council, who also recommend that within this zone, "typology and a wide variety of land use give this area an inconsistent character and make this area's character resilient to intensification" (Wraight and Associates).

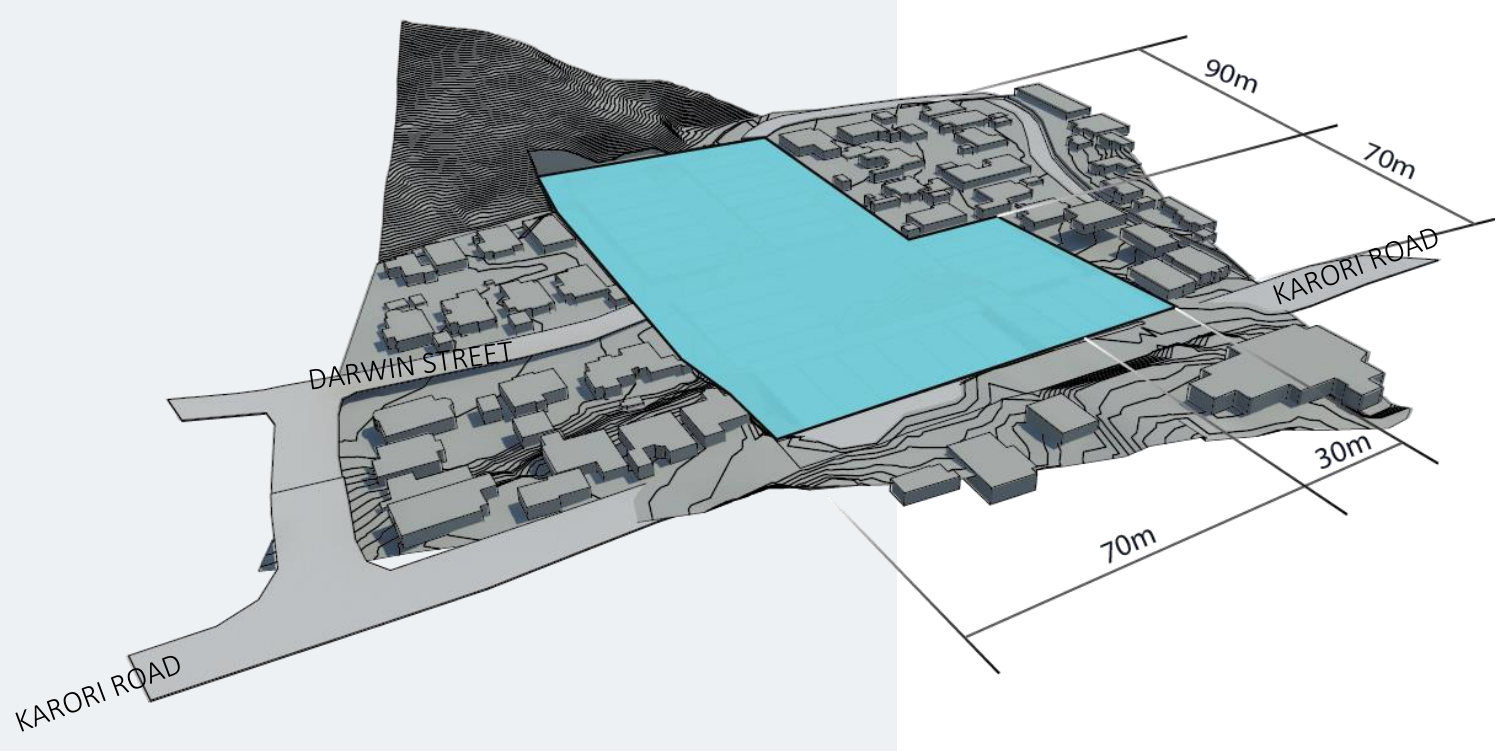




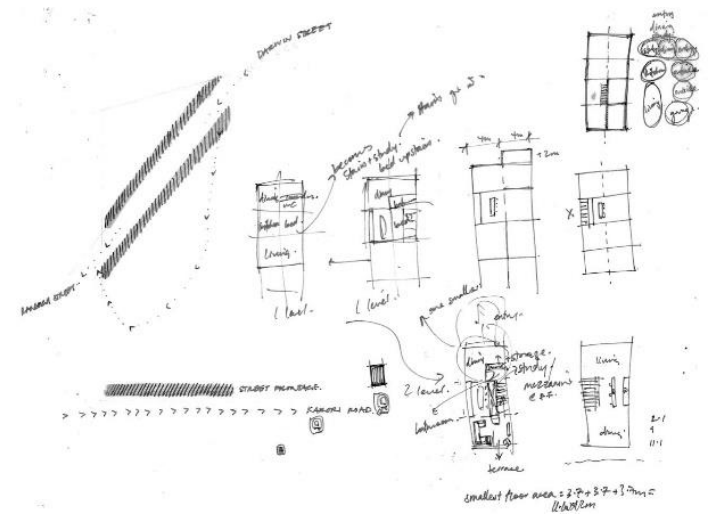

Figure 2.4.2: Understanding site layout to inform the lineal growth of the home

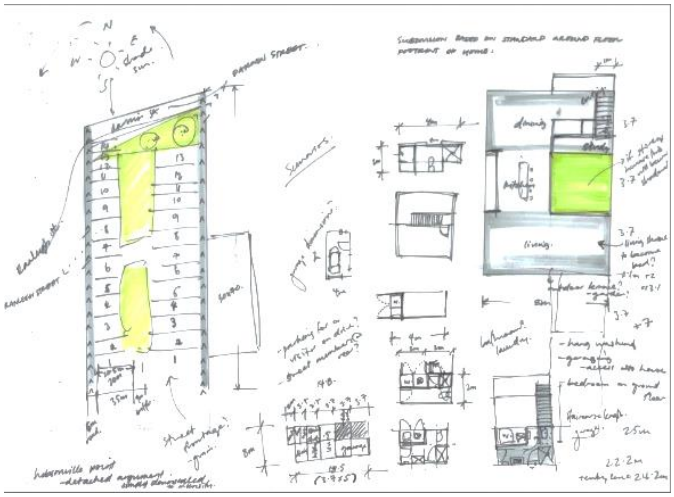

Figure 2.4.3: Site layout plans to maximise land to increase density.

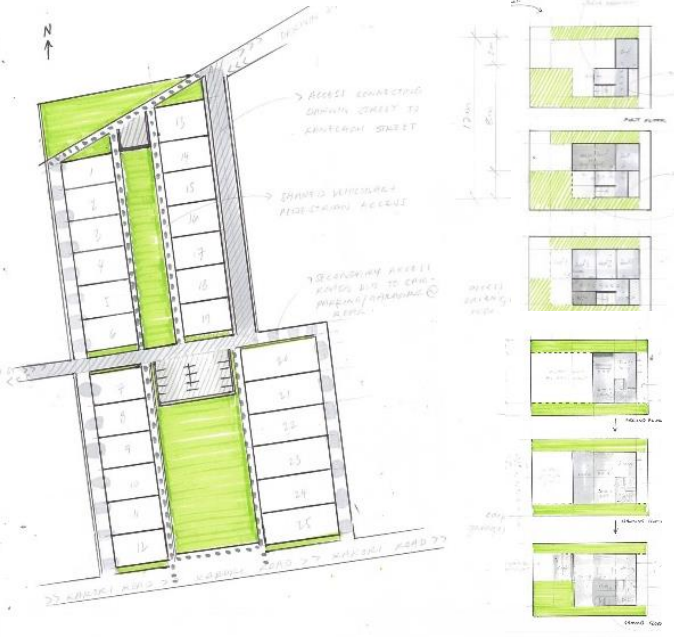

Figure 2.4.4: Site layout sees sections oriented east-west to maximise solar exposure. Layout allows for public green space central to the development.

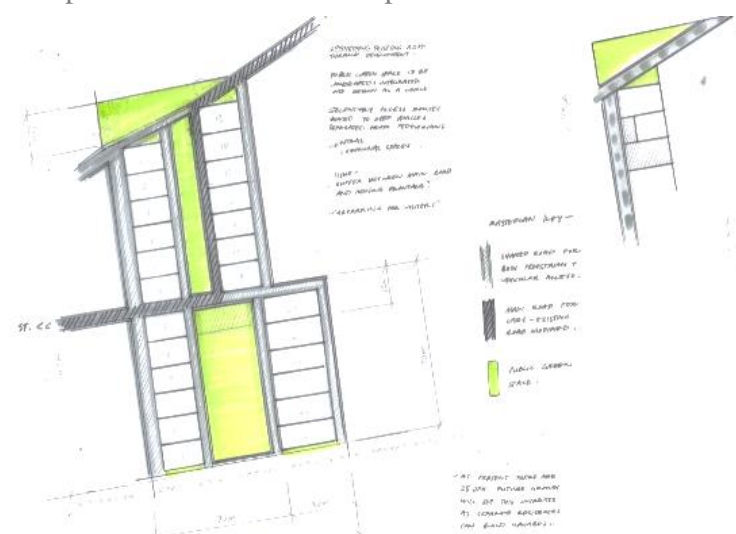

Figure 2.4.5: Site introduces primary and secondary roads to ensure the safety and wellbeing of residents.
Understanding the site-specific issues of topography and solar exposure, the impact these factors is understood in relation to the aims of the research. The following figures explore the implications external factors will have on the design outcome.

The health and wellbeing of occupants and the ability to age in place, sees the site employ level sections as seen in figure 2.4.3. This allows for ease of accessibility of all age groups. Flat private land not only provides elderly with a safe and secure outdoor space but also gives children access to a safe environment to play.

As an aim of the research is to see the MDH development appropriate for all ages, children must have ample, safe outdoor space to play. The masterplan in figure 2.4.4 adopts primary and secondary access roads to ensure the safety of the central public green spaces.

Sections are oriented east-west to maximise solar exposure as tested in figure series 2.4.6, to benefit the health and wellbeing of occupants. However, this does create segregation between the existing Karori community and the new complex which contradicts the aim to create an inclusive environment to mitigate loneliness and isolation. 


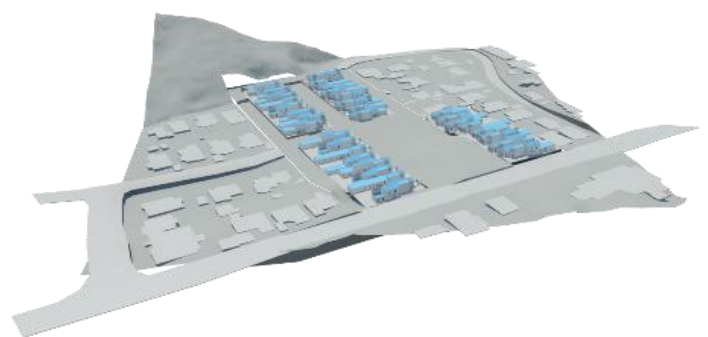

MASTERPLAN: SUMMER SOLSTICE
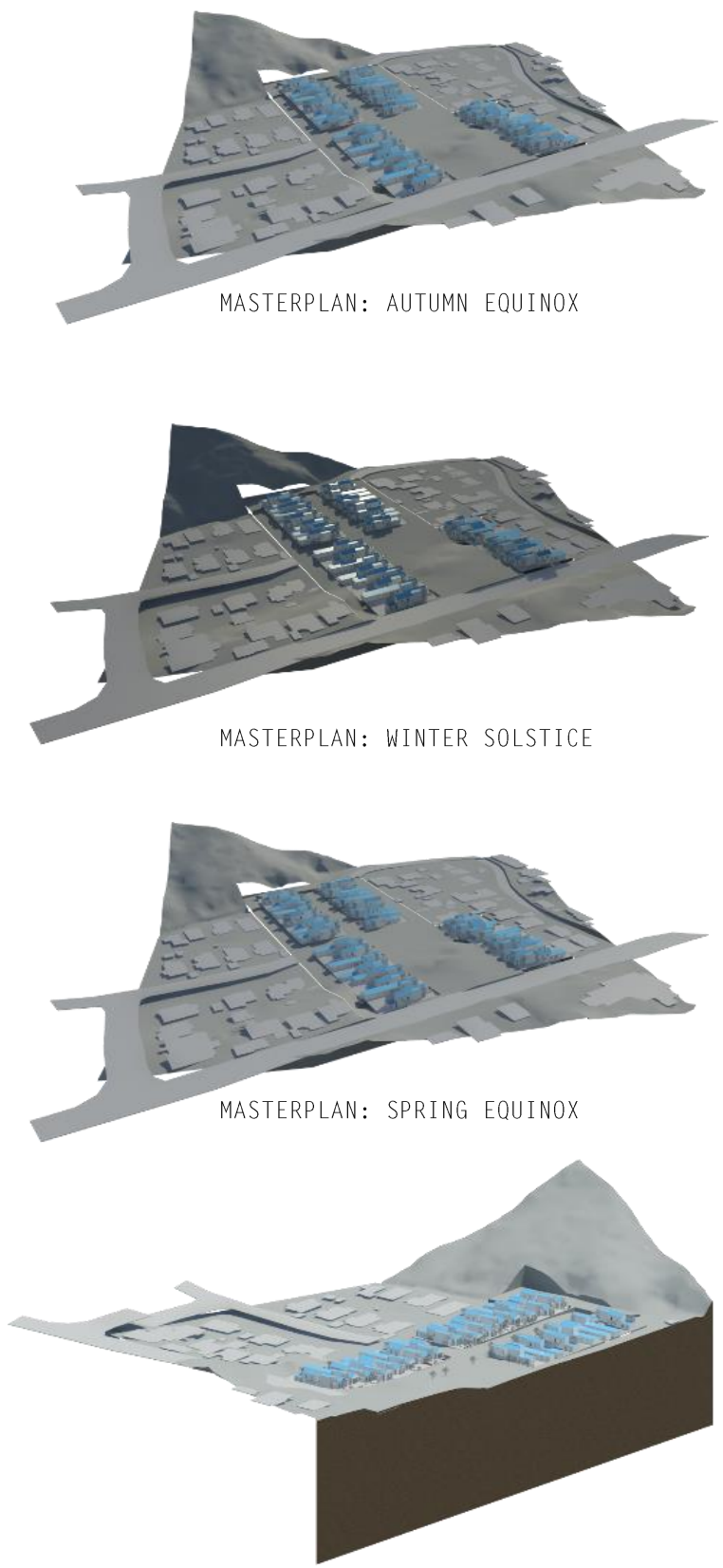

MASTERPLAN: SITE SECTION

Figure Series 2.4.6: Houses oriented east-west sees all properties maximise sun exposure during all seasons. 


\section{SITE EXPLORATION | 2.5}

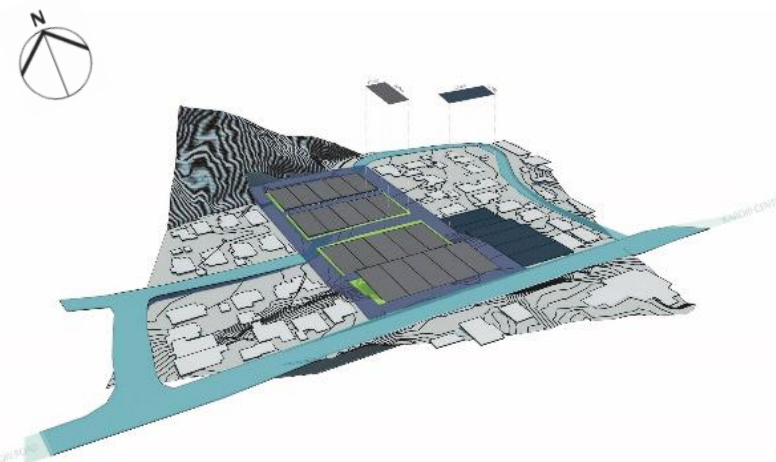

Figure 2.5.1: Site layout exploration one. All properties oriented north-south.

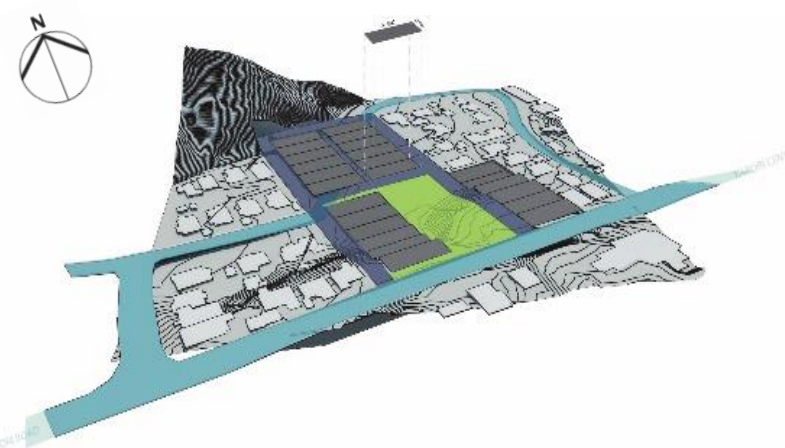

Figure 2.5.2: Site layout exploration two. All properties oriented east-west.

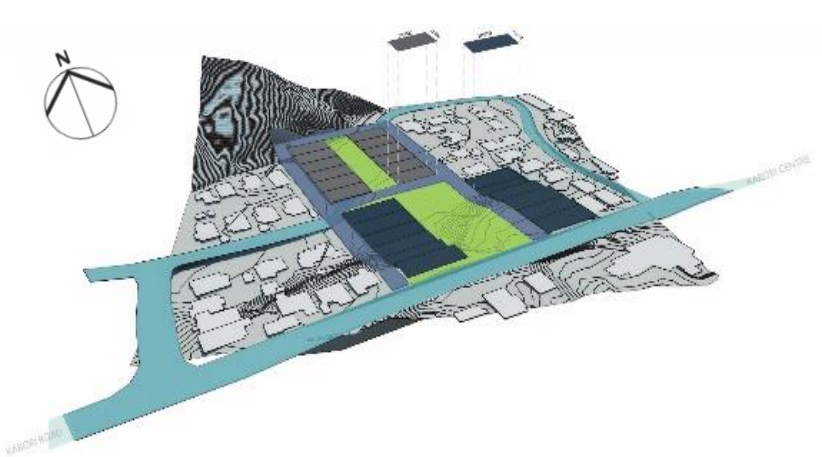

Figure 2.5.3: Site layout exploration three. All properties oriented east-west with an outlook to public green space.

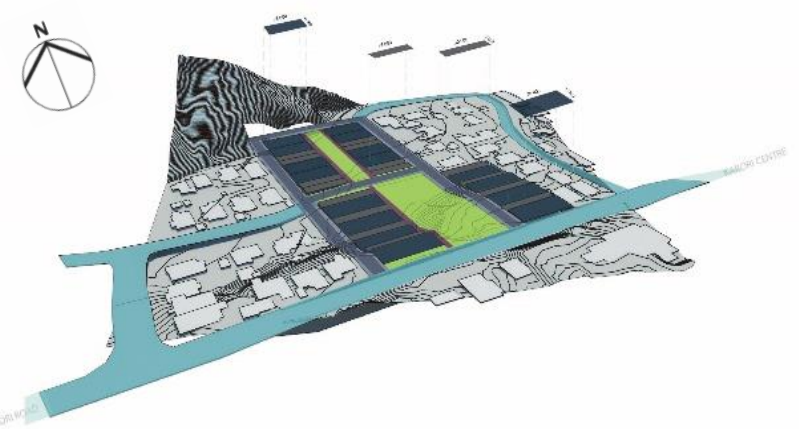

Figure 2.5.4: Site layout exploration four. All properties oriented east-west with an outlook to public green space and varying site widths.
Oriented north-south, sections are subject to shade during most the day due to the hill on the northern end of the site as shown in figure 2.5.1. Summer sun would see the north facing rooms of the home receive some sun, however in winter there would be greater shade from the low-lying sun behind the hill. With regard for the health and wellbeing of residents, this layout is undesirable. The south end homes do however see the complex integrate into the wider community by following the existing grain of homes along Karori Road.

With sections oriented east west as shown in figure 2.5.2, the front and rear of the home receive morning and afternoon sun. Homes are also oriented to face each other, improving community connection within the complex but not the surrounding context. A large public green space would encourage interaction and inclusion of all residents to improve wellbeing.

With primary roads for vehicle use and secondary roads for shared use, good access is achieved to aid ageing in place with taxis and ambulance access to all front doors via secondary roads. Fire services and trucks transporting new modules on primary roads ensures the safety of children using public greenspace contributing to a design appropriate for all ages. 
The final site configuration below in figure 2.5.5, will require extensive earth work to ensure all sections are level. This decision to level all sections is justified by the aim to create a home that is suitable for all groups and all abilities. It allows for the ground floor of the home to be level for wheelchair access, the safety of elderly and provides secure and safe outdoor space for children.

Primary roads and secondary roads help to achieve the aim of an adaptable home over time by allowing easy access for the delivery of prefabricated modules.

The final site configuration allows for 30 sections all with ample outdoor space. There is the possibility to create a new residence on the upper levels to increase density to 60 dwellings.
The site itself has two dedicated visitor/resident car parking areas with the capacity to park 25 cars within the complex and additional on road parking on main streets.

Homes along Karori Road are oriented northsouth to follow the existing grain of the street and avoid segregation from the wider community. Exclusion from the surrounding neighbours is also mitigated by ensuring connections to existing roads.

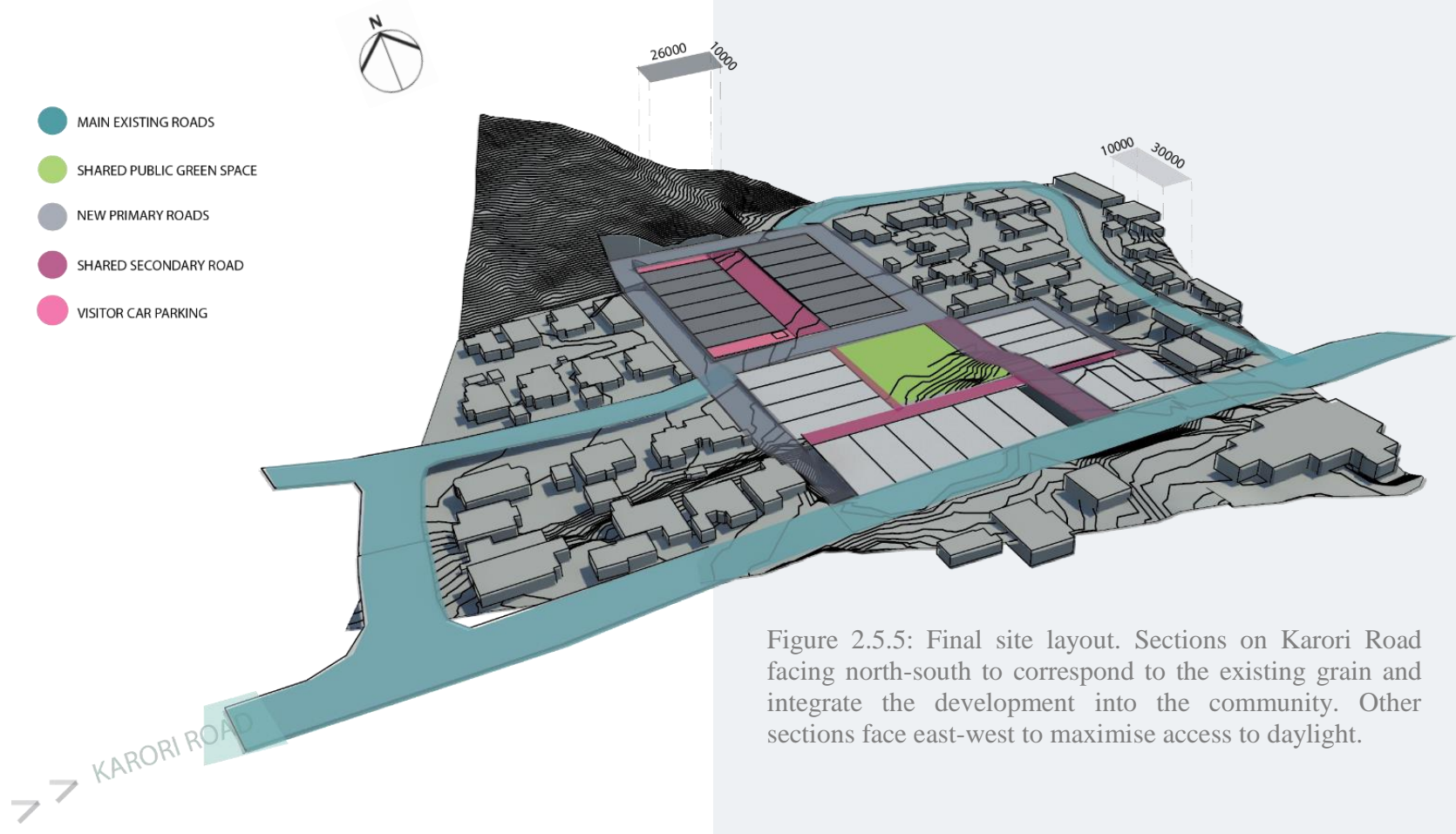


The site invites a narrow section and home comprised of modules of a maximum width of $3700 \mathrm{~mm}$ for transportation on wellington roads.

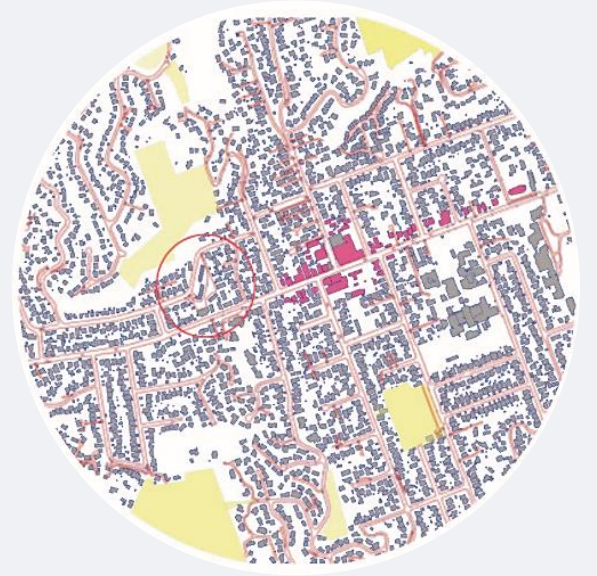

Figure 2.6.1: Figure Ground Study: Karori

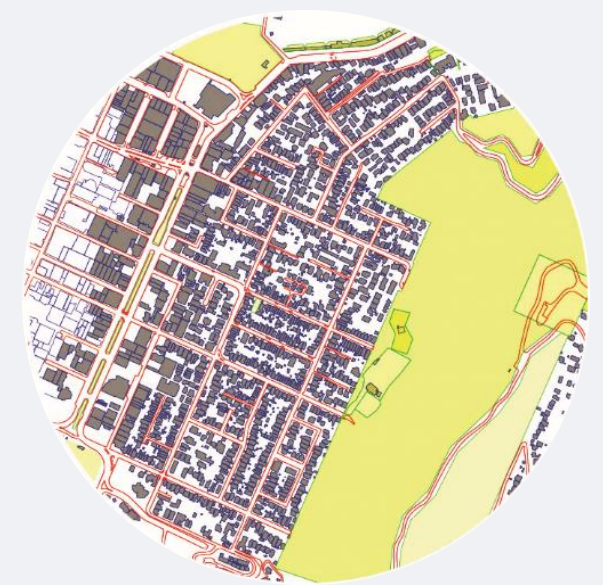

Figure 2.6.2: Figure Ground Study: Mount Victoria

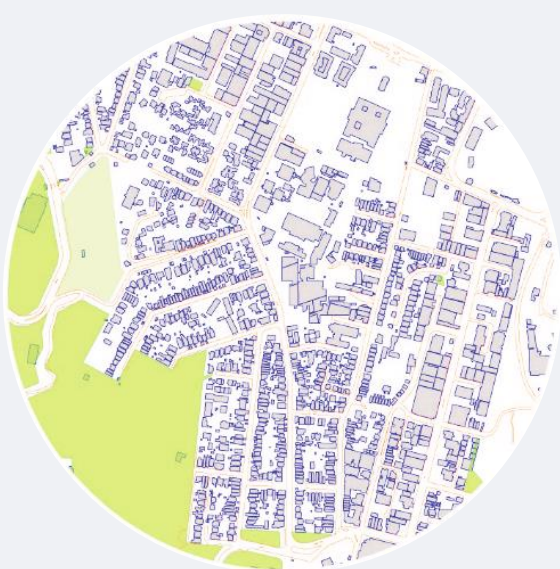

Figure 2.6.3: Figure Ground Study: Mount Cook

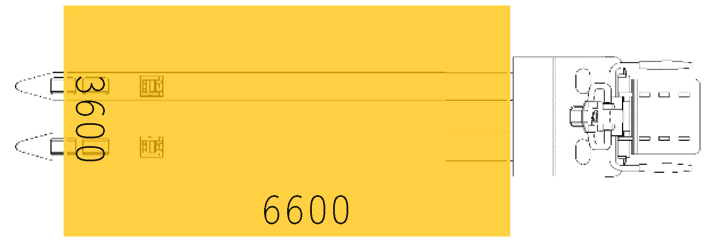

The smaller footprint of the home encourages intensification and increases the overall density of the development.

The motivations for this scaled down iteration of the 'quarter acre dream' aims to ensure people still have access to private outdoor space while making the necessary move to intensify. Narrow sites are proven in terms of functionality within the wellington region. Highly valued and boasting unique charm, the narrow dimensions of the site give help give this character to the home.

Accessibility is essential for facilitating ageing in place. The $3.6 \mathrm{~m}$ wide module ensures that hallways are wide enough at $1 \mathrm{~m}$ in width, allowing for wheelchair access should it be required in future. This dimension is also divisible by $900 \mathrm{~mm}$ for façade panels and $1200 \mathrm{~mm}$ for standard length of materials such as GIB and plywood.

The figure ground studies of Mount Victoria and Mount Cook shown in figures 2.6.2 and 2.6.3, illustrate an increased density where the character of the home is induced by narrow sites. 
This context analysis has established a strategic set of design principles that are incorporated into the design experiments. The design principles arising from the context analysis include:

- Creating a home and section that is level to facilitate young families with children and ageing in place.

- Ensuring the masterplan creates an environment to encourage inclusiveness without dividing the complex from the existing community.

- Orienting the sections to best integrate the design into the existing context while also providing enough sun and an inviting outlook for all homes.

- Adjusting the gradient of the site to be accessible for people of all abilities.

- The use of primary and secondary roads to allow for truck access to deliver a home capable of growing over time with the addition of prefabricated modules. Secondary roads to facilitate ageing in place with taxis and ambulances able to reach all front doors.

The context analysis highlights the important factors to be addressed in preliminary design experiments to best achieve the aims and objectives of the research.
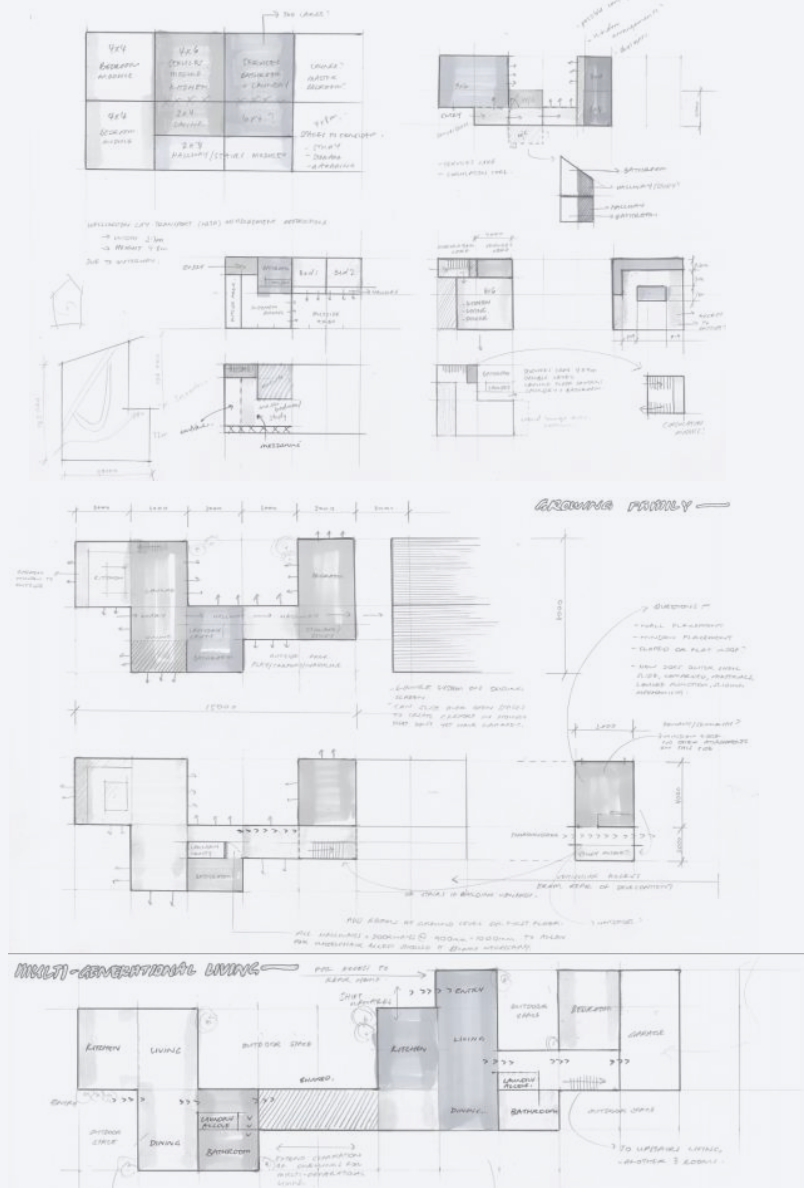

Figure 2.7.1: Design explorations of the plan of the home. From the analysis, above, sketch experiments in figure 2.7.1, collate findings to explore how the home might grow in a linear sequence to maximise land and utilize restrictions of transport dimensions to benefit the overall design of the smaller scale home.

The outcomes of the context analysis are addressed by leading theorists in the following literature review to gain insight into how these issues have been dealt with previously. They are applied to the research through design experiments and furthered to understand how the adaptable home might resolve these issues in a medium density context. 



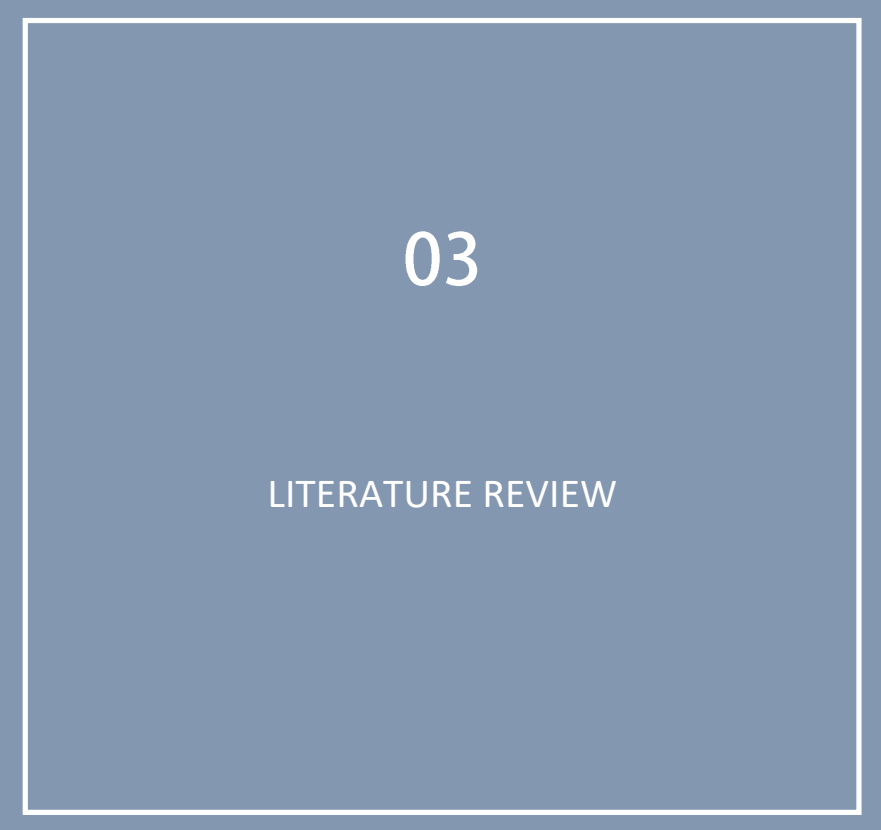





\section{LITERATURE REVIEW}

3.0

The literature review establishes a theoretical framework to address and resolve the issues highlighted in the context analysis. These issues have been condensed into three main areas of research to include ageing in place, wellbeing through residential amenity and prefabrication as a vehicle to produce an adaptable home. The design experiments are assessed against the resulting framework to further the research and produce new findings within a medium density context. 
Housing in New Zealand has long been motivated by the quarter acre dream, resulting in sparse residential environments of relatively low density in comparison to other countries. (Vale and Khajehzadeh)

To cope with the pressure of an increasing population, residential zones would benefit from intensification. However, medium density housing in New Zealand is often met with resistance by the public, due to a culture of entitlement and fear that "any move to build more apartments might threaten the existing value of standalone houses" (Howden Chapman). This perception is evident in the pattern of suburban standalone homeownership that has resulted in urban sprawl. When approached correctly, MDH can mitigate this spread and the associated negative environmental and social impacts of urban sprawl.

The literature review explores theoretical approaches to consider the wellbeing of occupants through residential amenity and a universal, lifetime appropriate design. Prefabrication is explored as a means to achieve these aims to deliver an adaptable home. 


\section{LIFETIME DESIGN: AGEING IN PLACE | 3.2}

Ageing in place has been identified by elderly as "an advantage in terms of a sense of attachment or connection and feelings of security and familiarity in relation to both homes and communities" (Wiles, Leibing, Guberman, Reeve, and Allen 1).

The co-authored paper 'The Meaning of "Aging in Place" to Older People' by New Zealand academics Janine L Wiles, Annette Leibing, Nancy Guberman, Jeanne Reeve, Ruth ES Allen, was conducted for the journal, 'The Gerontologist' 2011. The study illuminates the concept of ageing in place in terms of functional, symbolic and emotional attachments and meanings of homes, neighbourhoods, and communities. Conducted with 121 people ranging in age from 56 to 92, the study investigates how older people understand the meaning of ageing in place; a term widely used in ageing policy and research but underexplored with older people themselves. (Wiles, Leibing, Guberman, Reeve, and Allen 1)

The adaptable home aims to facilitate the dweller to age comfortably in place through independence and autonomy but also with the support and security of familiar surroundings. The adaptable nature of the proposed medium density housing also provides an opportunity for additional support through multigenerational living. Relocation is often associated with the need to realign the home to accommodate the transition between various life stages and the consequent demands of each stage. (Wiles, Leibing, Guberman, Reeve, and Allen 1) Due to the lack of flexibility in current housing, people are forced to shift home when circumstances change.

Prefabrication offers the flexibility required to see the home contract for elderly and expand for family living on the upper floors. A home capable of responding to the changing needs of its occupants will create an environment suitable for all stages of life. Through reciprocating the changing needs of the household via expansion and contraction, people will be encouraged to remain in wellestablished communities; a common request of the elderly population.

Participants of the study requested that choice around ageing was necessary and recognised that "getting too attached to a place can limit a person's ability and willingness to move to a more appropriate living environment when necessary" (Wiles, Leibing, Guberman, Reeve, and Allen 5). The overarching message around ageing in place was that older people would like to have choices about their living arrangements and could age comfortably with access to services and amenities. (Wiles, Leibing, Guberman, Reeve, and Allen 5) 
The study participants identified the need for independence with a strong desire to remain living in the community in housing that they are accustomed to. For this to be possible, the home must be universally accessible, with certain features to aid safely.

The graph in figure 3.2.1, is created from data provided by report 'What makes older people consider moving house and what makes them move?' (Hansen and Gottschalk 39) Derived from 2002 data with a focus group of 1134 people, academics Eigil Boll Hansen and Georg Gottschalk examined factors that motivated seniors (52 to 77 years of age) in Denmark both to consider moving and to actually move. consideration is given to moving. It is often sought by the elderly population to downsize in retirement due to safety and maintenance issues. This new typology would allow downsizing to occur without the stress associated with having to move home.

Home has a deep psychological meaning, not only in the form of the house but the community as well. Through housing communities over the course of their lifetime, a well-integrated neighbourhood of all ages is likely to form, where residents feel a sense of belonging. This identity and place making is said to have positive effects on both the mental and physical health of people over the course of their lifetime, lessening the risk of serious health problems in later life. (McNeill)

\section{REASONS PEOPLE CONSIDER MOVING}

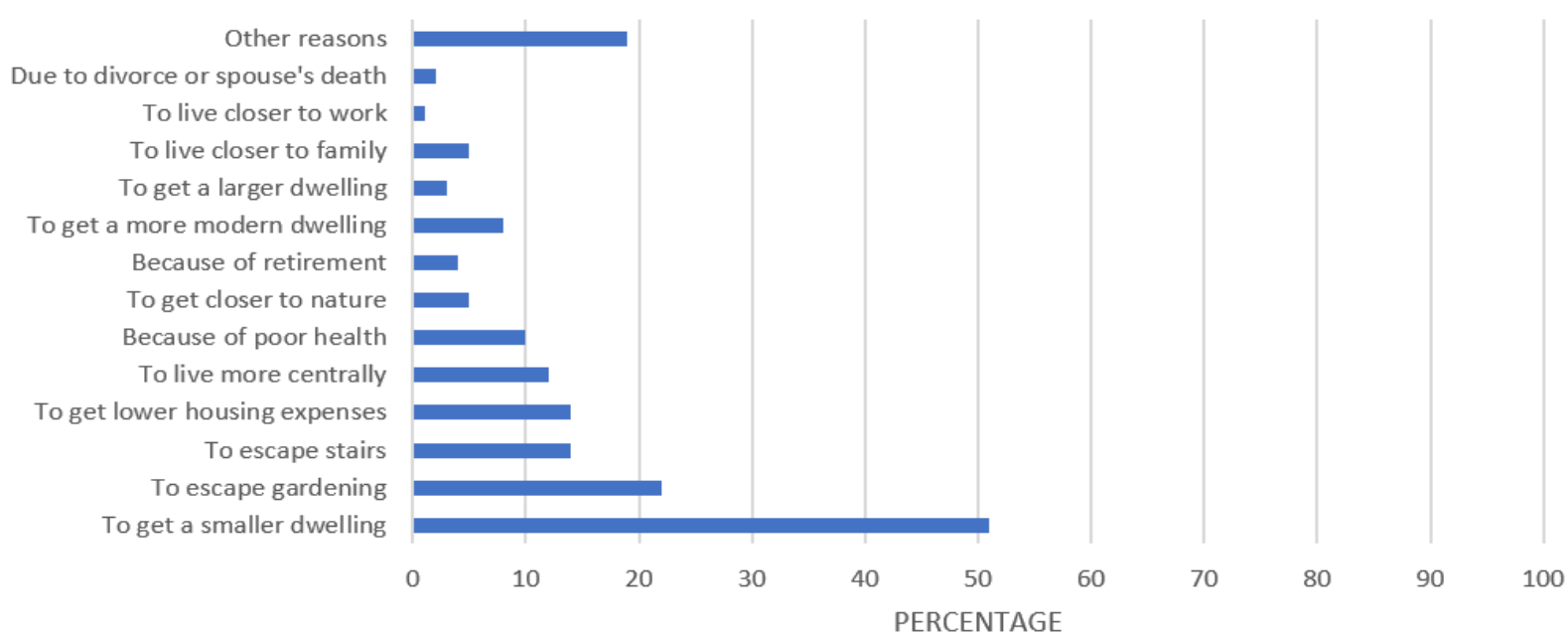

Figure 3.2.1 Graph of reasons why elderly consider moving.

If the home is unable to meet these requirements of elderly highlighted by Davey, 
WELLBEING + RESIDENTIAL AMENITY | 3.3

A home designed to meet the needs of all age groups from children to elderly also intends to increase the overall health and wellbeing of occupants through residential amenity.

Dr Judith Davey, former Director of the New Zealand Institute for Research on Ageing is a leading theorist with extensive publications centred around intergenerational issues. The article "Ageing in place: the views of older homeowners on maintenance, renovation and adaptation" for the Social Policy Journal of New Zealand 27 (2006) provides the framework for understanding the needs of elderly in a universal, lifetime design for the home.

The report, saw seniors highlight the features required to ensure an environment that would allow for security and comfort in later life.

This included:

-No stairs (all on one level)

-easy access from the street

-warm and sunny

-a garden that is small and easy to manage

-a modern bathroom and kitchen

-room for visitors and for an

office/hobby space (many now need

space for a computer)

-low maintenance (brick, aluminium

windows, low-maintenance roofs) -safe (steps that are not slippery and with rails; grab rails in the bathroom) -accessible for transport, health services and social networks.

(Davey 137)

This list builds the framework against which design experiments will be assessed to validate suitability for ageing in place for the wellbeing of occupants.

Children also stand to benefit from a home that is carefully considered to meet their needs. In $\mathrm{MDH}$ the key residential amenity qualities are privacy, access to outdoor space, access to sunlight and outlook and sufficient space for children to play safely. (Cooper Marcus and Sarkissian)

Author of 'Housing as if People Mattered: Site Design Guidelines for Medium-Density Family Housing', Clare Cooper Marcus is a Professor Emerita at the University of California, Berkley. Internationally recognized for her research on the social and psychological implications of design, particularly urban open space, affordable housing, outdoor space in healthcare, and environments for children and the elderly.

Marcus and Sarkissian address a set of design guidelines aimed to improve the residential amenity of medium density housing. The resulting framework is built upon to engage new ways of solving issues of residential amenity (e.g. privacy, light, natural ventilation 
and outdoor space) in an adaptable environment and are used to evaluate design experiments.

The issues of residential amenity are often over-looked, affecting the health and wellbeing of residents. Other negative impacts on wellbeing arising from poor qualities of amenity include sufficient open public space, pedestrian accessibility/wayfinding, traffic and safety, vehicular access, street parking, noise and communal privacy.

Effective intensification of residential living requires careful consideration for the provision of amenities, especially in an adaptable $\mathrm{MDH}$ development where the relationship between buildings and outdoor space is subject to continual change.

Recently published results of the Dunedin Multidisciplinary Health and Development Study, in the documentary 'Why Am I?' suggests that loneliness, stress and isolation in early life are directly correlated to deteriorated health in later life. Not only are these factors detrimental to the mental health and wellbeing of people, but to their physical health as well. (McNeill) If an adaptable housing typology could seek to integrate people into a community to establish a sense of belonging, it could be possible to reduce the effect of ill health in later life. The benefits of this could be vital to relieving strain on public facilities and aged care in the future as the forecast of elderly in New Zealand is set to total a quarter of the population by 2050 .

A universally accessible home would enable people of all abilities to live in their own home for longer, making sound economic and emotional sense. When aiming to house people for the duration of their life it is important to make provisions to quite literally, expect the unexpected. A universally accessible design enables the user, no matter their level of ability.

BRANZ suggests in 'Homes without Barriers', "when a person is unable to live in a house because of physical barriers it is the house that is inadequate, not the person" (Bulleyment 5). Understanding that the home is considered a place of comfort and refuge, especially to the older generation or people of different abilities, the home should facilitate independence and seek to extend the possible boundaries of housing for life. 


\section{PREFABRICATION | 3.4}

Prefabrication offers the flexibility required to achieve the aim of an adaptable home, capable of meeting lifetime requirements of occupants to improve health and wellbeing.

Prefabrication is the off-site construction of building elements, designed to meet time and cost restraints negatively impacting the construction industry as a result of the housing crisis.

The efficiency of mass produced modules with standardised openings would see the adaptability of the home met with ease. The traditional model for prefabrication sees standardisation and customization as mutually exclusive. This research aims to achieve adaptability through standardised prefabricated modules, that offer mass customization through prefabricated façade panels for individual preferences of the aesthetic of the home.

The term 'adaptable' has been defined based on the findings of leading theorists of residential flexibility; Schneider and Till, who have entwined adaptability and flexibility with prefabrication in the paper 'Flexible housing: the means to the end'.

They state, "in terms of use it may appear a contradiction that flexibility can be achieved through being either very indeterminate in plan form or else very determinate, but historically both approaches have developed in parallel through the course of the twentieth century" (Schneider and Till 7). Adaptability through a determinate approach often produces highly specialised designs suited to a determined brief. However, as the requirements of the home are intended to evolve to align with the occupants changing needs, it is the indeterminate approach to adaptability that is employed.

The design suggests space for occupants to inhabit and imply use as they require while having the determinate provisions in place through standardisation to expand and rearrange the home as change will occur. Determinate in its programme but determinate in its form and framework for future growth, the design is governed by a framework that ensures the amenity of other neighbouring properties is not compromised as the home adapts. Offering an architectural design with moments determinate in aesthetic, but indeterminate programme.

The hybrid model of prefabrication sees modular units easily transported to site to meet large circumstantial changes, while standardised infill panels in regulated positions sees the home adapt on a smaller scale to add a window, door, opening or wall panel for smaller needs of flexibility. An example of this may occur when an older couple seek to downsize the home to live solely on the ground floor. Panelised infill will see the inter-floor opening sealed to create two separate 
residences within a medium density environment.

While the benefits of panelised prefabrication in transport sees greater quantities able to arrive at site, modular prefabrication has been employed over panelised prefabrication construction due to benefits of onsite constraints. The delivery of modules allows for minimal disruption to existing homes regarding noise, interference and access.

Modular prefabrication is a vehicle to create a means to allow people to stay in their communities where life changes would otherwise see them move, by offering the flexibility of re-aligning the home without the hassle of moving.

A correlation between ageing and lessening of ability is occurring as health problems hinder mobility in later life. Although an adaptable housing typology looks to provide an alternate housing solution to the current issues faced in relation to housing in New Zealand, it also aims to help reduce the growing health issues associated with poor living conditions through residential amenity. Assisting ageing in place through multigenerational living and downsizing of the home using panelised infill to separate upper modules, prefabrication helps bring the idea of the adaptable home into reality. Answering the question, 'How can the home be redefined to allow for adaptability to better suit the changing needs of its occupants?' 


\section{CONCLUSION 3.5}

The urgent need for housing to intensify to meet current demands can be met efficiently through prefabrication.

Underlying all medium density developments is a need to ensure that any new addition fits within an existing urban context and provides appropriate levels of residential amenity to improve the health and wellbeing of occupants. This includes adequate privacy both indoors and outdoors, access to sunlight, an enjoyable outlook and enough space to enjoy the home where all age groups can live safely and securely.
The resulting design framework is instrumental to further theoretical research and evaluate design experiments. The overall aim is to improve the health and wellbeing of residents of all ages through residential amenity of the home and the community. These demands can be met efficiently through prefabrication, offering a home capable of adapting to respond to the changing needs of the household dynamic.

\section{FRAMEWORK FOR MEDIUM DENSITY HOUSING IN AN ADAPTABLE CONTEXT}

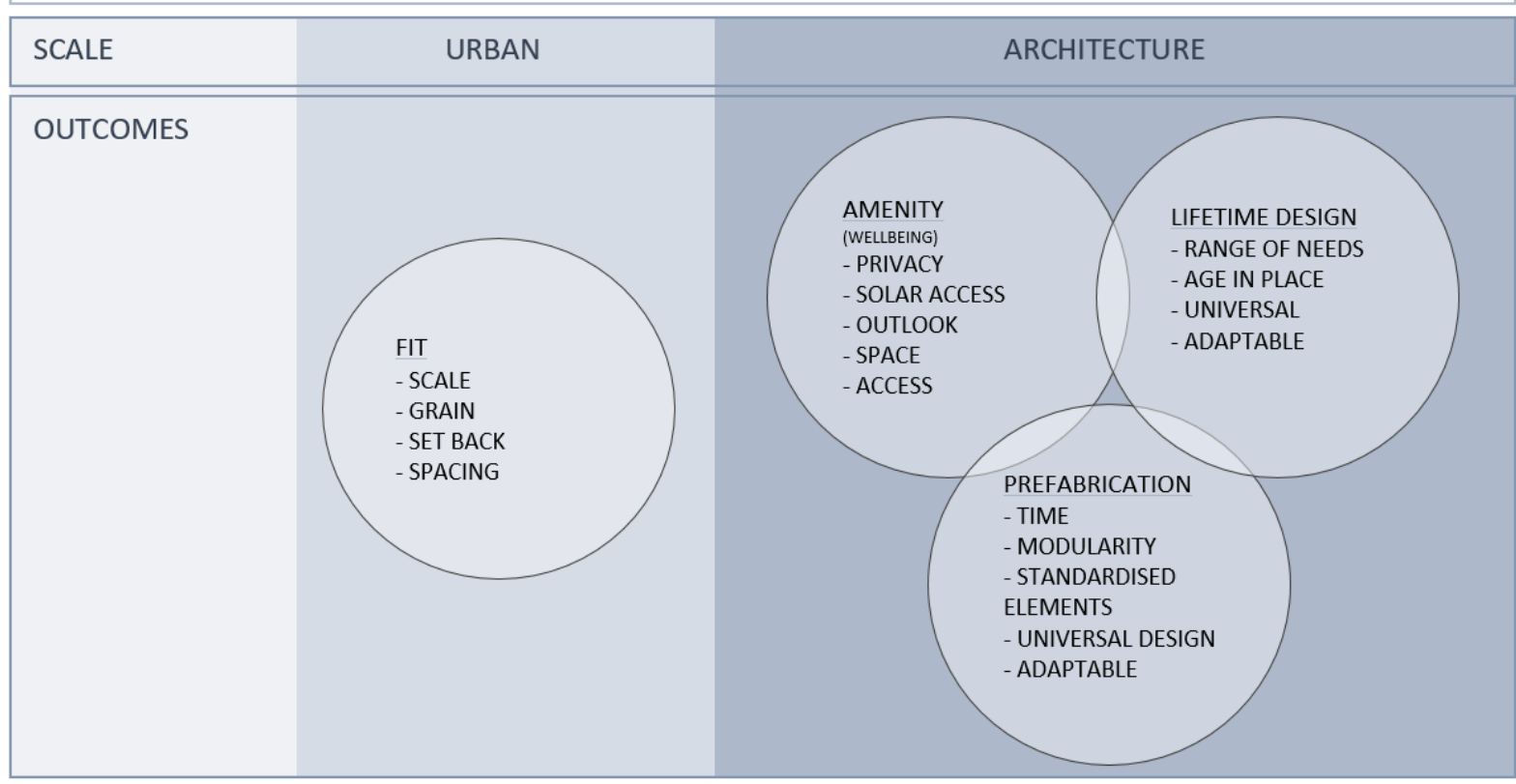

Figure 3.5.1: Framework for MDH in a development susceptible to change. 
The final design was influenced by strategic decisions made based upon the findings of the literature review.

The needs requested by the elderly in Judith Davey's report, provided a framework for all design decisions to be justified against, ensuring the home would be suitable to age in place. The list of fundamentals of residential amenity by Clare Cooper Marcus and Wendy Sarkissian ensured the design was suitable for all other ages and abilities. The design guidelines influenced the design in terms of wellbeing specifically for the context of medium density housing. (Appendix A)

The theory from these two research areas enabled the literature to be applied to an adaptable housing typology to create new findings. Understanding the benefits of prefabrication to allow adaptability, the home responds to the needs of its occupants through change.

Clare cooper Marcus posed the question in the 1986 text 'Housing as if People Mattered', what happens when the nuclear family changes and the kids grow up? (Marcus and Sarkissian 7) In the decades since these design guidelines were recommended, the speculated change in dynamic has already occurred. However, housing has yet to respond this change. This research seeks to take the initial steps to combine the three areas of theory to create a superior solution in the form of medium density housing.
The three key issues that have been addressed in the literature including, ageing in place, wellbeing through residential amenity and prefabrication as a vehicle to produce an adaptable home are also located within key design precedents. The following case studies focus on wellbeing and residential amenity and have been produced through prefabricated modular designs. 


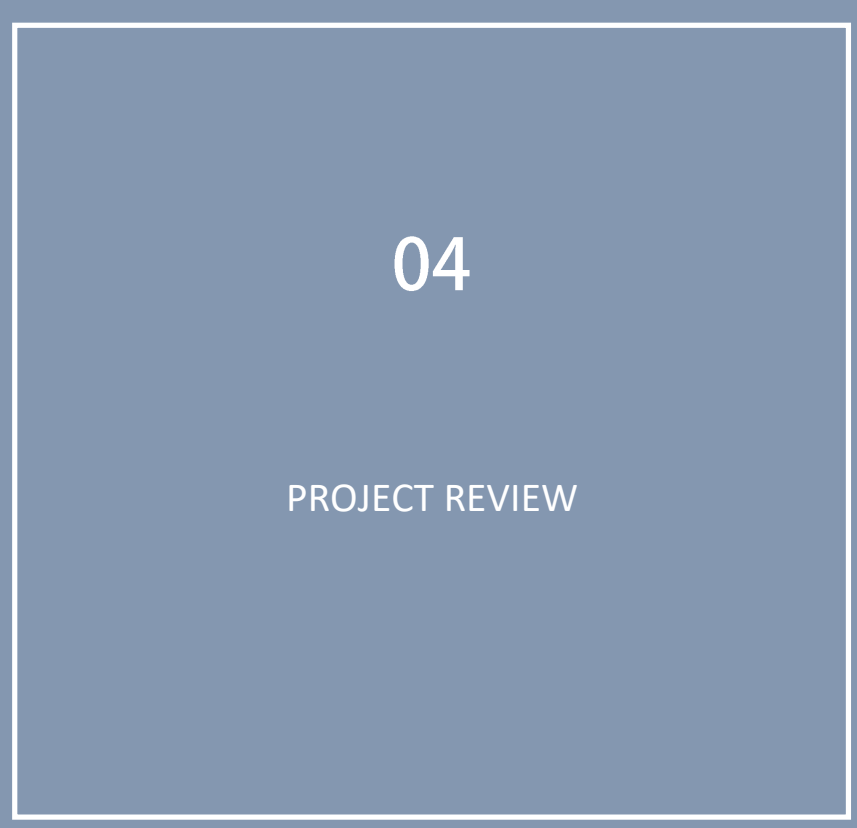





\section{PROJECT REVIEW}

4. 0

Architects have attempted several different approaches to create a home responsive to the needs of its occupants.

This chapter discusses and analyses three case studies that build upon the three key areas defined by theoretical research.

1. Wellbeing considered in the residential amenity of the home.

2. Lifetime design suitable for all ages and abilities.

3. The use of prefabrication to offer a universal design capable of adapting to meet the ever-changing needs of the household.

The relevant case studies have been selected to provide an approach to $\mathrm{MDH}$ that considers the wellbeing of occupants through residential amenity: Moshe Safdie's monumental 'Habitat 67' in Montreal, Shedkm Architects 2016 medium density housing project 'hoUSe' in Manchester and Herreros Arquitectos growing home in Spain.

The projects offer an approach to adaptability using prefabrication to a high level of amenity. The findings are then furthered through design to apply lifetime design attributes to allow residents to age in place and suitably house all age groups and abilities. 
CASE STUDY ONE | 4.1

Project: Habitat 67

Location: Montreal, Canada

Designer: Moshe Safdie

Year: 1967

The experimental modular housing, known as Habitat 67, designed by Moshe Safdie is comprised of 354 identical prefabricated concrete modules to form 158 apartments. (Habitat 67) The structure demonstrates highquality housing using modular units to create a dense urban environment as indicated in figure 4.1.1.

Habitat 67 pioneered the combination of two major housing typologies - the urban garden residence and the modular high-rise apartment building, achieving a high level of amenity for all residents. Stacking the modules in a variety of combinations delivers the maximum amount of air and sunlight into each apartment. The landscaped terraces provide ample outdoor space for each apartment with adequate privacy and sun exposure.

Habitat 67 was selected to demonstrate the ability to consider wellbeing through highly resolved residential amenity in a dense living environment. The high density complex resolves both residential and community amenity to improve the wellbeing of its occupants with the following characteristics:

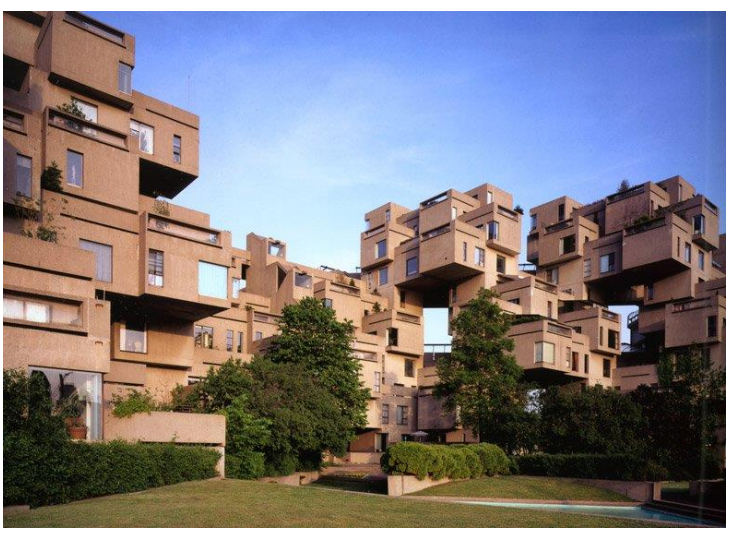

Figure 4.1.1: Habitat 67 High Density complex in Monreal, Canada.

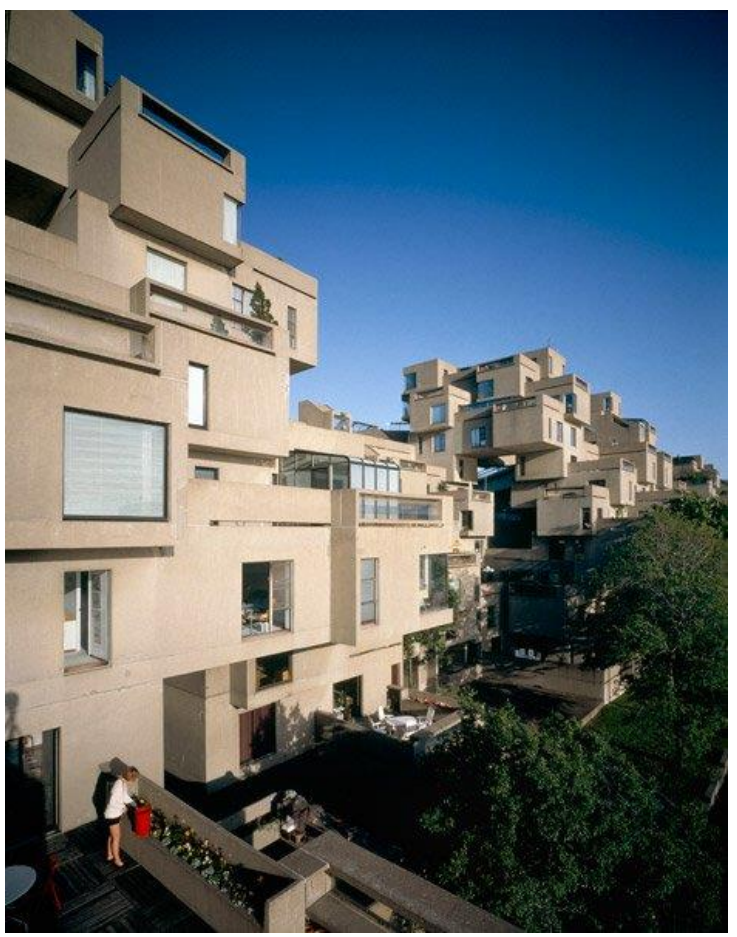

Figure 4.1.2: Habitat 67 outdoor terraces.

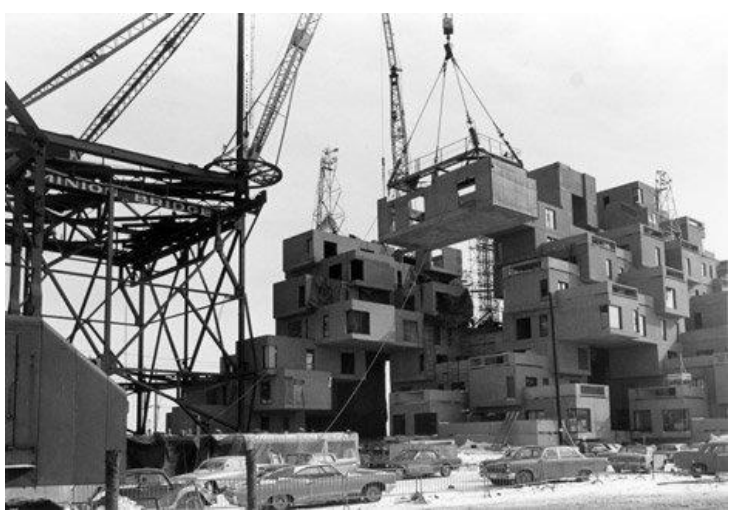

Figure 4.1.3: Habitat 67 assembled on-site. 
- 15 models varying between 1 and 5 modules offers choice for the buyer to suit their needs

- Views on 3 sides with landscaped terraces (outlook)

- Private terraces ranging in size up to 1000 square feet

- Elevators and stairs for accessibility

- External walkways at various levels giving access to residences

- Central heating and air conditioning

- Excellent sound proofing

Situated next to a tennis club, play area, walking paths and bicycle path connecting to the regional bike path network, the complex also addresses public amenity to encourage the health of residents. Included within the complex is:

- Security including 24-hour doorman service

- Shuttle bus between the complex and Downtown Montreal, 6 days a week to provide great connectivity to the community

- Maintenance of common areas

- Postal delivery to doors

- Reception of parcels in your absence

- Storage space

- Maintained gardens
Considerations from Habitat 67 that would be relevant to inform a $\mathrm{MDH}$ design research experiment include:

- Providing comfortable access for all abilities across a multi-level design.

- Employing prefabrication as a highly efficient means to allow this mass customization.

- Prefabricated modular units to efficiently build high density housing.

This case study highlights the importance of guidelines when expanding the home to avoid compromising the level of residential amenity of other properties.

The wellbeing of residents is highly regarded in the fundamentals of public and residential amenity. A disadvantage of Habitat 67 is that it does not allow buyers to have input into the layout of the home to best suit their lifestyle and needs.

The following case study, House, sees MDH use the advantages of prefabrication to mass customize homes to best meet the immediate needs of the dweller. 
CASE STUDY TWO $\mid 4.2$

Project: house

Location: New Islington, Manchester UK

Designer: Shedkm Architects

Developer: Urban Splash

Year: 2016

The House project located in Manchester, UK designed by Shedkm Architects and developed by Urban Splash in 2016, is an example of MDH designed to meet the needs of the dweller. The mass production of prefabricated timber modules offers an attractive alternative to the typical cookie-cutter developments where buyers design the layout of their home to suit their lifestyle. (Xie)

A pioneering modular development comprised of 43 prefabricated timber pods, sees mass customization delivering homes to meet the household needs.

The homes are prefabricated within a factorycontrolled environment before being transported to site, where each pod is stacked into place with the use of a hydraulic crane as pictured in figure 4.2.2. The modular home minimizes waste and noise pollution in an established housing development, providing a superior housing solution compared to the traditional house build. (Xie)

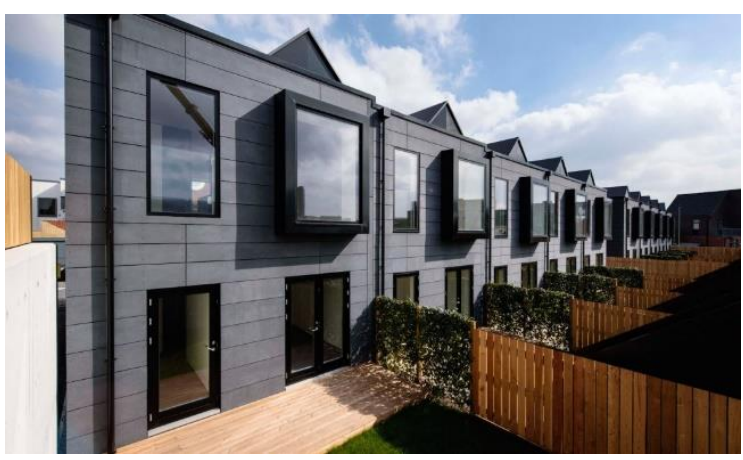

Figure 4.2.1: 'hoUSe' is a medium density housing solution.

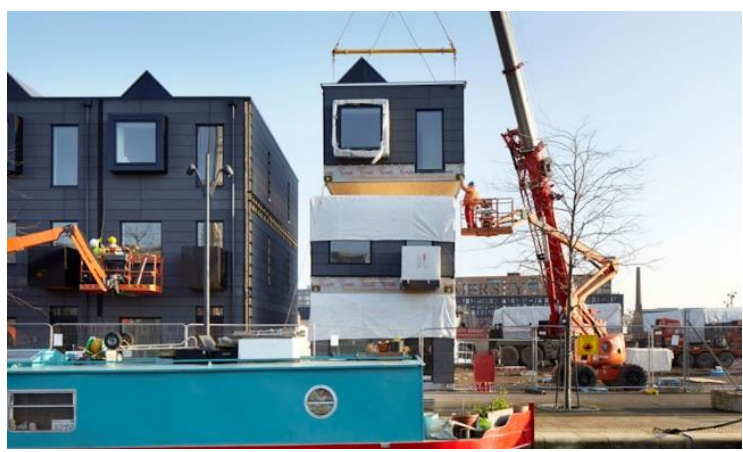

Figure 4.2.2: 'hoUSe' is comprised of prefabricated modules.

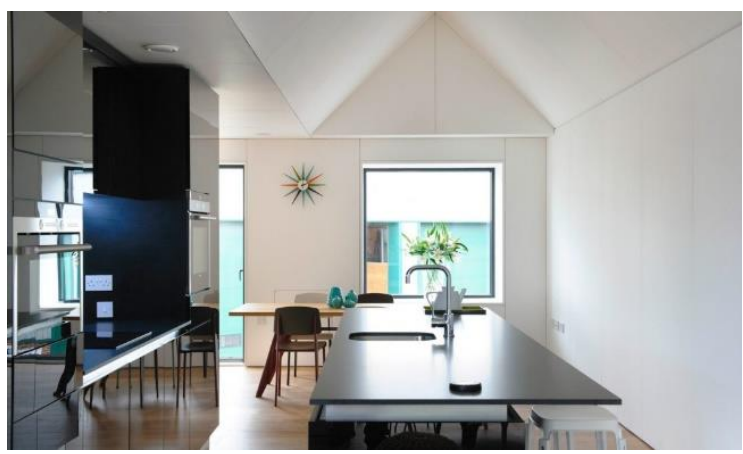

Figure 4.2.3: 'hoUSe' allows the buyer to design the layout of the home to best suit their needs.

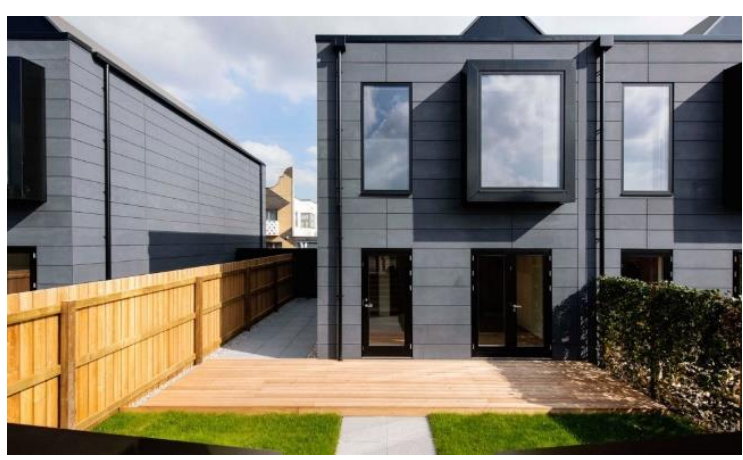

Figure 4.2.4: Considers the fundamentals of residential amenity for the wellbeing of occupants. 
This thesis aims to address the issue of intensification through prefabrication to minimise time and cost restraints, especially during a housing crisis.

House is selected as a case study to address the issue of medium density housing aligning to meet the occupants needs. While the intention of the design research is to meet these needs continually as circumstances change, House sees $\mathrm{MDH}$ developments break from the traditional approach to consider the needs of the dweller.

The home considers the wellbeing of its occupants in the immediate stages of conception by allowing them to plan the spatial layout relevant to their lifestyle. However, the design research aims to continue to meet the requirements of the occupants as circumstances change.

Considerations from the House case study that inform the design research experiment include:

- Offering choices to the buyer to determine size, layout and materiality of the interior of the home to suit their lifestyle, encouraging good health and wellbeing.

- Employing prefabrication as a highly efficient means to allow this mass customization.

- Modular construction, pre-assembled off site to minimize on site disruption to existing homes.
A disadvantage of House is that it does not have provisions in place to see the home expand as circumstances may change in the future.

The following case study, Casa Garoza, allows the home to grow over time to accommodate the changing needs of the family. 


\section{CASE STUDY THREE $\mid 4.3$}

Project: Casa Garoza

Location: Spain

Designer: Herreros Arquitectos

Year: 2016

This simple prefabricated home by Herreros Arquitectos in Spain is designed to seamlessly grow over time to accommodate the changing needs of the family. Despite being a standalone home design, this case study is selected to understand the provisions taken for future expansion. This method is then incorporated into a medium density context.

Casa Garoza is comprised of an initial rectangle module consisting of a studio, kitchen, living and dining rooms and loft as the interior shows in figure 4.3.3. The potential to expand the home over time is made possible through the standardisation of openings. Utilizing appropriately arranged openings in the module allows for interchangeability of panelised infill to create a window, door or opening into a new room.

It is the "first model for a new industrialized modular prefab prototype" for a growing house. It is a relevant solution to current and future housing problems, incorporating adaptability, resource efficiency, recycling and sustainability. (Meinhold)

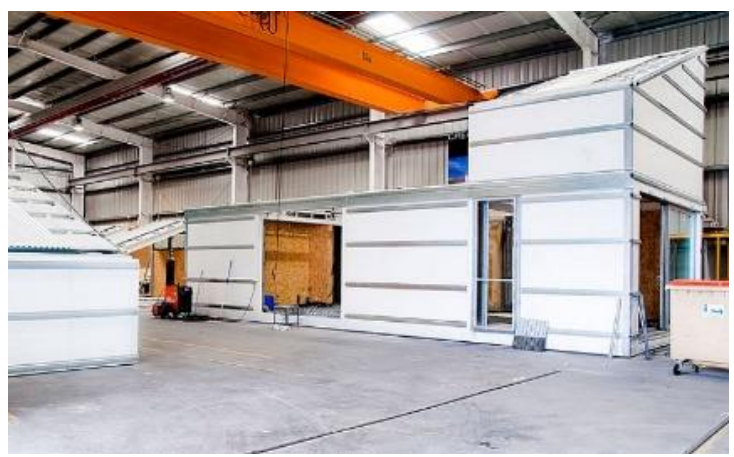

Figure 4.3.1: Prefabricated offsite in a controlled environment before being transported to site.

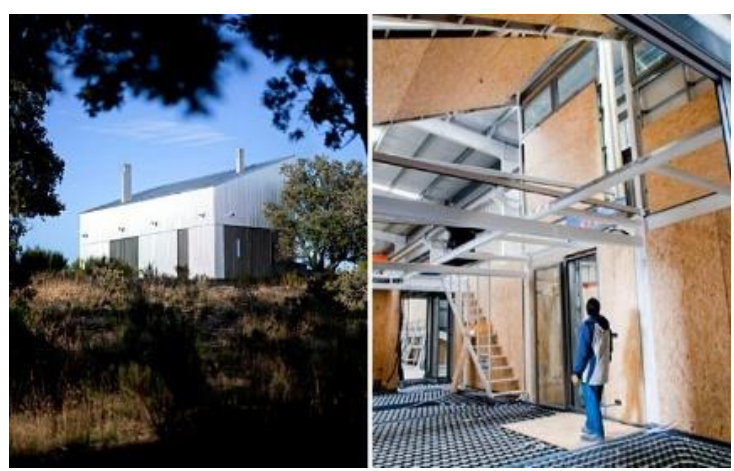

Figure 4.3.2: Potential for growth is accounted for in the early stages of design.

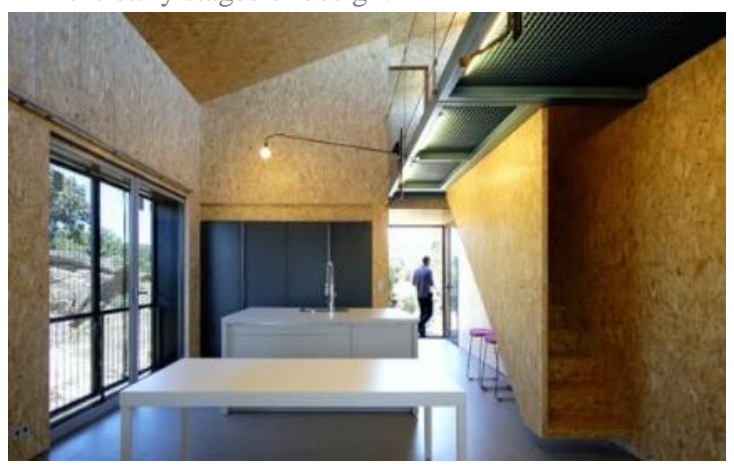

Figure 4.3.3: The smallest possible home is still fully functional with all necessary rooms.
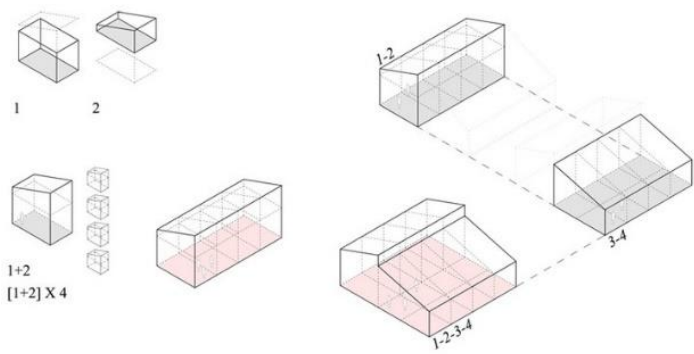

Figure 4.3.4: Standardisation of modules and openings sees expansion occur seamlessly. 
While there are many benefits to the offsite prefabrication of modules, local restrictions apply for transportation to site. Consequently, these restrictions influence the dimensions of the units. Casa Garoza is restricted to $3 \mathrm{~m}$ in width, $2.5 \mathrm{~m}$ in height and up to $12 \mathrm{~m}$ long in Spain. (Meinhold) This is an important consideration for the context of Wellington, New Zealand with overhead bus cables and tunnels affecting most routes into the city.

Other considerations highlighted by Casa Garoza that can be used to inform the design research experiment include:

- Module dimensions for transport.

- Consequent interior dimensions for comfortable spaces and wheelchair accessibility.

- Standardisation of openings to allow for future growth of the home.

- Potential growth guidelines: strict placement of future modules to ensure residential amenity of surrounding properties is not compromised.

- Employing prefabrication as a highly efficient means to allow this mass customization.

- Modular construction, pre-assembled off site to minimize on site disruption to existing homes.

A disadvantage of Casa Garoza is that it does not currently apply to a medium density context. The preliminary design experiments will further the benefits of Habitat 67, House in conjunction with Casa Garoza's proven ability to adapt the over time, creating an adaptable home designed to meet the lifetime needs of its occupants. 
All architects employing prefabricated modular designs encounter transportation restrictions that ultimately influence the design outcome. The response in these examples sees the modules take the shape of the maximum allowed dimensions relative to the context of each country. An alternative approach could see modules near the stage of completion transported to site to be finished and fused on site to overcome this limitation of modular prefabrication.

It is understood that there are many benefits to panelised prefabrication, but the design intends to remain volumetric and arrive at site almost entirely complete to minimize waste and noise pollution in an established housing development.

The findings from the literature and case study reviews in relation to ageing in place, wellbeing through residential amenity and prefabrication as a vehicle to produce an adaptable home create the basis of the design explorations. 
05

PRELIMINARY DESIGN 


\section{PRELIMINARY DESIGN}

5.0

This chapter documents the design-led research of the thesis through eight preliminary design experiments.

Each design experiment investigates the objectives that have been reiterated throughout the context review, literature review and case study review, producing various issues for the design experiments to address.

This initial preliminary design experiment addresses the implications of modular prefabrication and the consequent transport restrictions.

The New Zealand Transport Agency (NZTA) enforces the dimension restrictions of $4.8 \mathrm{~m}$ in height and $3.7 \mathrm{~m}$ in width. NZ Transport Agency

The resulting dimensions of the module must not exceed $3.7 \mathrm{~m}$ in width and $3.6 \mathrm{~m}$ in height, provided the truck deck is no taller than $1.2 \mathrm{~m}$. 


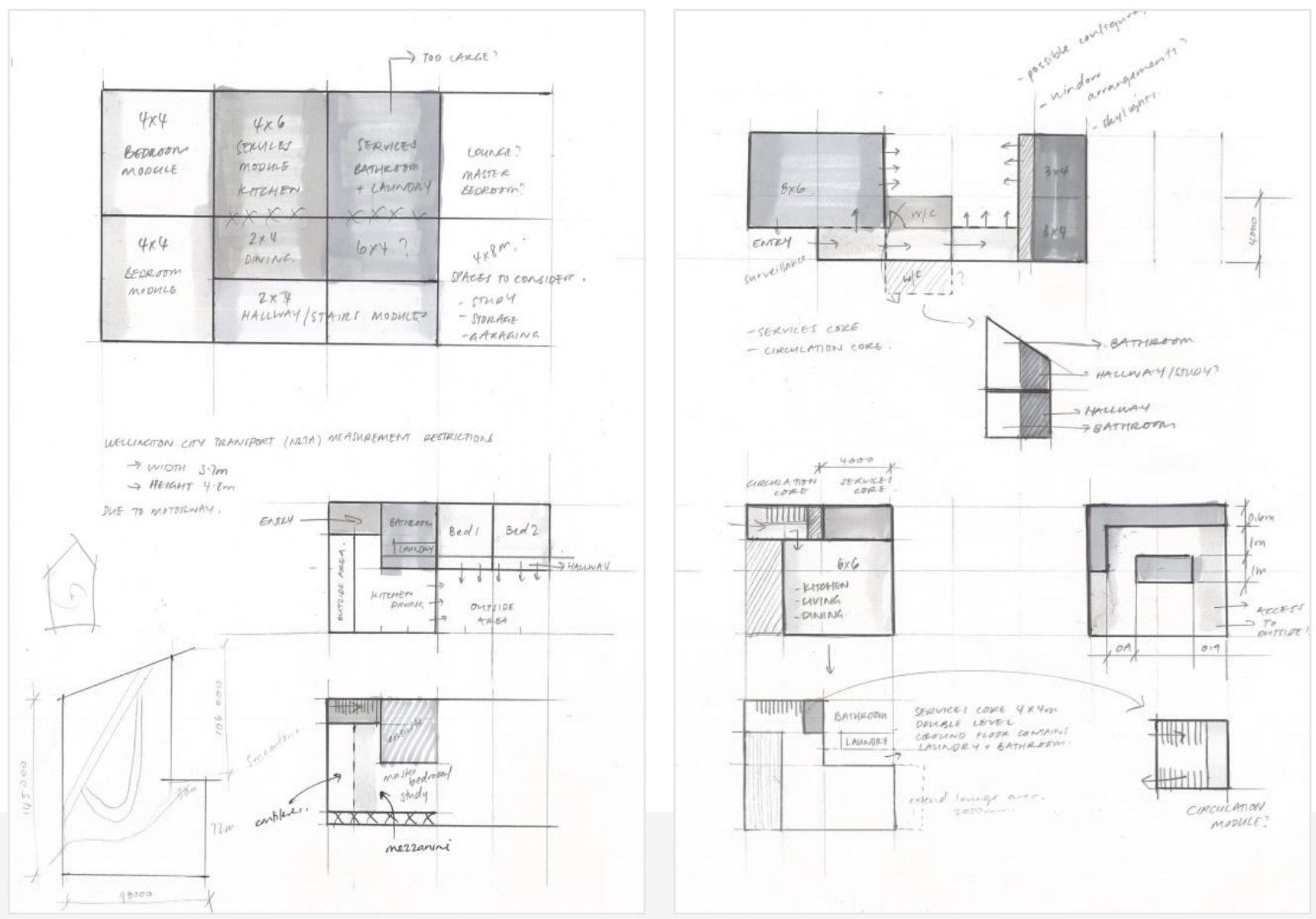

Figure Series 5.1.1: Dividing the floor plan of the home into modules to achieve practical dimensions for both interior configurations and transportability. The plan accommodates for a maximum width of two modules, each at $4 \mathrm{~m}$ wide. 


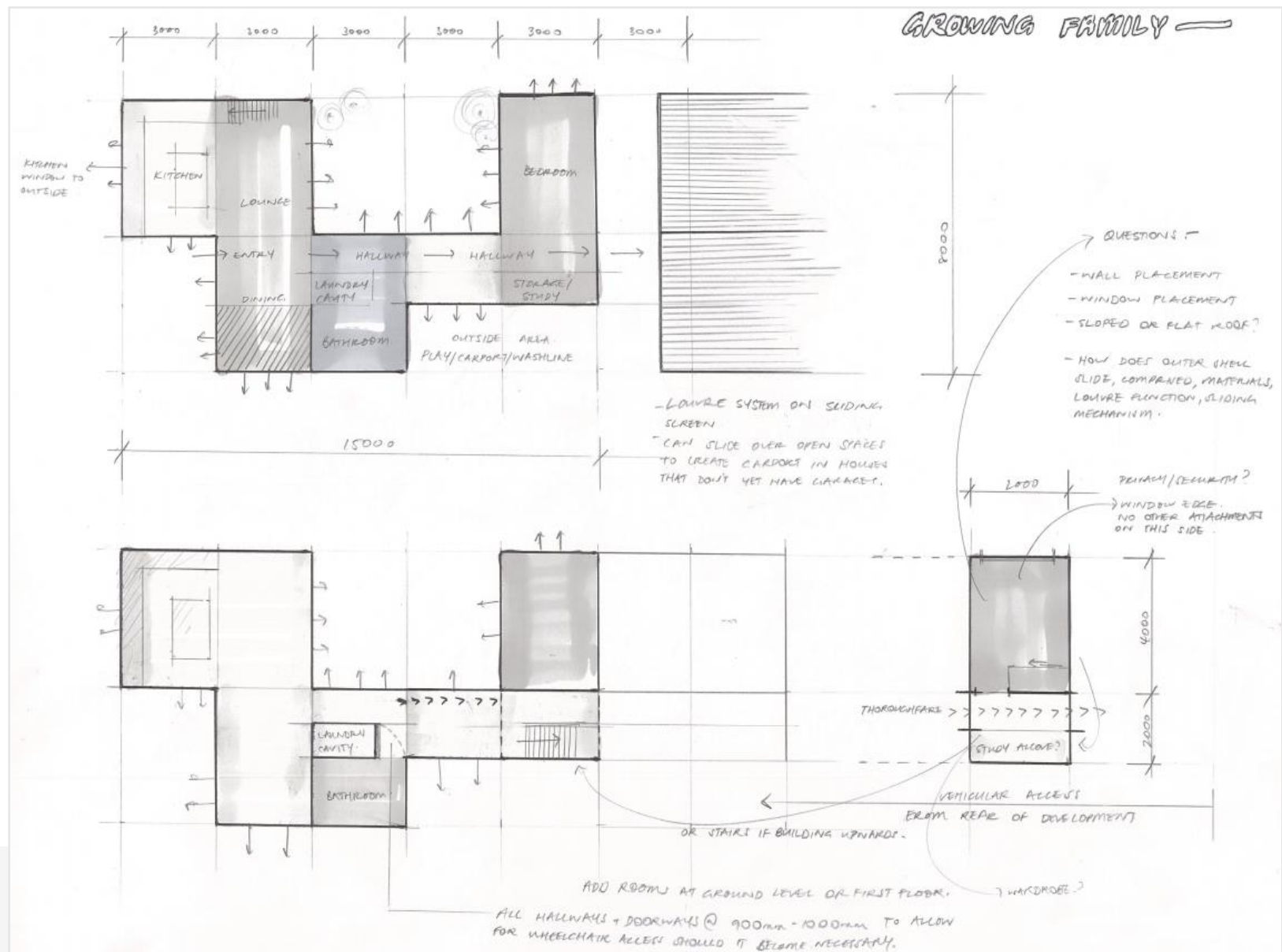

Figure Series 5.1.2: The initial home layout looks to comprise of the following modules: living, kitchen, bathroom, laundry and bedroom. The home then grows, adding bedroom and bathroom modules as required. The layout incorporates the fundamentals of residential amenity including outlook, private outdoor space with plenty of surveillance for the safety of children, orientation for sunlight, and accessibility within the home is provided with hallways of 1 metre in width. 


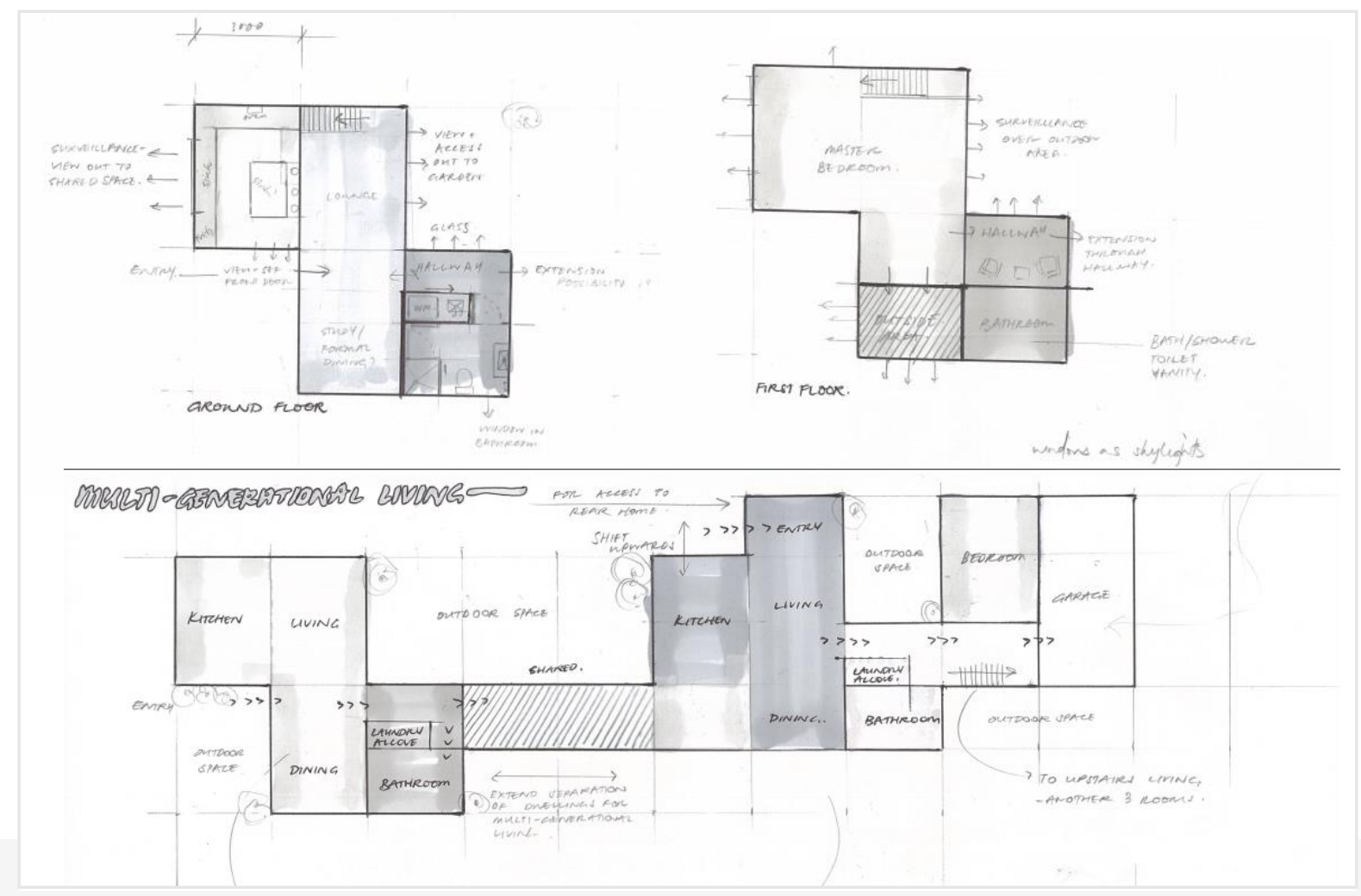

Figure Series 5.1.3: The least number of modules possible to create a liveable home to expand as financial circumstances improve. The homes accommodate ageing in place by allowing expansion for multigenerational living. 


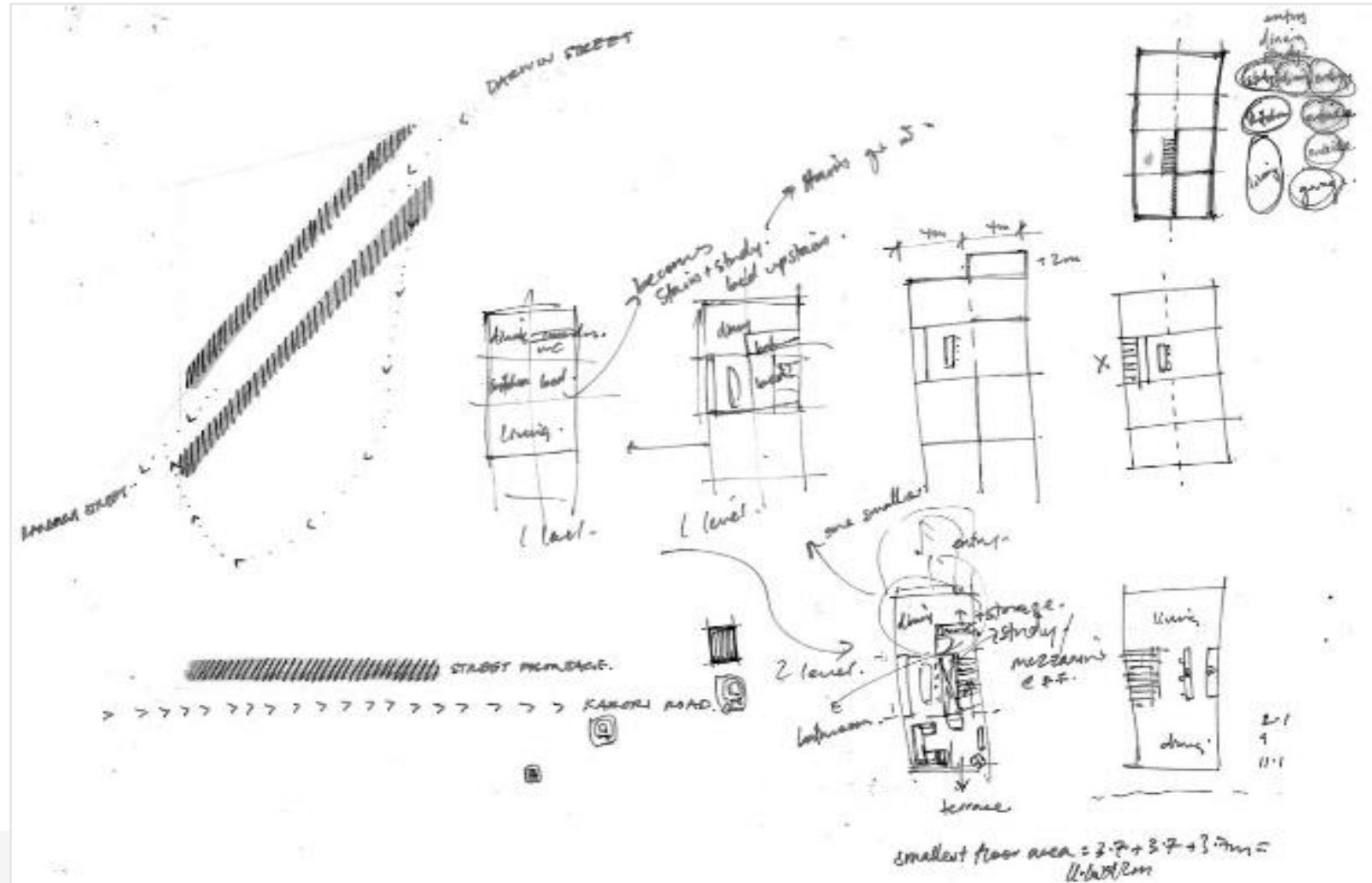

Figure Series 5.1.4: The growth of the home impacts the layout of the site to achieve the best possible level of residential amenity for all properties. 


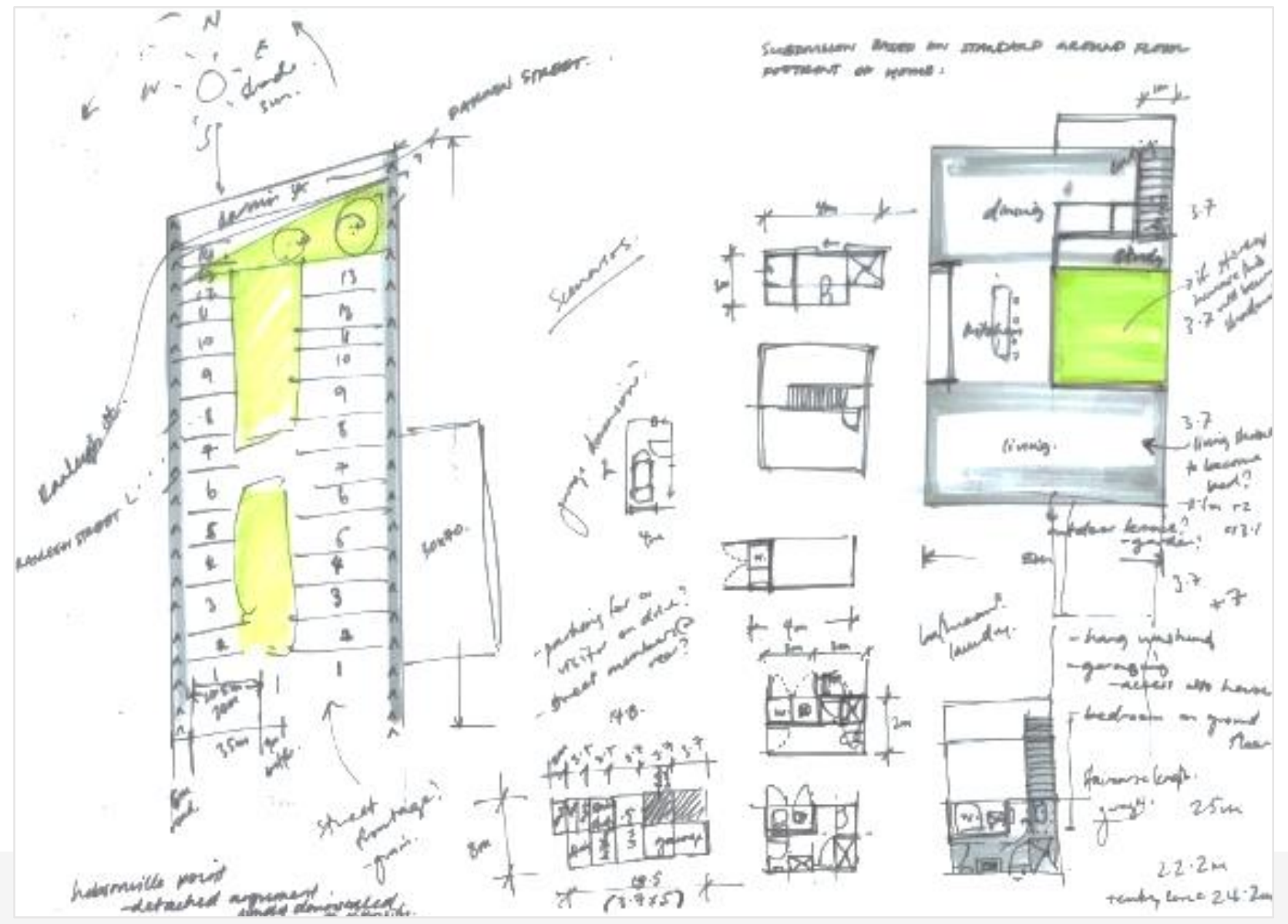

Figure Series 5.1.5: The plan of the home accommodates for a width of two modules, each at 4m, resulting in the site adopting long narrow sections to achieve medium density. 


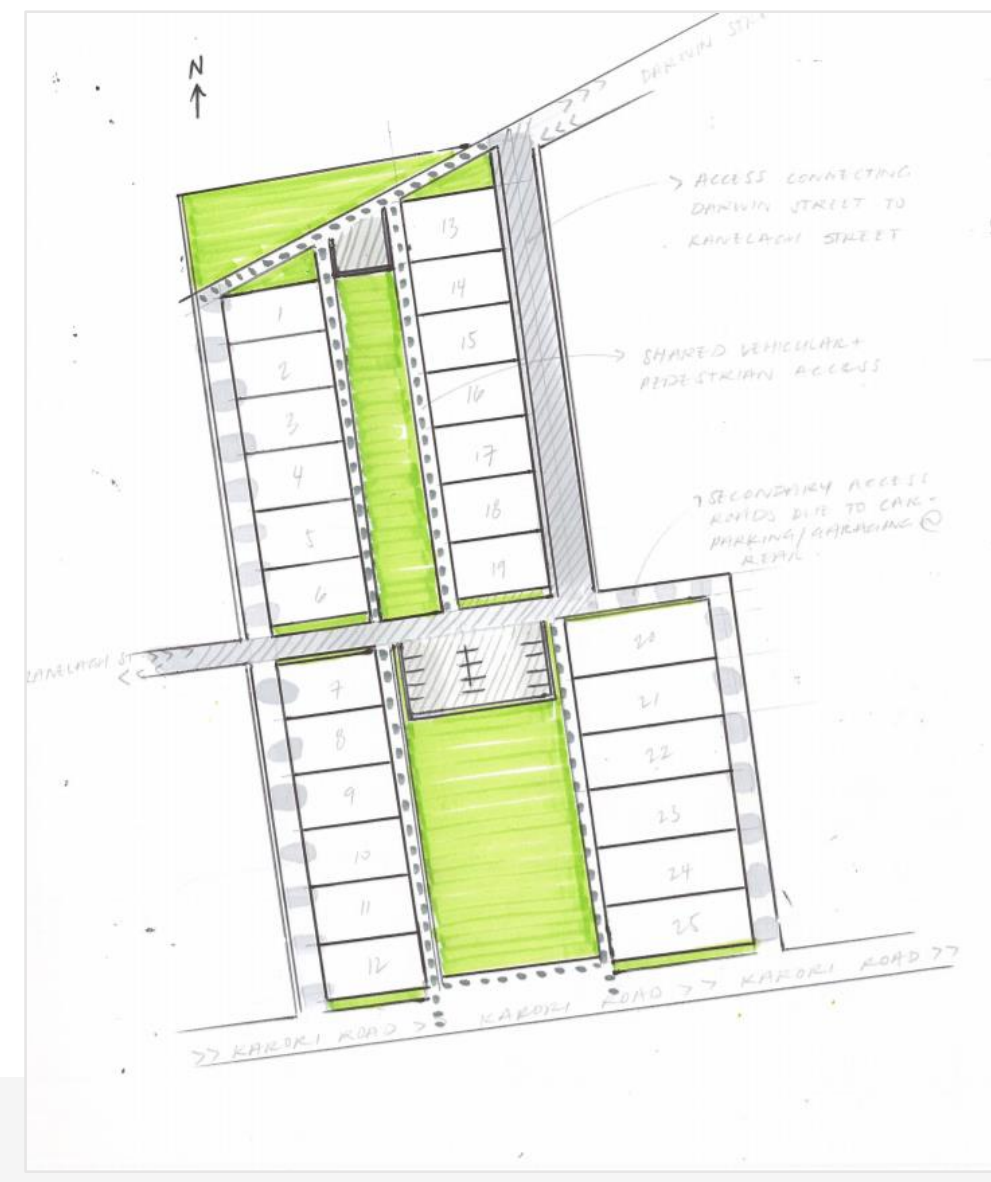

Figure 5.1.6: 25 sections are possible at ground level, with the potential for a second residence on the first and second levels of all properties to 50 possible households. 


$$
\text { 面筧: }
$$




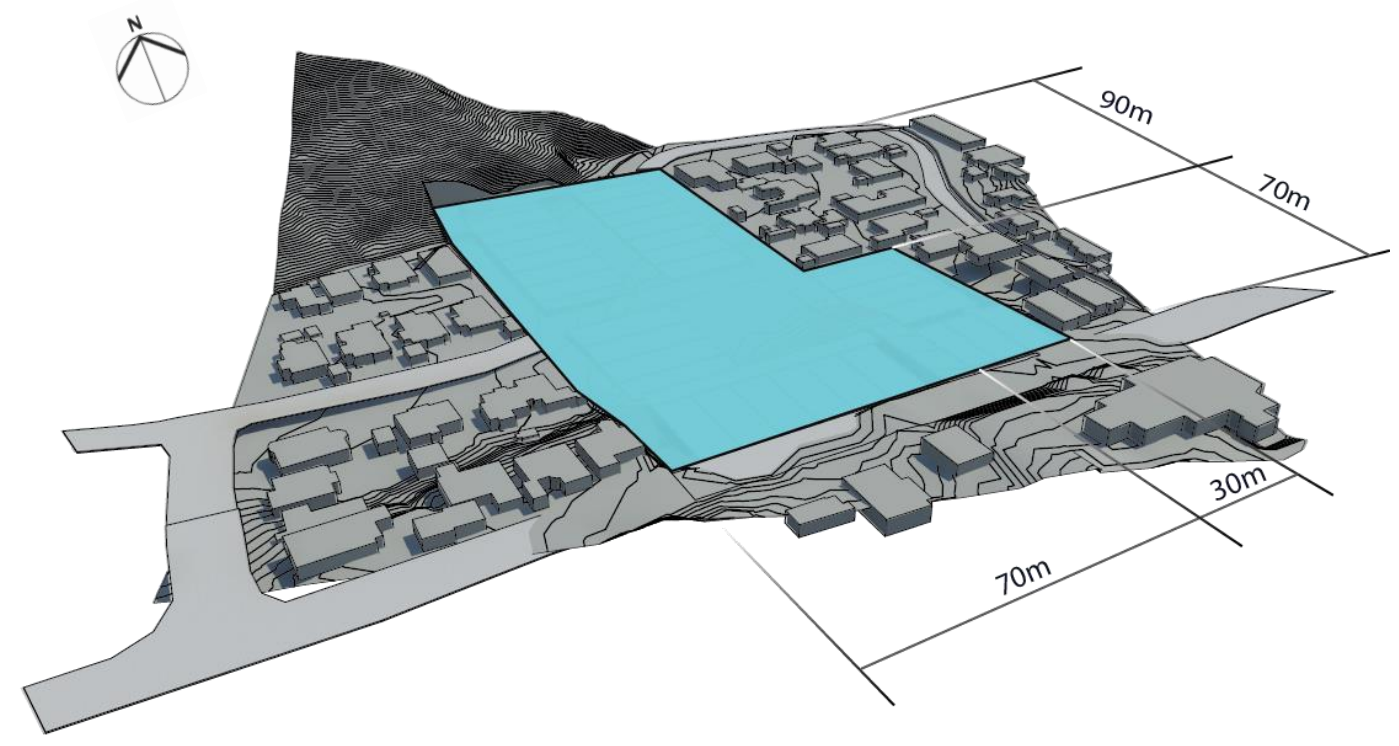

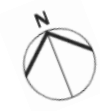

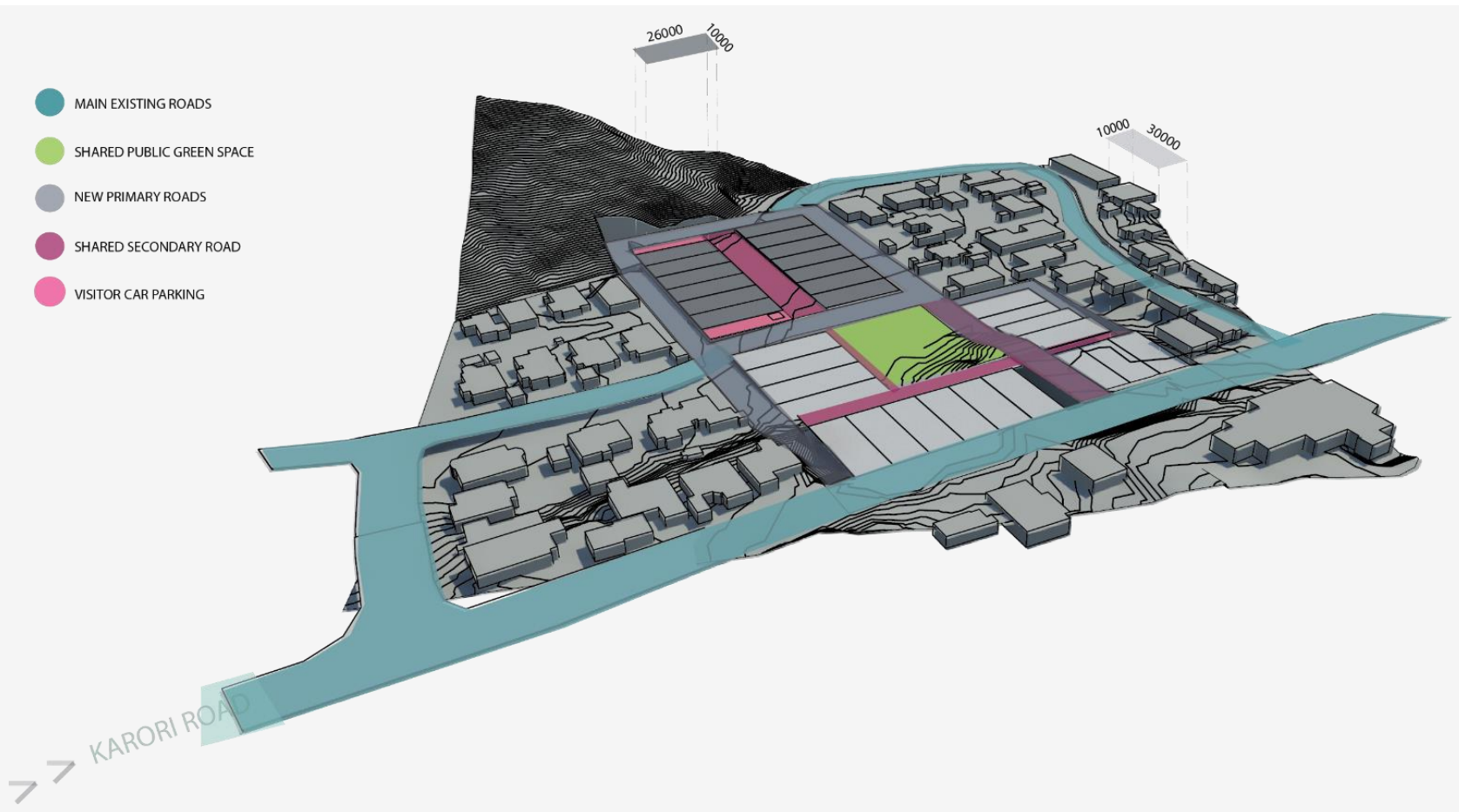

Figure Series 5.1.8: The perspective view illustrates the new road access through the site to allow for maximum intensification. The existing primary road of Darwin Street will remain to ensure the development is still connected to the wider community and existing context. Final site layout sees sections on Karori Road facing north-south to correspond to the existing grain and integrate the development into the community. Other sections face east-west to maximise access to daylight. 

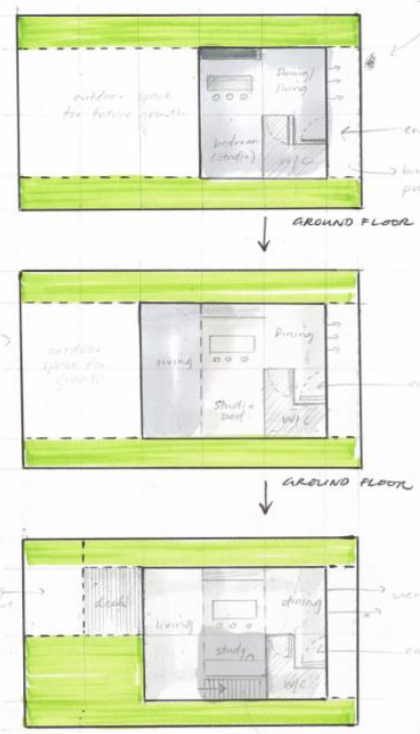

araun flook

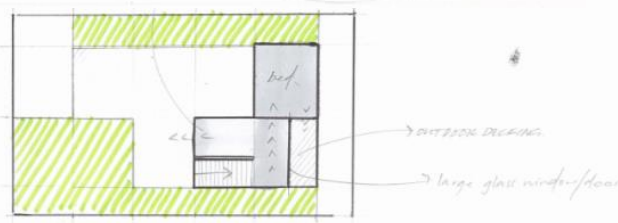

Fiest Floore
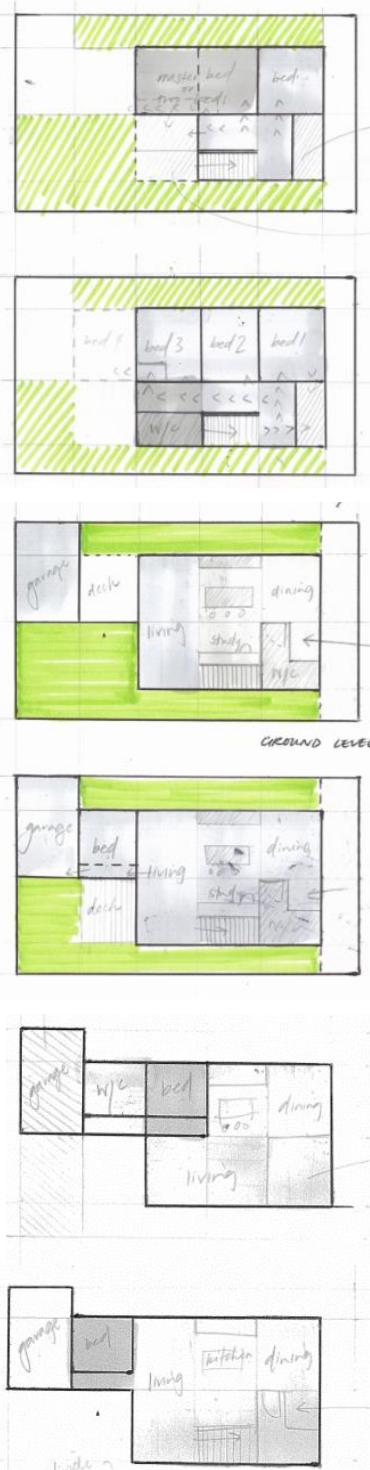

Figure Series 5.1.9: (Left) The plan view illustrates initial modules of the home positioned at equal set back distances from the centre of the development. The home then grows back towards to the rear of each section.

The plan of the home locating garaging nearest primary roads to ensure safer communal areas. However, this sees accessibility within the home decrease as the front entrance of the home is located on secondary roads.

Issues arising from this include:

- elderly access into home hindered

- functionality reduced e.g. carrying groceries from garage through to opposite end of the home

- lack safe driveway access for taxi pick-up and drop-offs to front door.

\section{CONSIDERATIONS}

Considerations arising from this design experiment include:

- The lineal growth of the home

- Transport restrictions on the dimensions of modules sees a narrow home emerge.

- The need for standardisation of openings required as the home expands in a linear pattern.

- Accessibility: dual entry to home for primary and secondary road network.

While hand drawing in plan is beneficial to realise the spatial planning of the home, the second design experiment furthers these plans to explore the notion of linear progression and the design characteristics of the home translating drawing into physical and digital modelling to realise form. 
The second preliminary design experiment addresses the form of the home. Understanding the lineal growth of sections sees the design experiment with temporality. Physical and computer modelling are instrumental in realising form, where the previous iteration has provided the basis of these experiments through planning relationships of the home which have been extracted to explore the ephemeral qualities of the design illustrated in figures 5.2.3 to 5.2.5.

The pitched angle emerging from the design exploration, emulates the existing qualities of Karori homes. The gable form roof is strongly associated with the feeling of 'home' and contributes to achieve the aim of a lifetime appropriate design giving the warm feel of home rather than the disconnection often felt in medium density housing complexes.

\section{CONSIDERATIONS}

- The design implication of the pitched roof sees reduced wall heights to allow for transport of the modules.

- Standardisation of openings on the $x$ axis to accommodate the lineal growth of the home.

- Arterial route running the length of the home for accessibility.
Figure 5.2.1: Physical model to realise linear growth of the home.

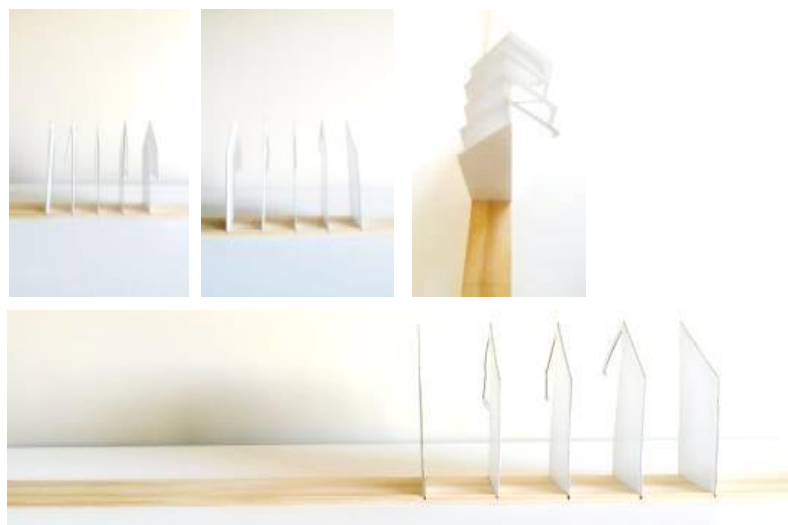

Figure Series 5.2.2: Consideration: The need for standardisation on the $\mathrm{x}$ axis for lineal growth.

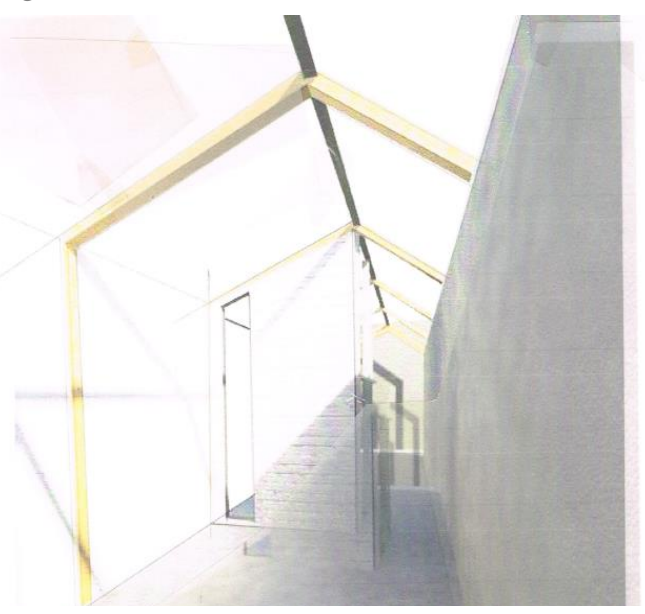

Figure 5.2.3: The home adds modules to the rear of the home to allow for growth.

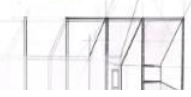

Figure 5.2.4 and 5.2.5: The solution is temporary and circumstances are always changing. These design explorations convey the temporality of the home to be reflected in the design to reduce the negative impact on the site.

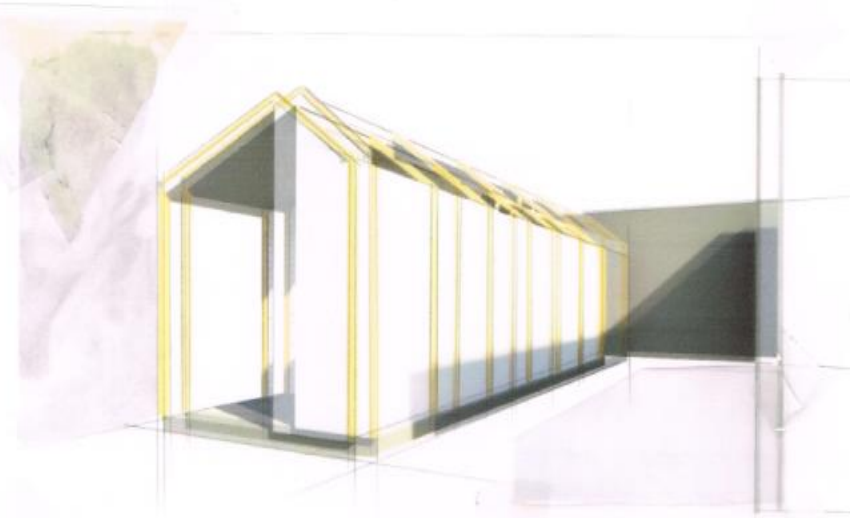


PRELIMINARY DESIGN EXPERIMENT THREE $\mid 5.3$

The third preliminary design experiment explores the relationship between modules to aid the realisation of form. Computer modelling is beneficial for this exploration as it provides an efficient means to produce three dimensional forms and make alterations.

\section{CONSIDERATIONS}

Considerations arising from this experiment include:

- The vertical expansion of the home is only possible where a flat roof is provided.

- Pitched roofs can act as an architectural feature to create the feel of 'home' as well as provide the necessary limitations for expansion, preserving the residential amenity of neighbouring properties over time.

Figure Series 5.3.2: Sees the modules group together in differen formations, highlighting the importance of regulated windows and openings in each type of module to ensure a high level of residential amenity is achieved.

Windows and skylights see plenty of sunlight enter the home as well as provide ventilation, surveillance and security for the dweller.
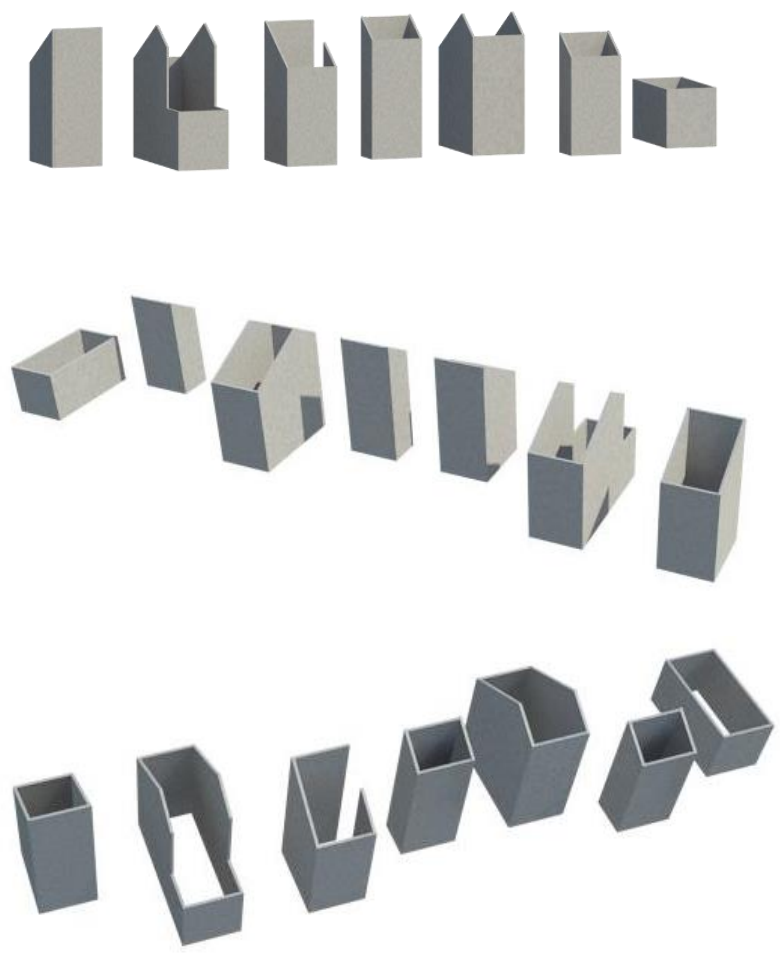

Figure Series 5.3.1: A range of modules available for mass customization of the home to express individuality within the complex.
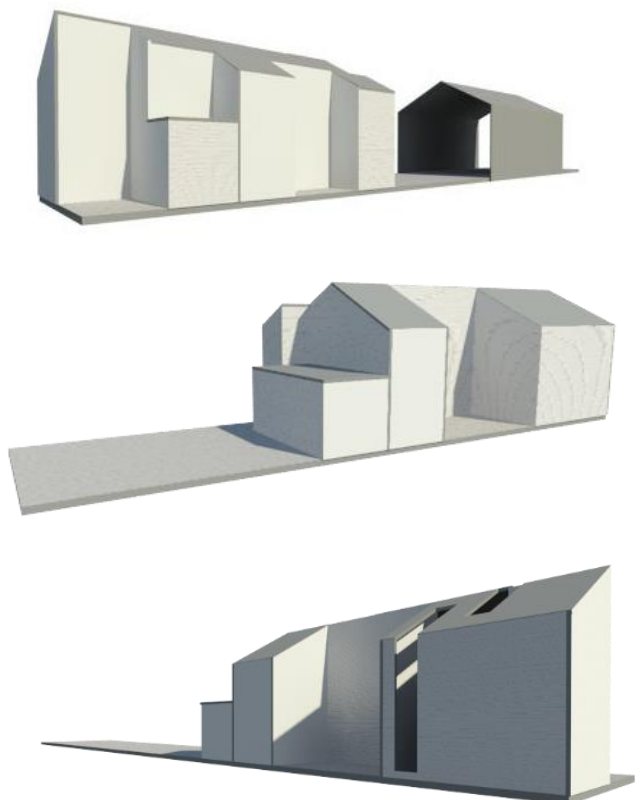
The following design experiment uses physical modelling to test the restrictions and capabilities of the form at 1:50 scale.

This iteration builds on the previous computer model, creating modules for each room of the home at the maximum dimensions for transportability.

The modules have the potential for growth embedded within their composition using standardisation of openings. These regulated openings can either be used as windows, doors, infill wall panels or as an entrance into an additional module, providing the framework for the home to expand.
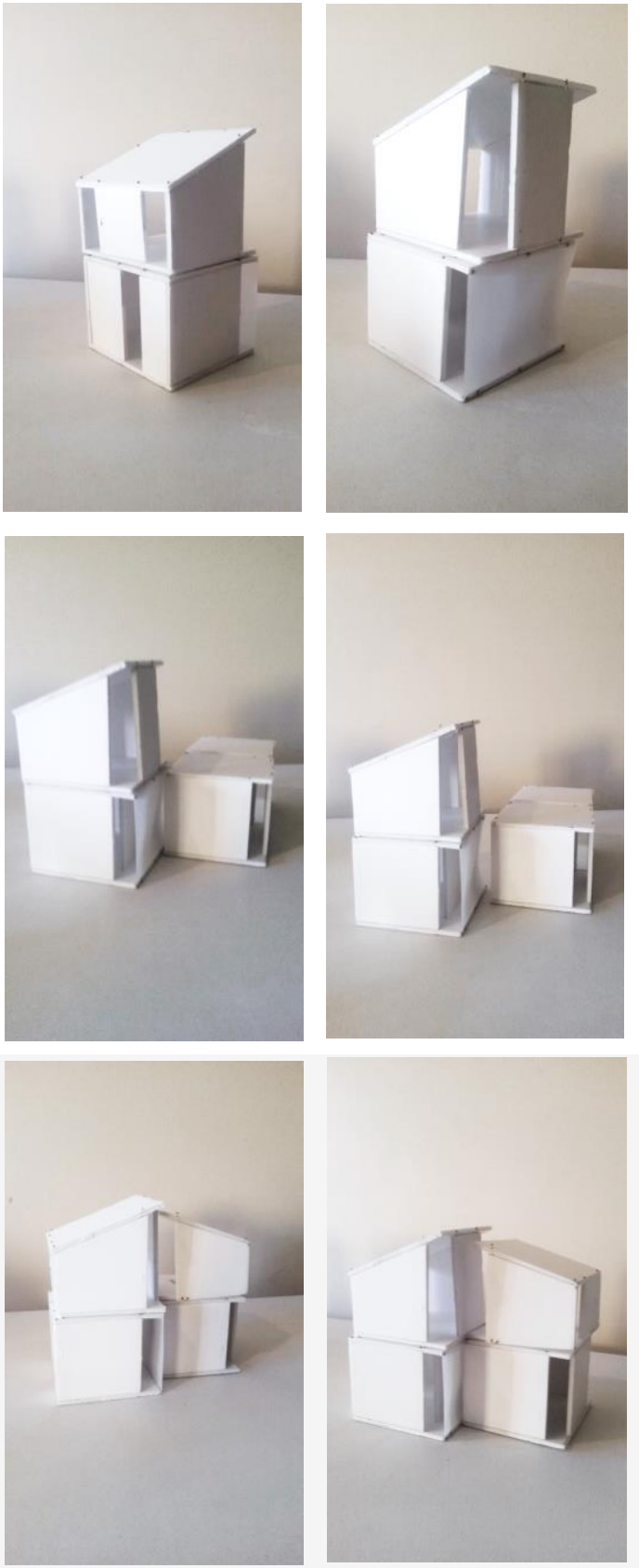

Figure Series 5.4.1: Physical models demonstrating the growth of the home, made possible through aligning standardised openings. 

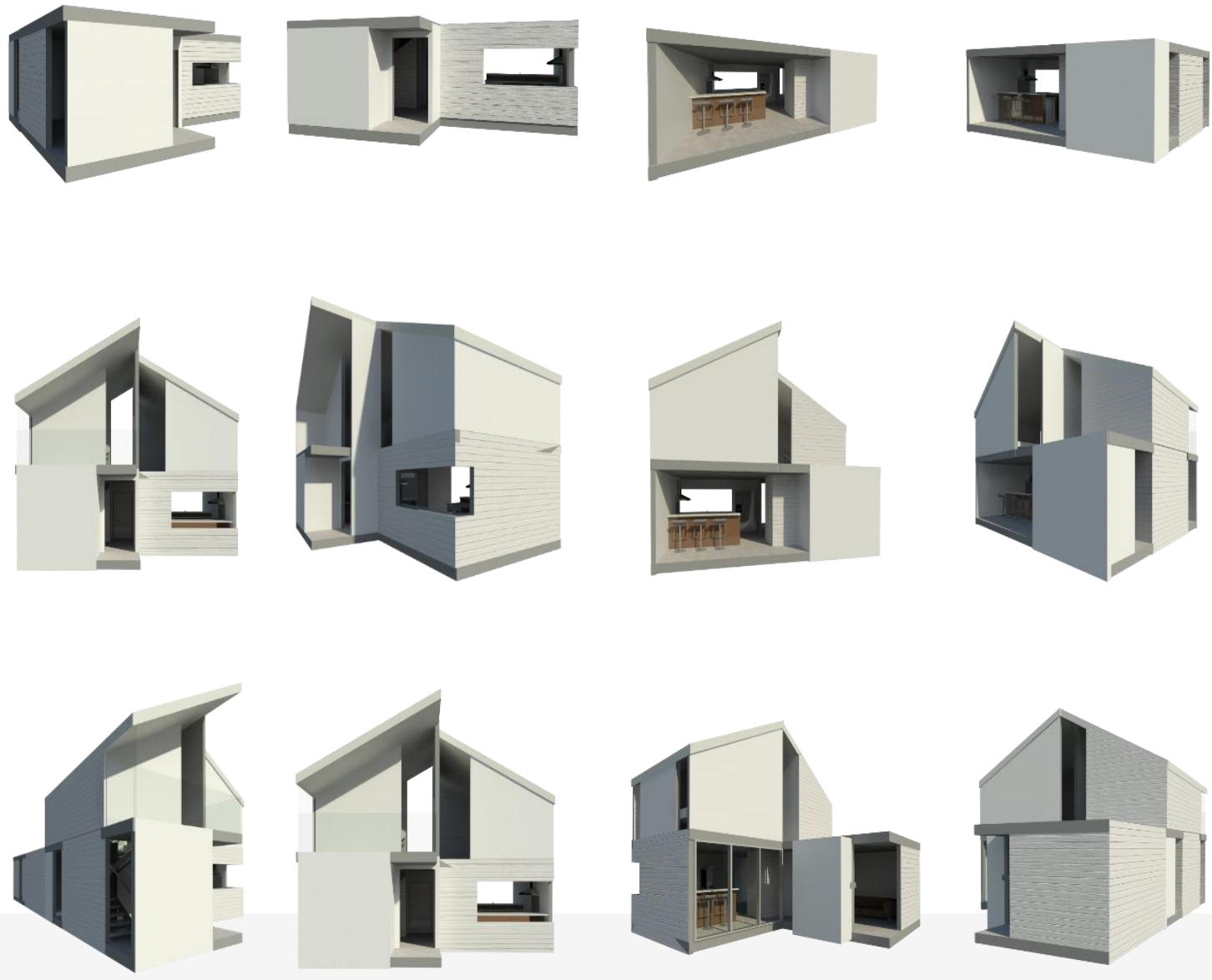

Figure Series 5.5.1: This fifth iteration converts the form of the physical modelling into computer modelling. The purpose of this exercise is to accurately determine the best possible locations for standardised openings in plan. This is then easily assessed in three dimensions to understand the effect these decisions have on the amount of light received internally and the implications this has on the internal configurations of spaces to still allow for wheelchair accessibility.

The issue with the current layout that sees the width of the home equal to two modules is that there are always two unfinished walls in preparation of expansion. Both the side and back walls must be prepared for change, whereas if the modules were longer in the $\mathrm{x}$ direction, but did not exceed $3.7 \mathrm{~m}$ on their shortest edge, only the back wall would ever have to accommodate for change. 
This design experiment resolves the issues highlighted in the previous iterations. The design utilizes the width of a single module to expand the home from the rear wall of the last exposed module.

This sees a central spine hallway run the length of the home and makes planning for potential changes easier through openings in the same place in each module.
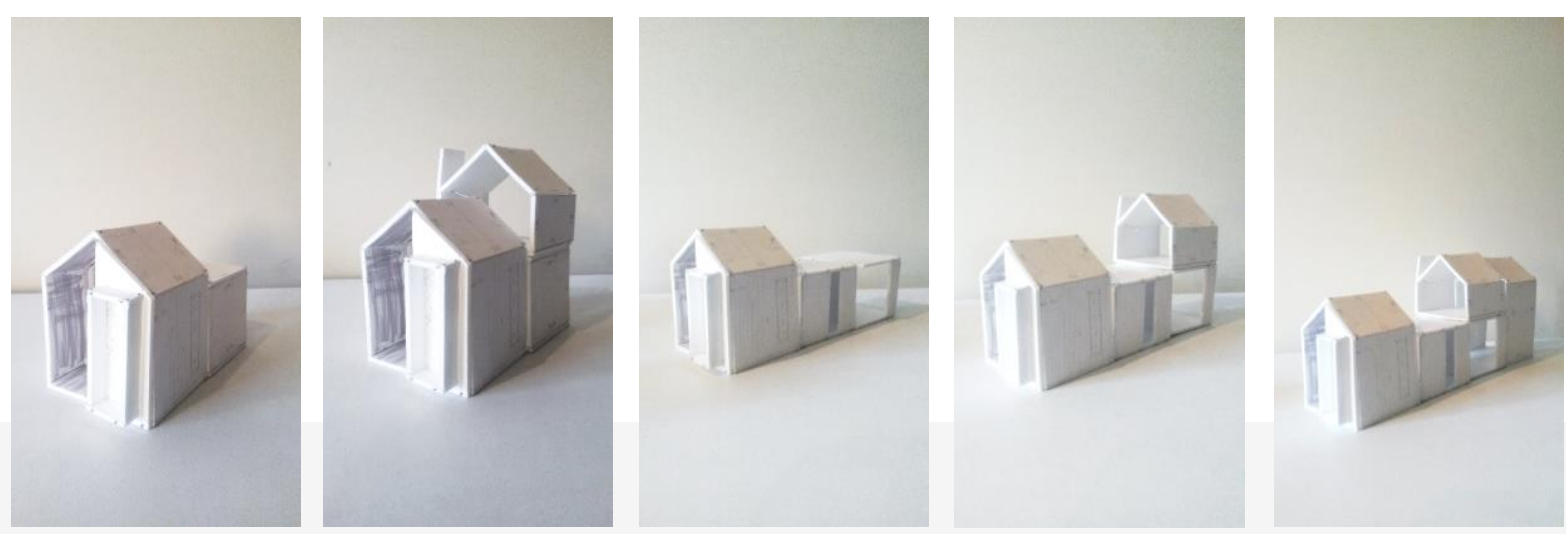

Figure 5.6.1: The physical models illustrate how the home would grow over time. Points of expansion are restricted to the rear of the last exposed wall and the upper floor where there is a flat roof. This makes regulating the locations of standardised openings simple, as this will be the same for each module. 


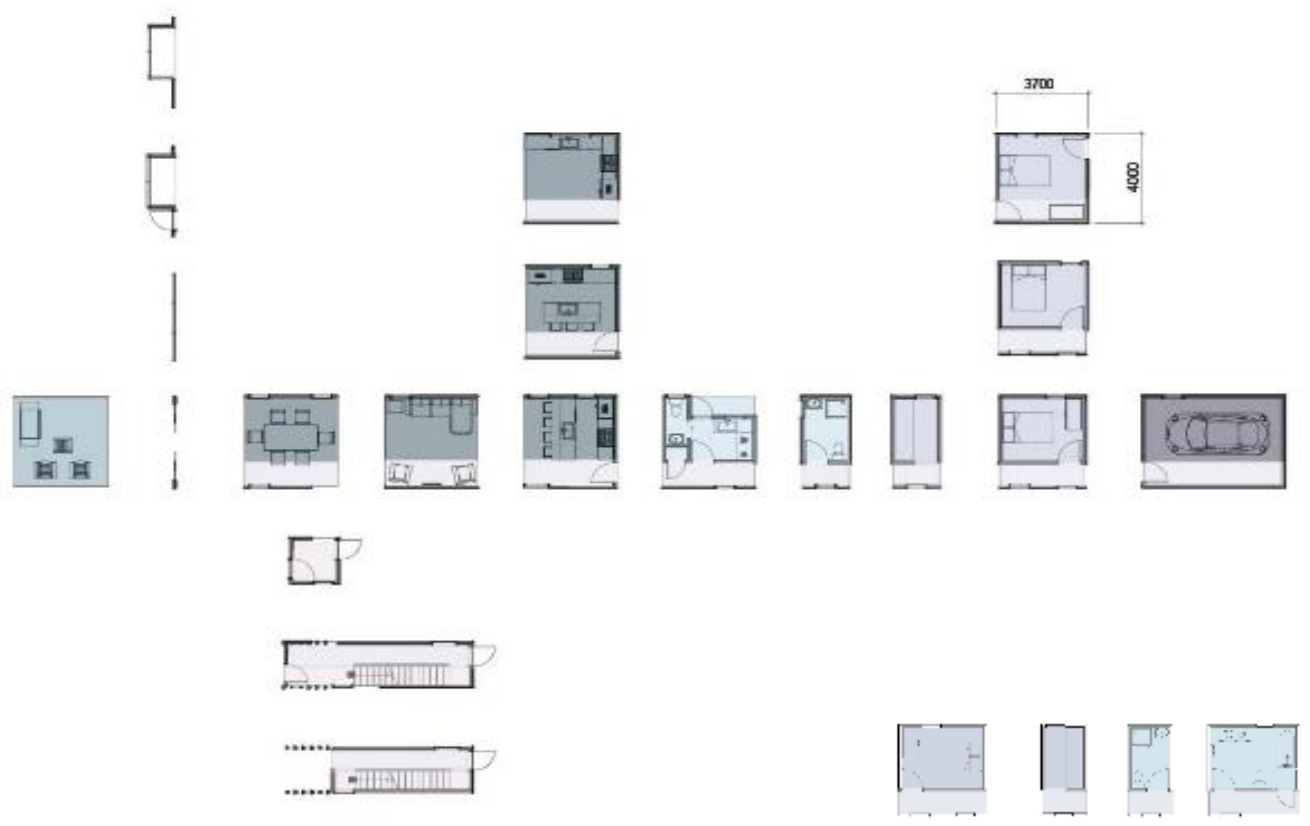

Figure 5.6.2: Modules translated into computer model to generate floor plans. The home is $4 \mathrm{~m}$ wide, with a $1 \mathrm{~m}$ wide hallway for accessibility. There is a standard opening in the hallway of each module to either be extended as the home grows or closed off with a window, door or wall panel. Large full height windows are also located on the length of the external walls to maximise daylight and sunlight within the home as well as provide future potential for the home to expand to the sides.

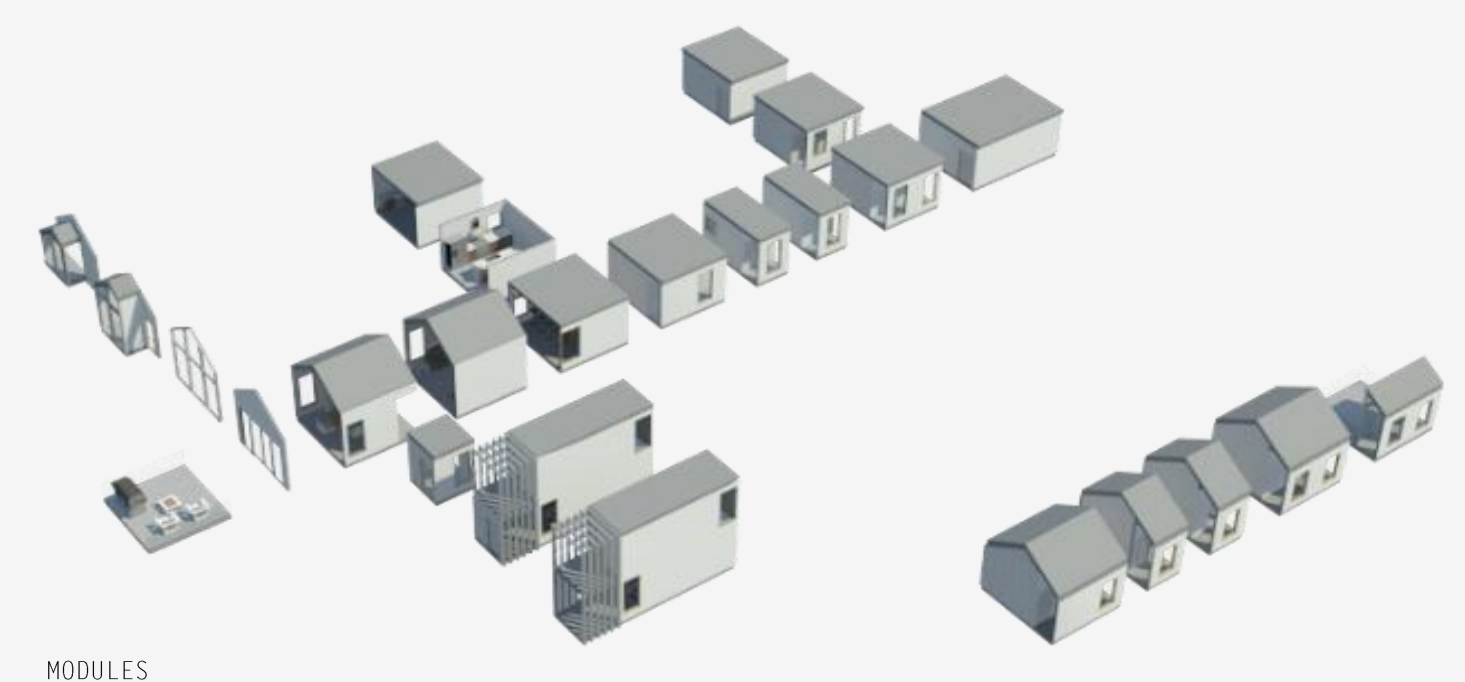

Figure 5.6.3: The selection of modules available to configure the home to the occupants needs. Mass customization offers individuality for the buyer in terms of the layout and aesthetic of the home. Prefabrication assists this with a range of front facades available to achieve individuality. 
PRELIMINARY DESIGN EXPERIMENT SEVEN |

5.7

This design experiment uses the set of modules from the previous exploration to illustrate the scenario of the home growing to accommodate a young family.

As the home expands to the upper floors, accessibility is not to be compromised. Provisions are taken to ensure the walls are strong enough to accommodate a chair lift should it be necessary in future. The bathroom is also designed to be easily altered should wheelchair accessibility be required.
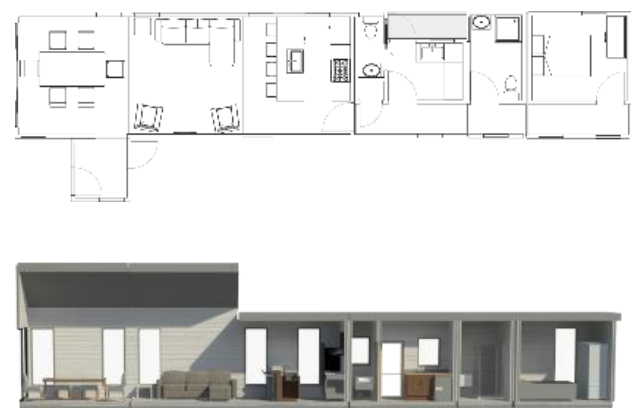

Figure 5.7.1: First iteration of the home: Dining, living, kitchen, laundry, bathroom and bedroom.
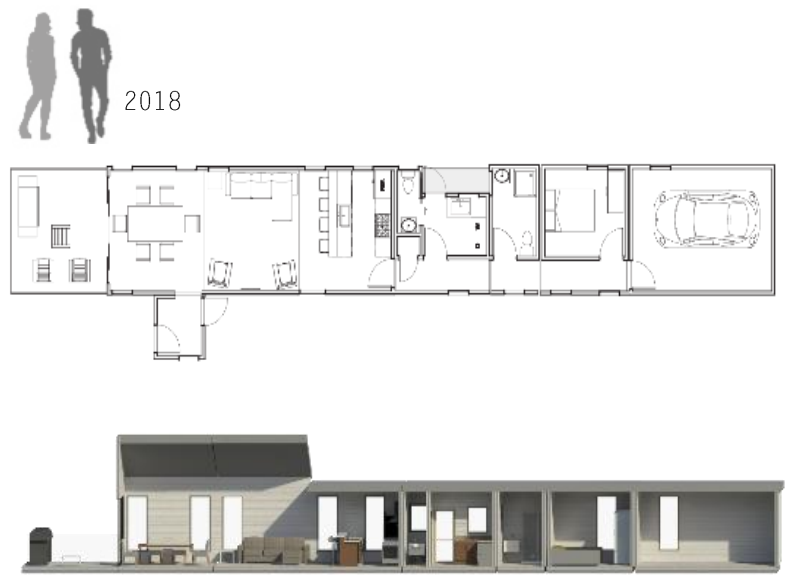

Figure 5.7.2: Second iteration of the home: Dining, living, kitchen, laundry, bathroom and bedroom, outdoor area and garage added as financial circumstances improve.
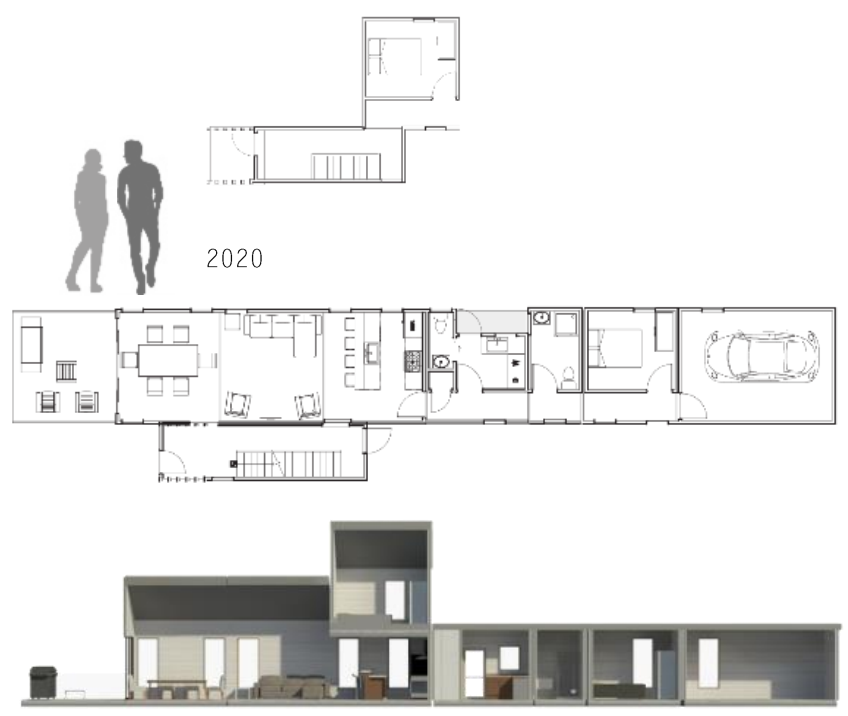

Figure 5.7.3: Third iteration of the home: Dining, living, kitchen, laundry, bathroom and bedroom, outdoor area, garage and circulation to upper floor with bedroom added. 


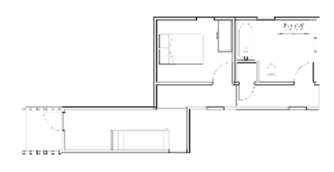

.
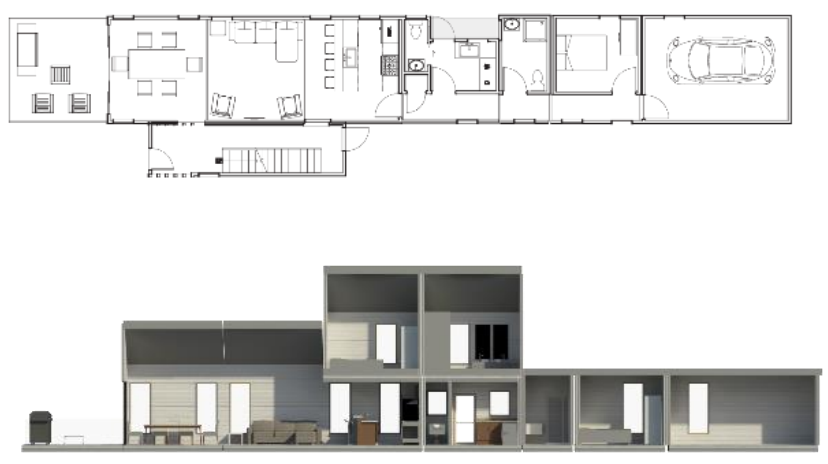

Figure 5.7.4: Fourth iteration of the home: Dining, living, kitchen, laundry, bathroom and bedroom, outdoor area, garage and circulation to upper floor, two upper bedrooms.
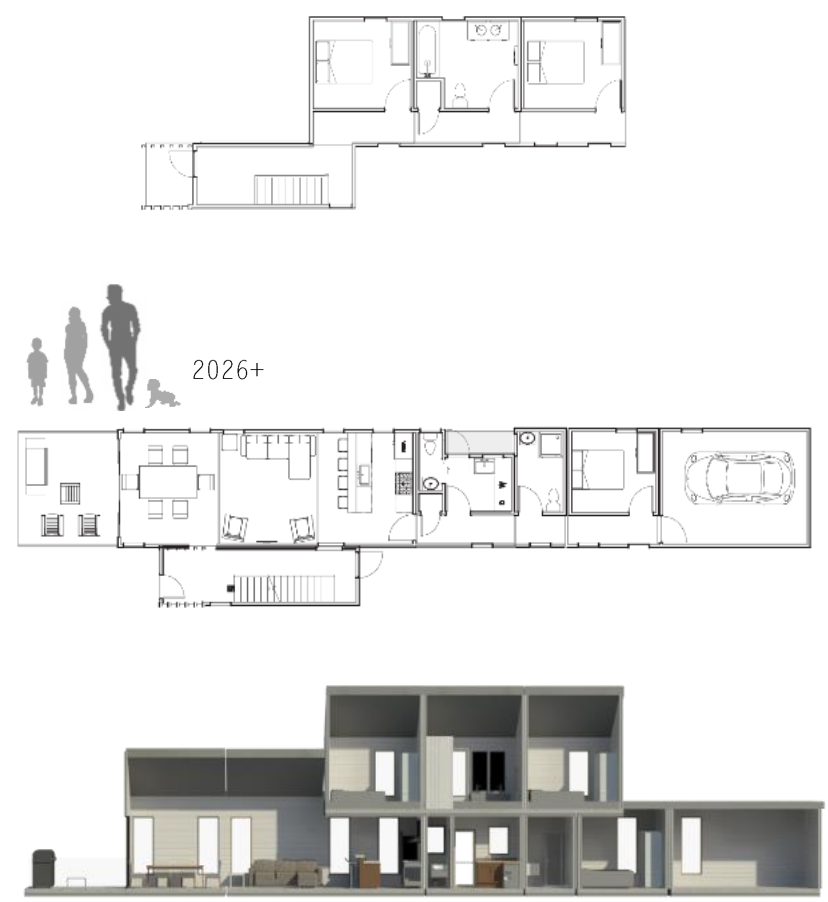

Figure 5.7.5: Fifth iteration of the home: Dining, living, kitchen, laundry, bathroom and bedroom, outdoor area, garage and circulation to upper floor, three upper bedrooms. 

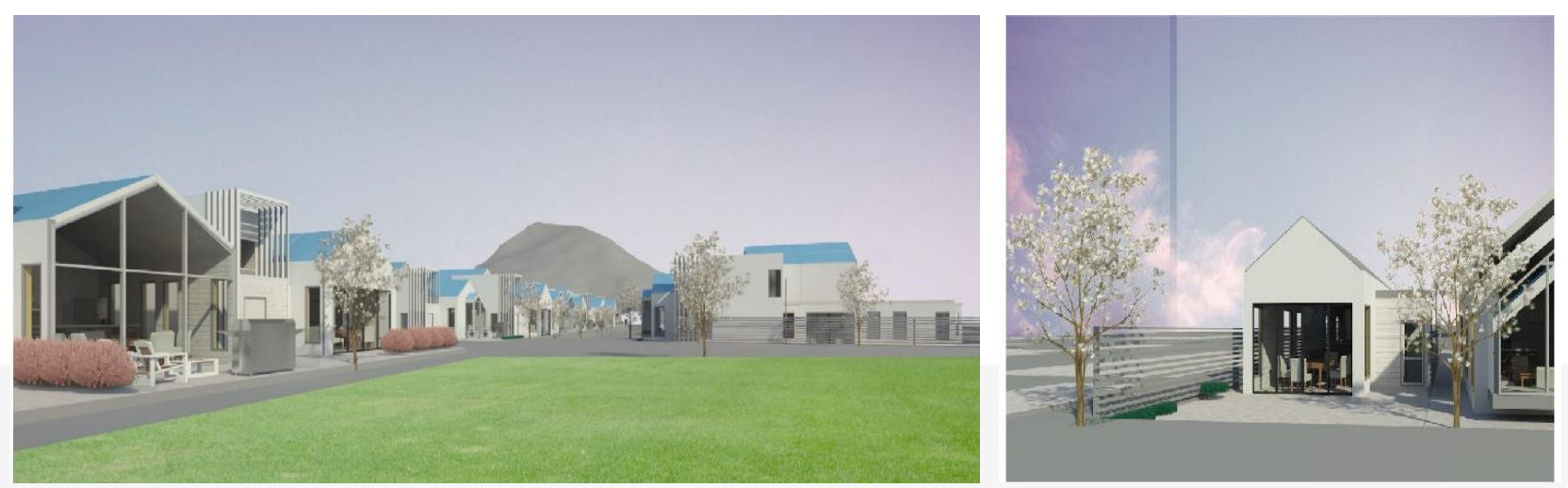

Figure 5.7.6: Exterior perspectives of the development. 
To deliver a home capable of adapting at ease, cross laminated timber (CLT) is employed for its suitability for modular prefabrication and structural integrity.

$C L T$ is non-restrictive like other materials that can limit designs due to product dimensions. CLT can be built to specification, allowing for varying wall heights and lengths.

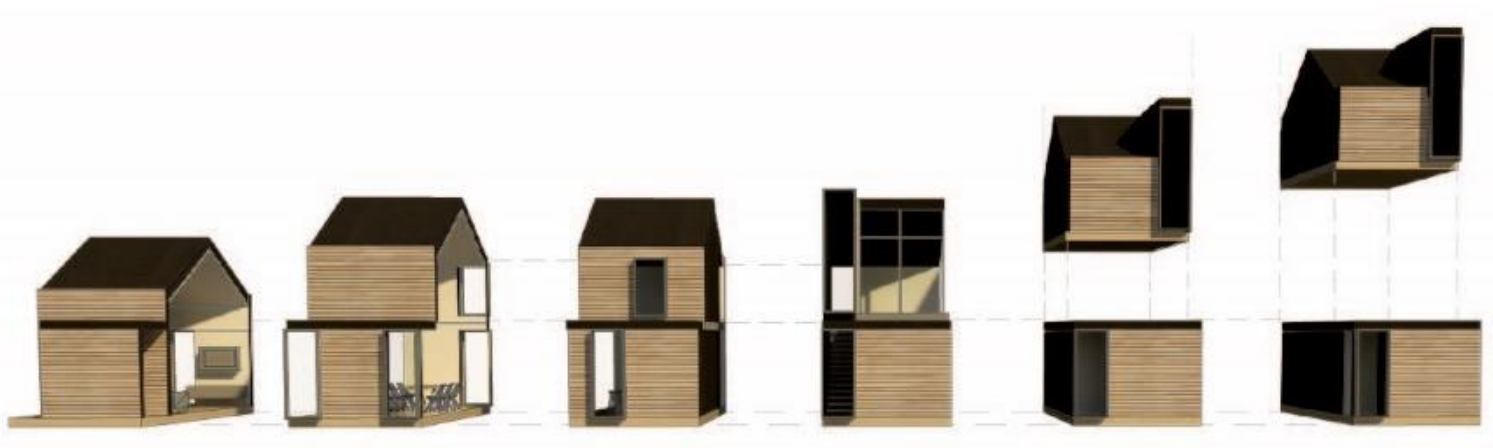

Figure 5.8.1: Exploded perspective of modules creating the adaptable home.

In addition to standardised openings, removable façade panels aid the growth of the home without the need to waste materials. 

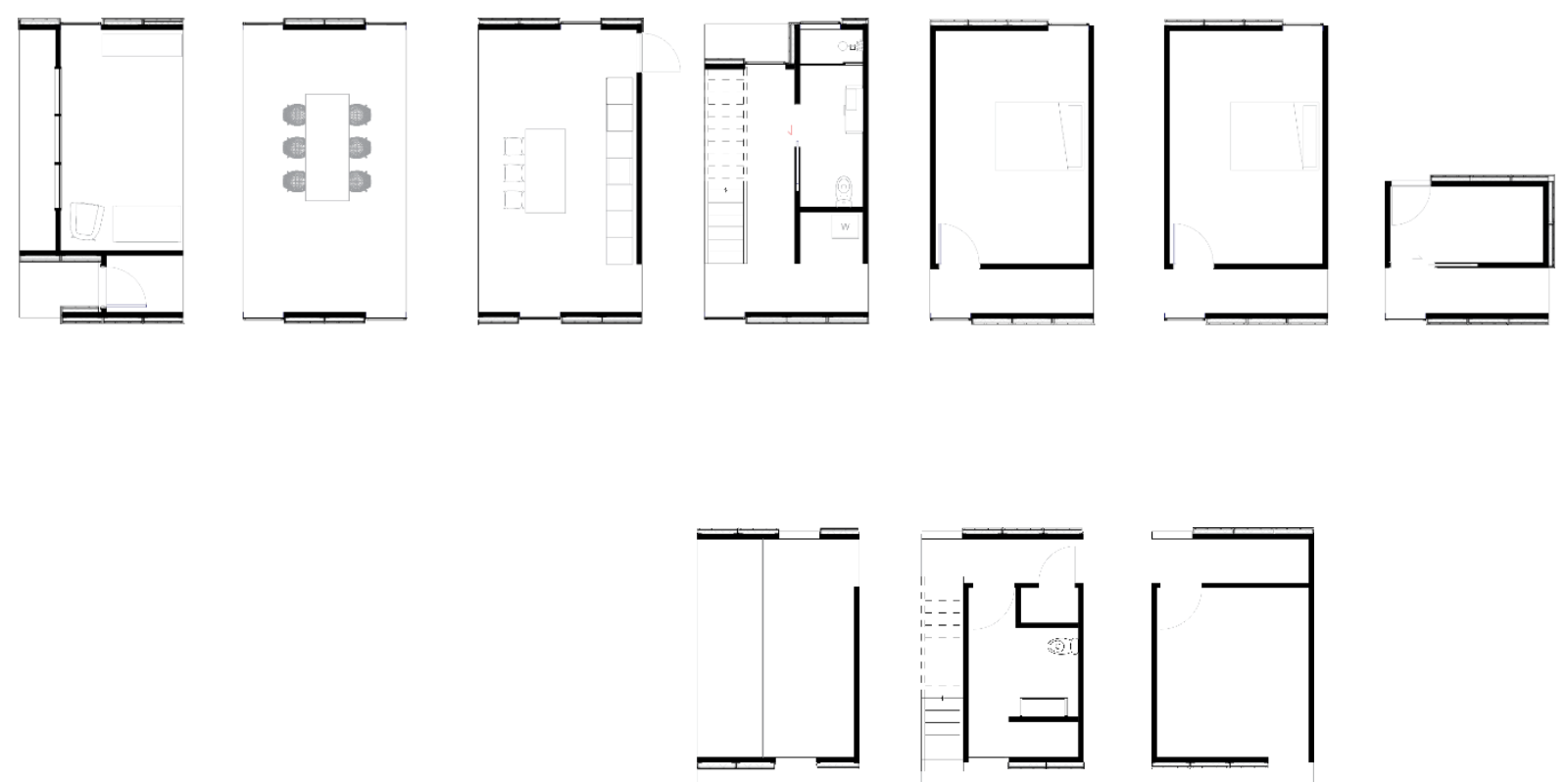

Figure 5.8.2: Floor plan of modules available for customisation of the home. The spine (hallway) allows for a regulated point for standardisation of openings for each module. This allows for easy expansion of the home or contraction with the use of infill panels.

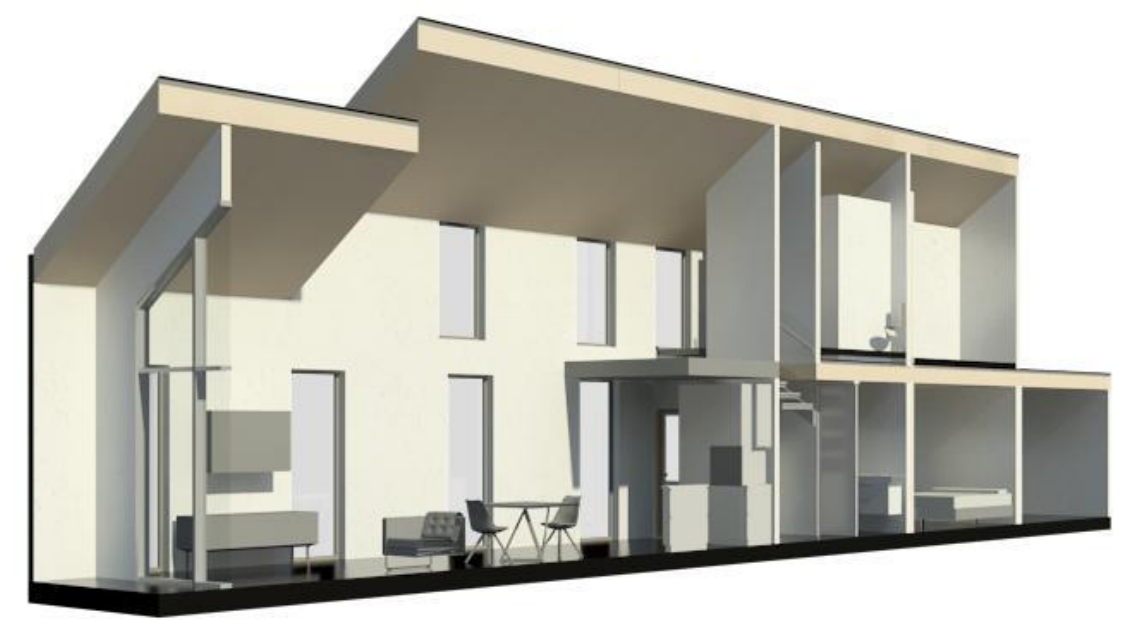

Figure 5.8.3: Section perspective of the home. 


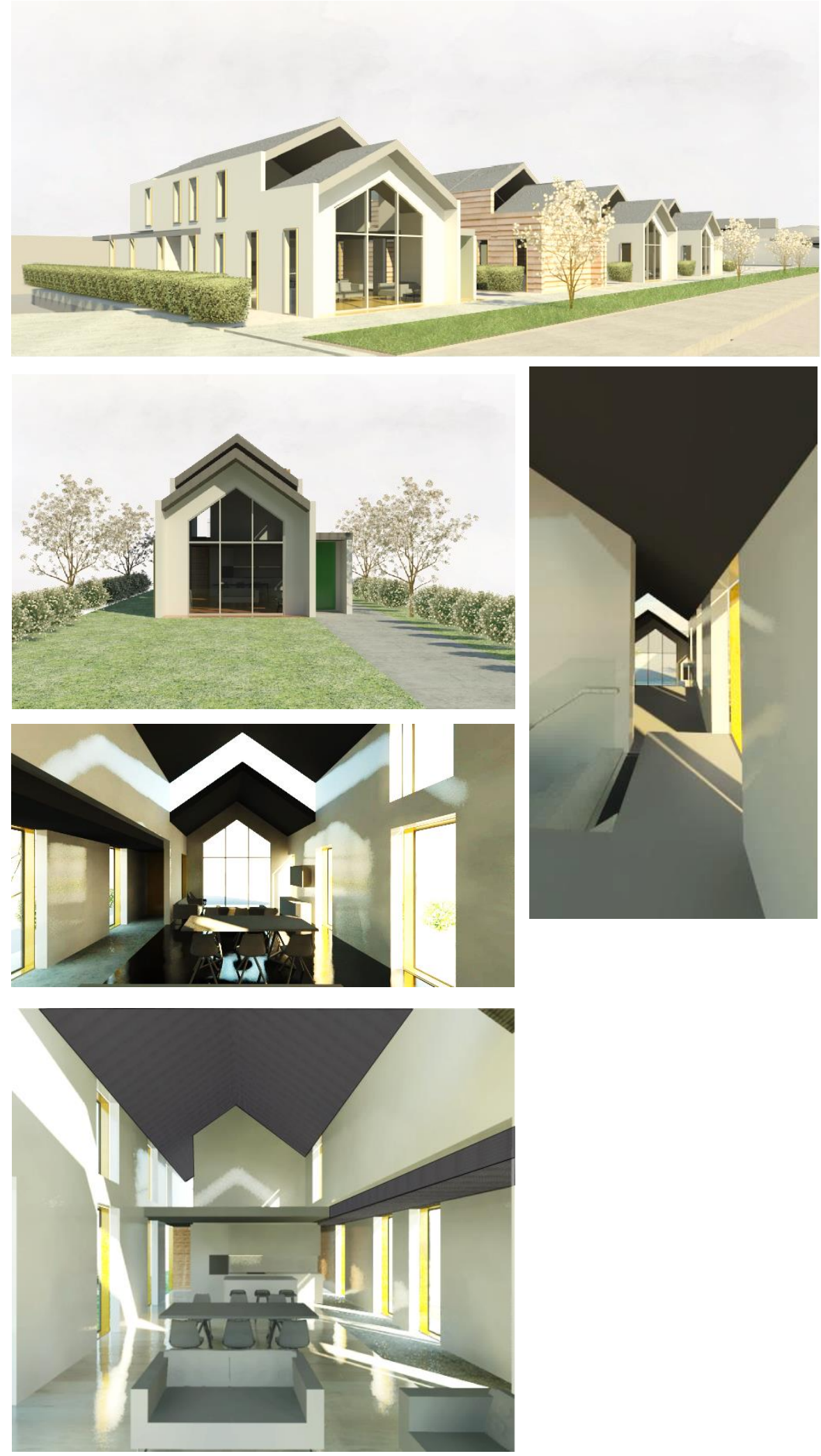

Figure Series 5.8.4: Perspective renders of interior of the home highlighting the spacious interiors for accessibility, yet compact enough for modular design. Connection to private outdoor space would see the solution address the fundamentals of residential amenity to a higher standard. 


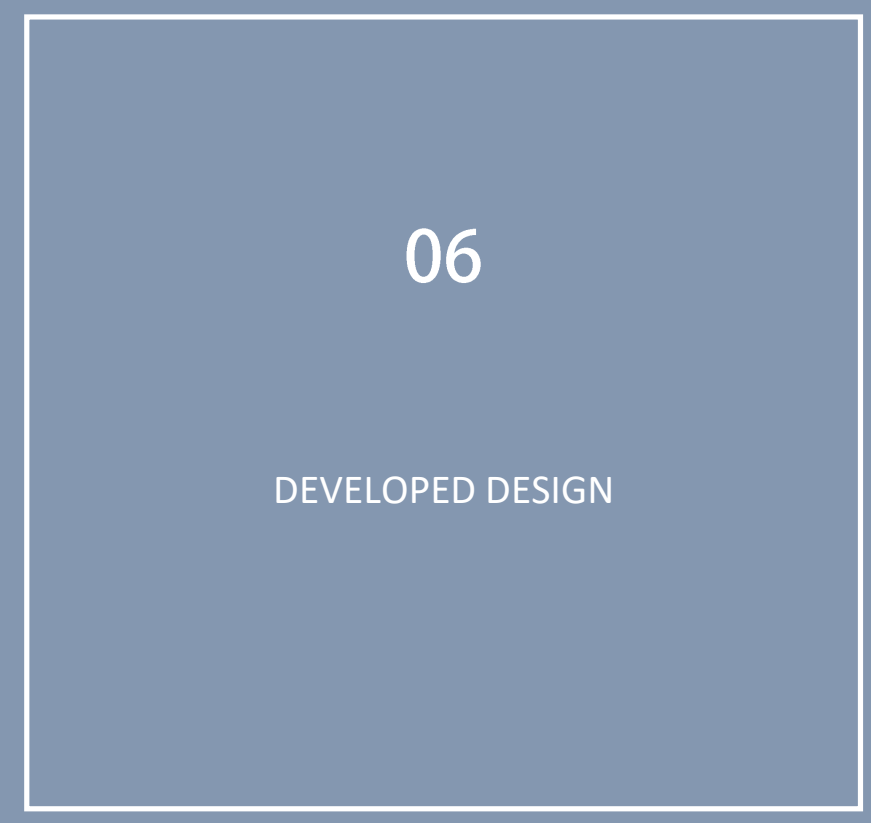




\section{DEVELOPED DESIGN}

6.0

The developed design integrates all previously successful design experiments into a cohesive design outcome that represents a solution to the research question, 'how can the home be redefined to adapt to the changing needs of its occupants?' The aims and objectives of the investigation are met by the developed design of this chapter and is concluded by appraising the strengths and weaknesses of the developed design experiment. 

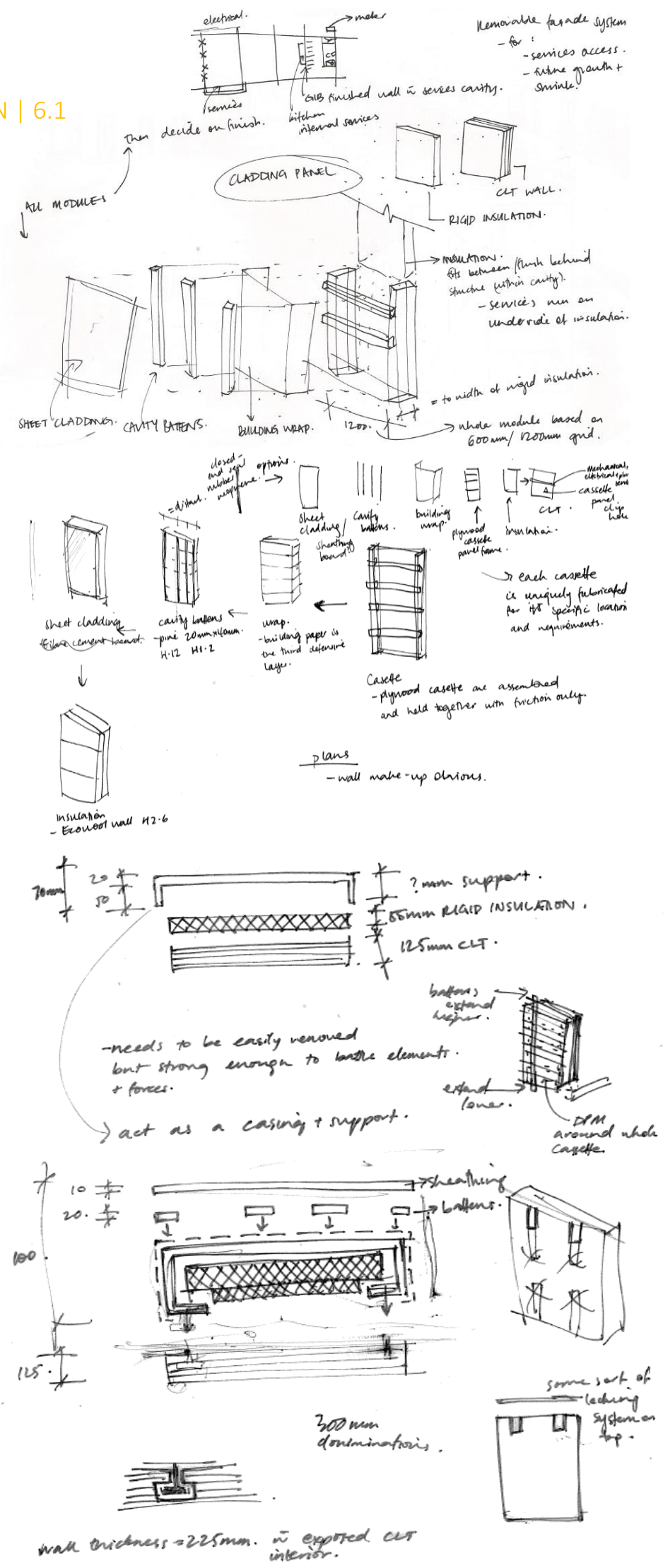

Figure 6.1.1: Removable façade panel clips into CLT wall. Services running externally for access and to have an exposed CLT interior. Façade panel works to a 900mm grid, as the $\mathrm{x}$ and $\mathrm{y}$ dimension of the module are also working to $900 \mathrm{~mm}$ grid. 


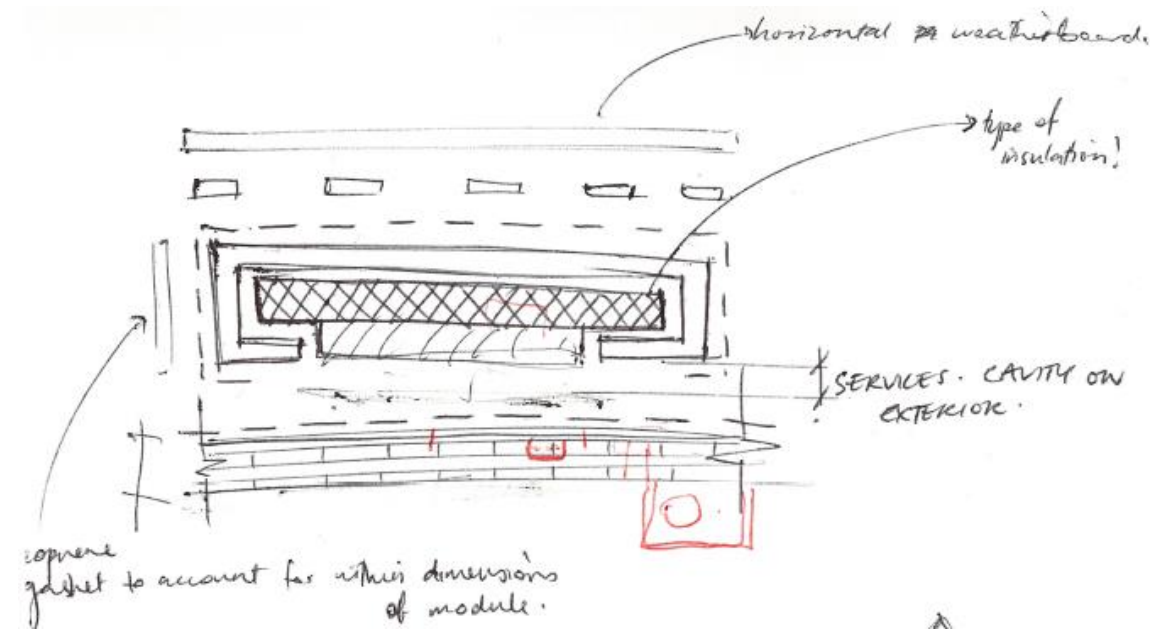

Figure 6.1.2: Removable façade panel clips into CLT wall to finish the exterior of the home. Easily removed to connect an additional module and the re-attach to the new outer wall of the home. Neoprene gaskets on the sides of each panel to ensure weather-tightness.

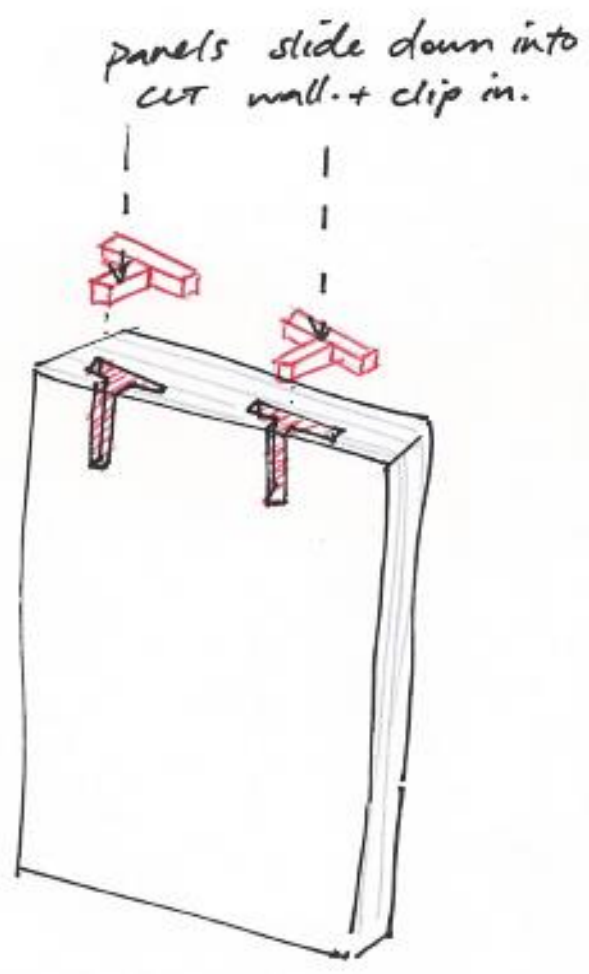

Figure 6.1.3: Removable façade panel facilitates the growth of the home to meet the needs of occupants. Services are easily accessible from the exterior of the home, located behind the façade panels on the side walls where expansion of the home is not occurring. 

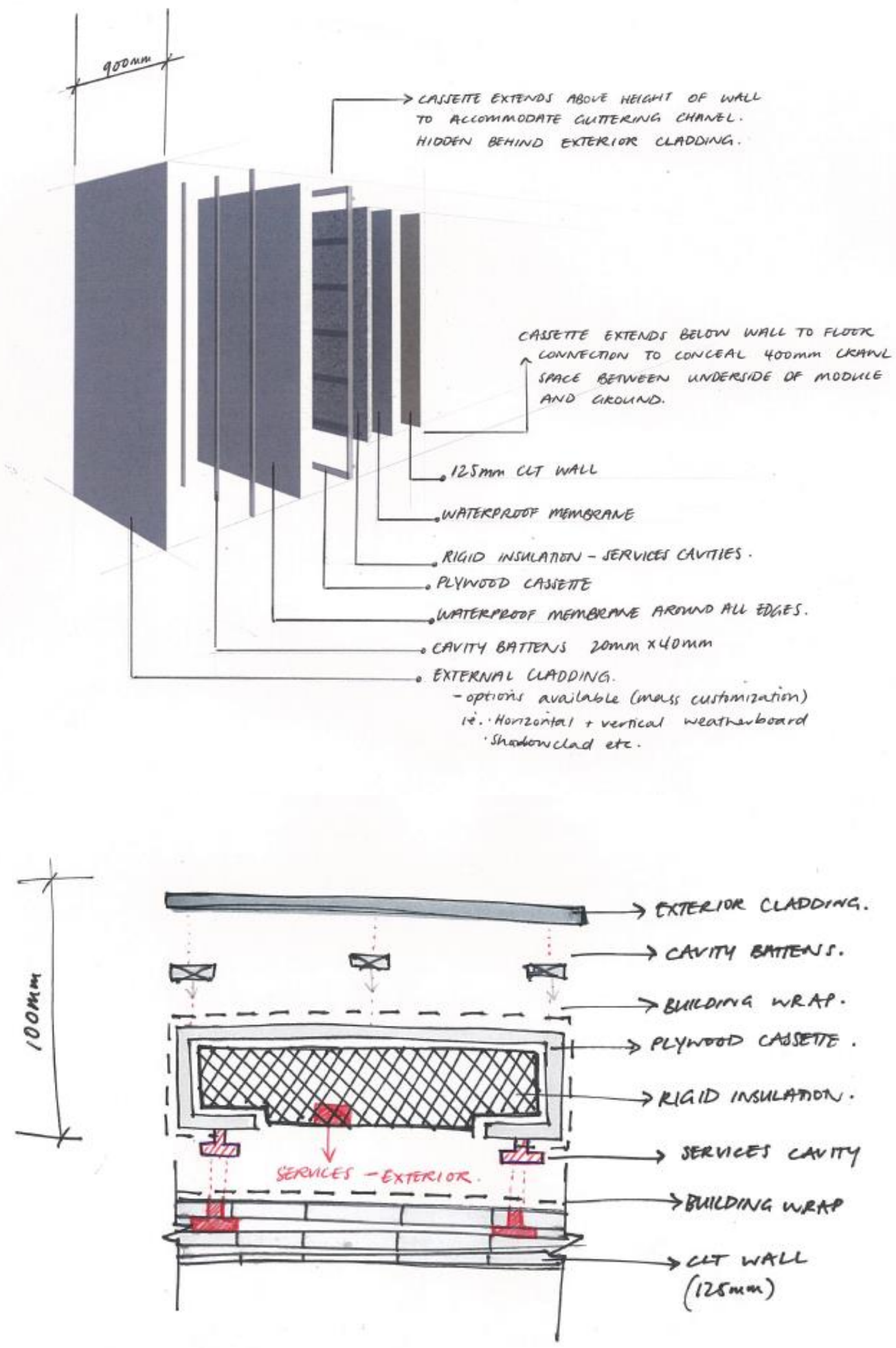

Figure 6.1.4: Composition of the façade panel allows for customization of exterior cladding to contribute to the need for individuality; a fundamental of residential amenity as highlighted by Marcus and Sarkissian (Appendix A). 

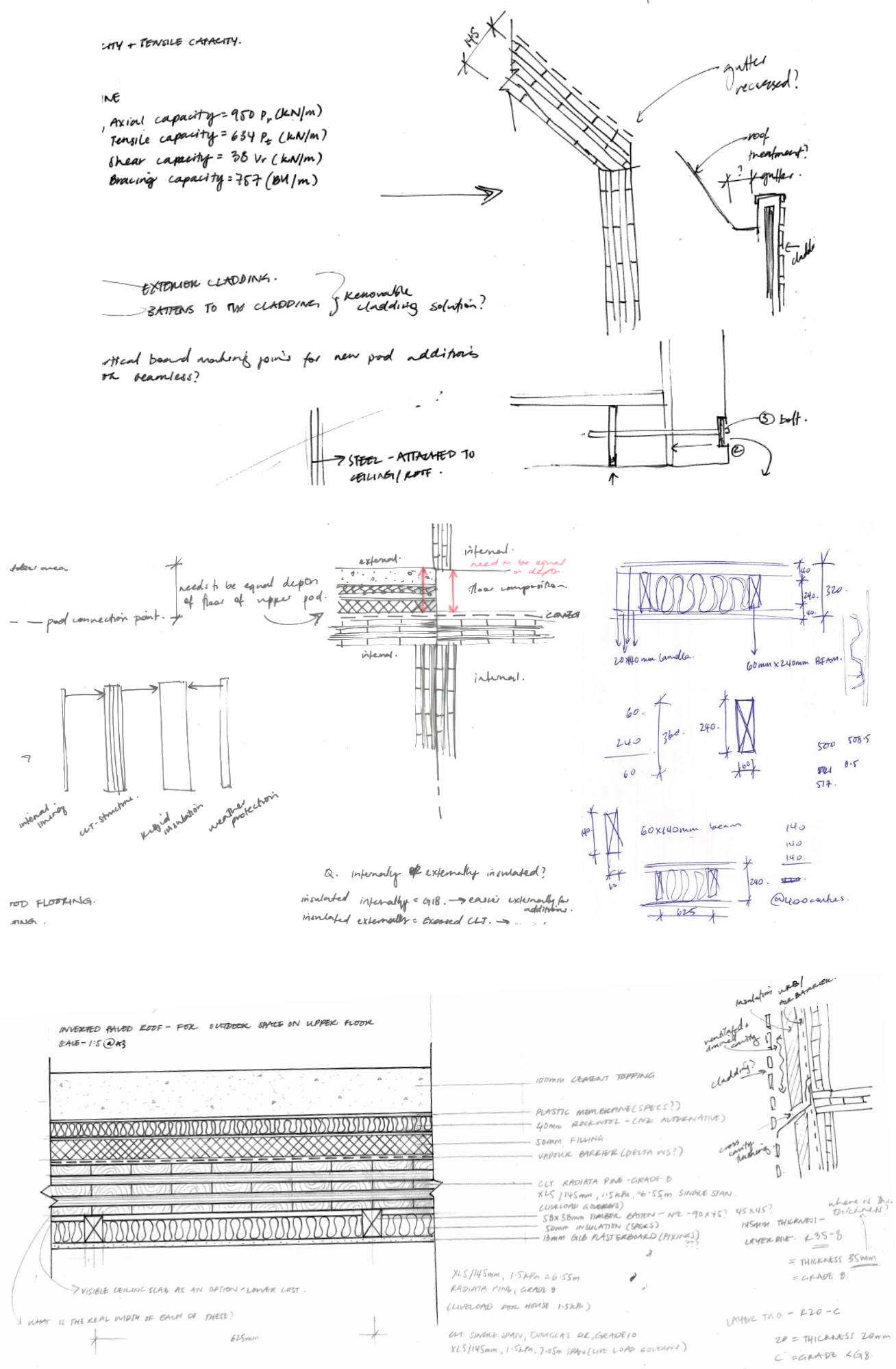

Figure Series 6.1.5: Understanding CLT as a self-supporting material: CLT allows for easy connection of additional modules through splines and large screws. It is structurally self-supporting, making it an ideal material for modular prefabrication. Floors and roofs are made from a CLT composite that sees these components act as a box beam to allow services to run through them. 

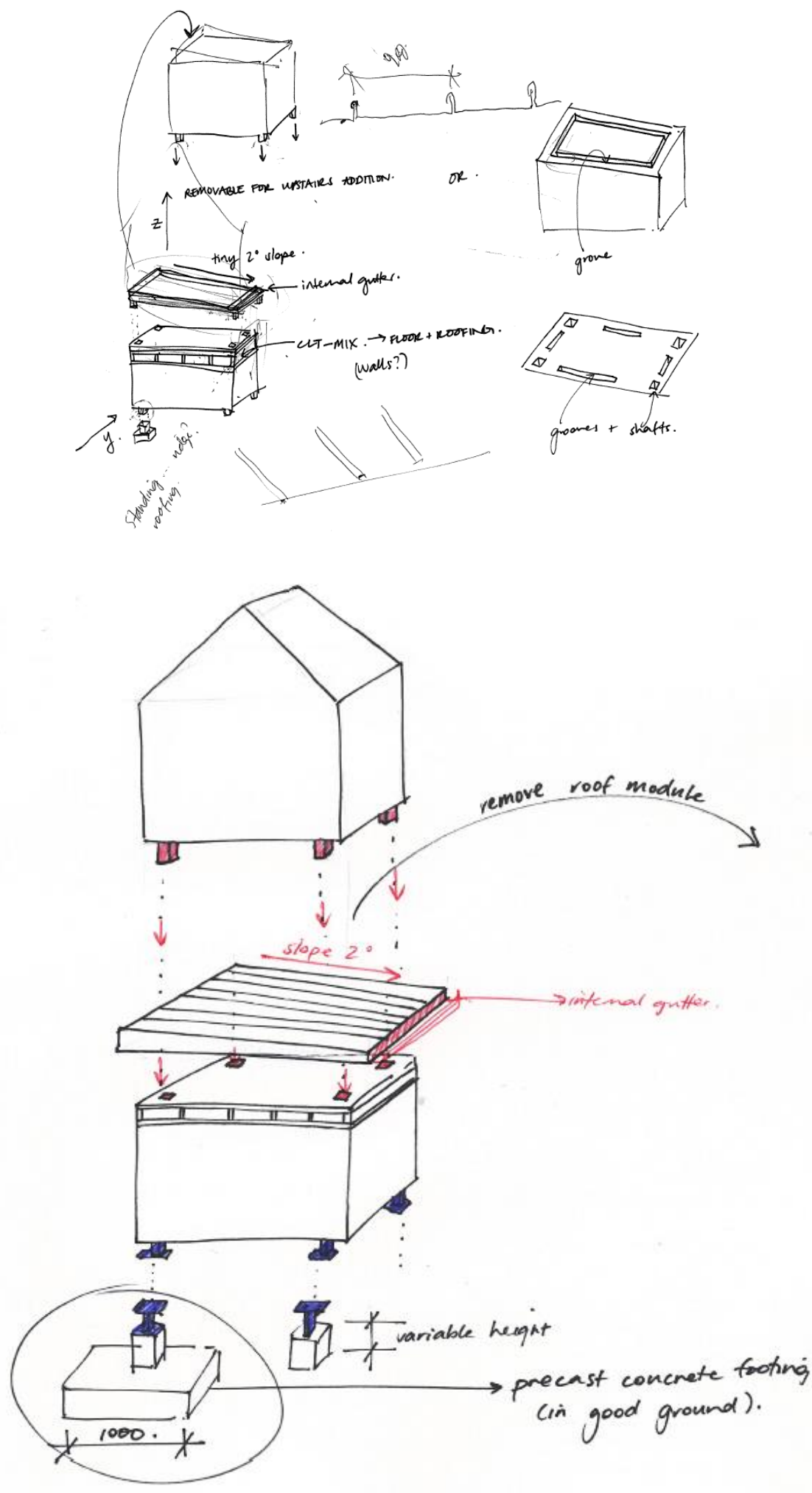

Figure 6.1.6: The home expands on upper levels by removing a roof panel before being replaced by a module. The roof panel can either be used elsewhere in the home expansion or sold to other neighbours. 


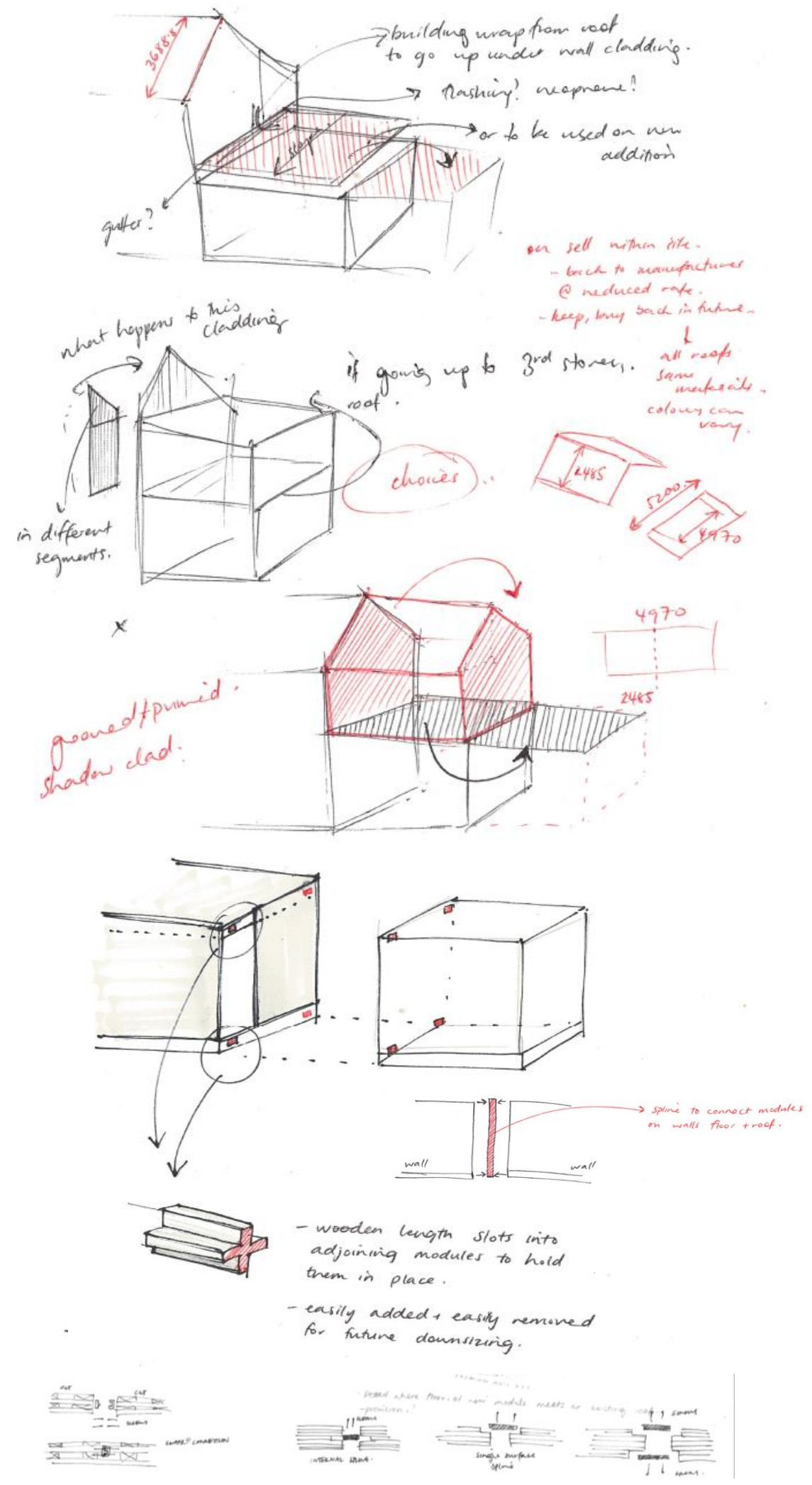

Figure 6.1.7: Understanding the connection of the home as new modules are added. It is not within the scope of this research to resolve this junction, but rather gain an understanding of the steps that would need to be taken to make expansion possible. Splines connect additional modules to the existing home by removing the façade panel to make this connection. 

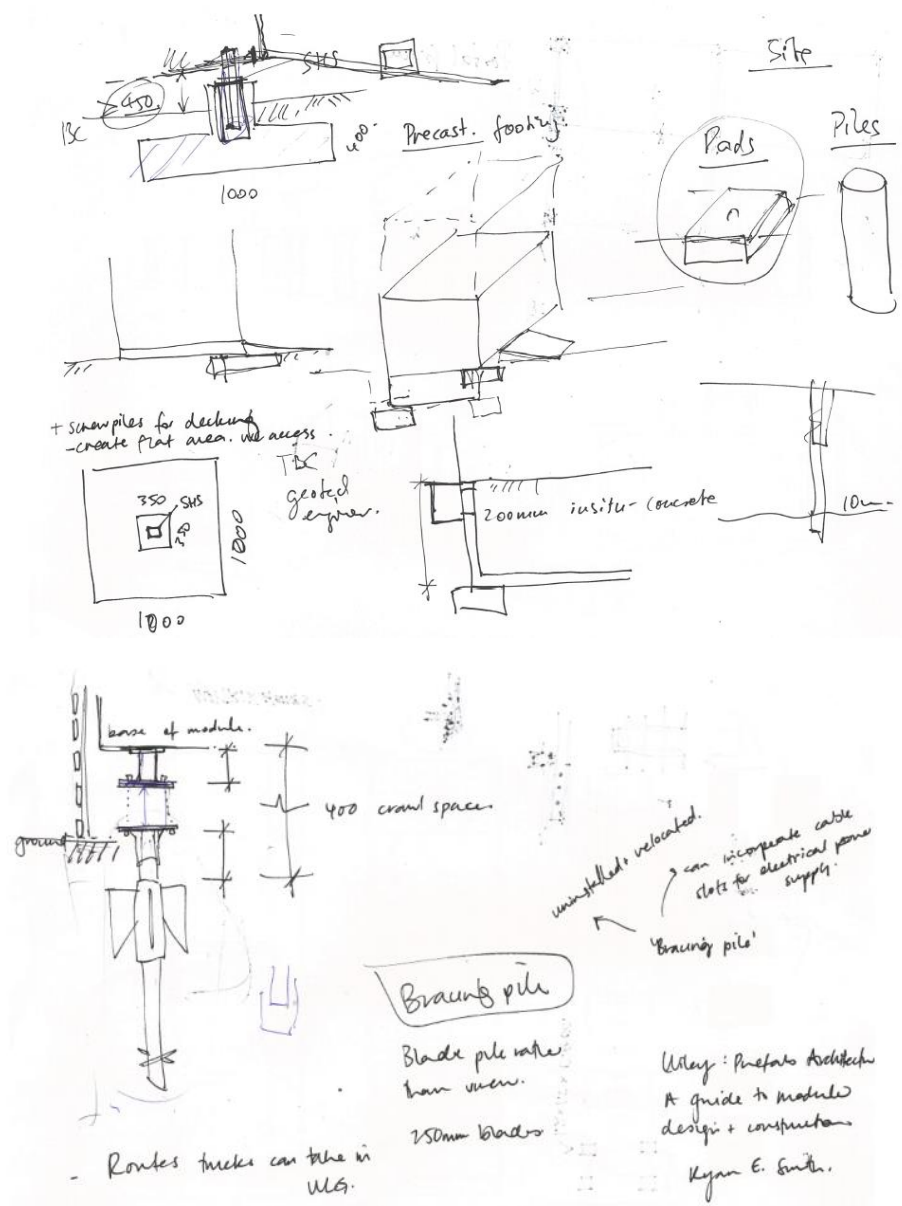

- phy-ir of moduls to semic core.

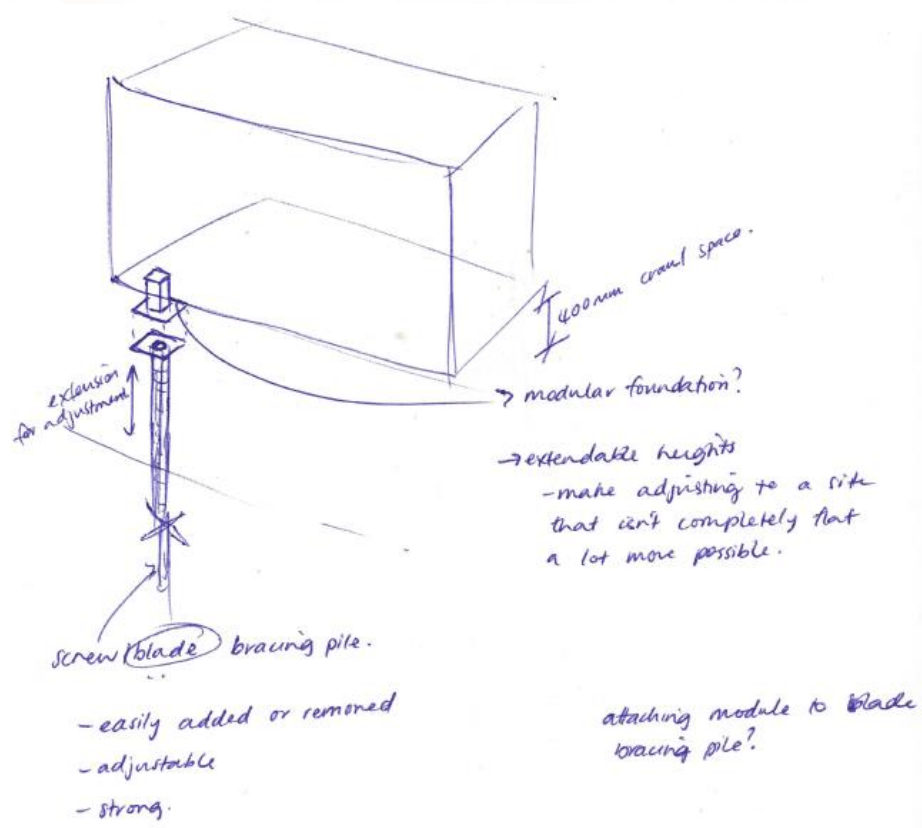

Figure 6.1.8: Previous design experiments highlighted the need to minimise impact on the land. To achieve this, screw piles are used as an alternative to concrete foundations that would see a waste of materials should the home be relocated in future. 


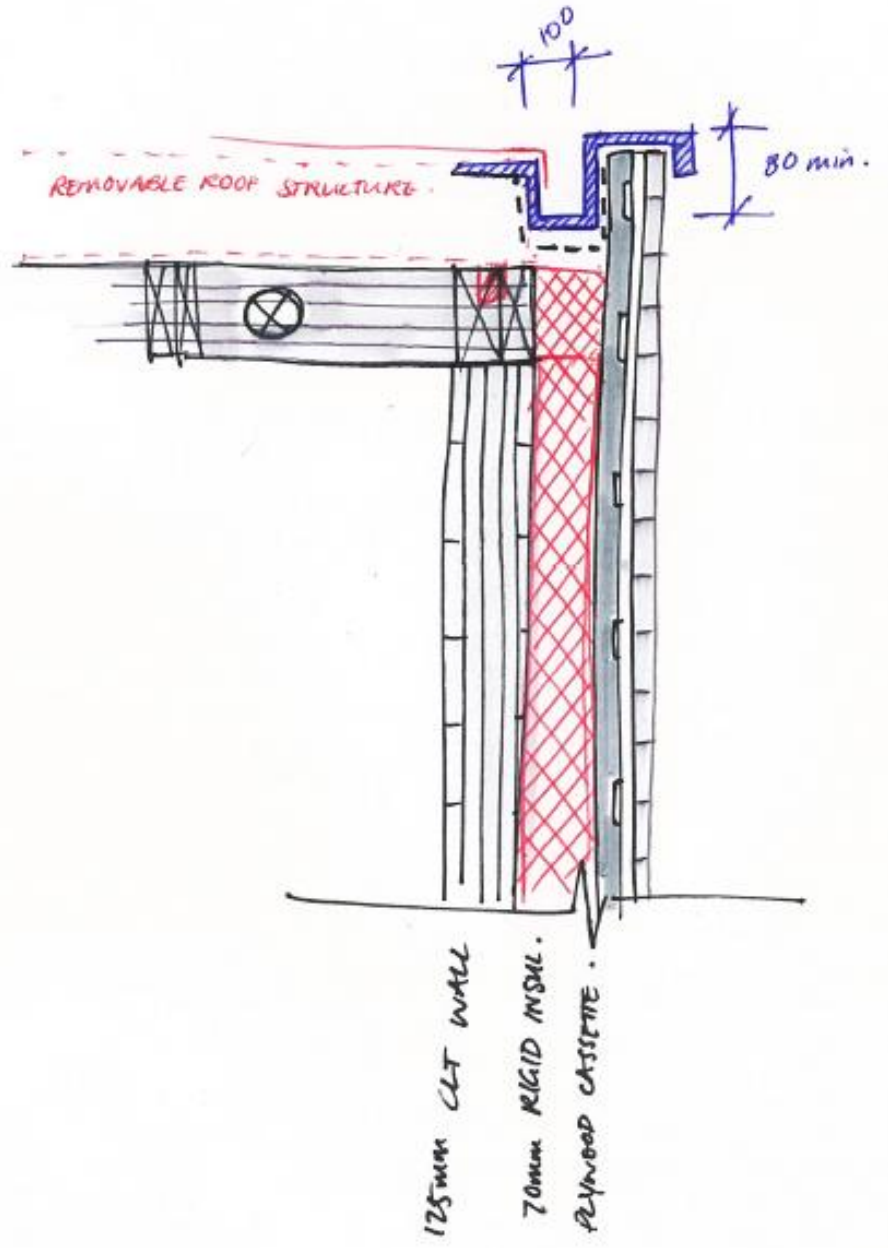

Figure 6.1.9 Wall to roof junction detail. Hidden gutter behind removable façade panel. Services shown also run through cavity within composite CLT structure. 


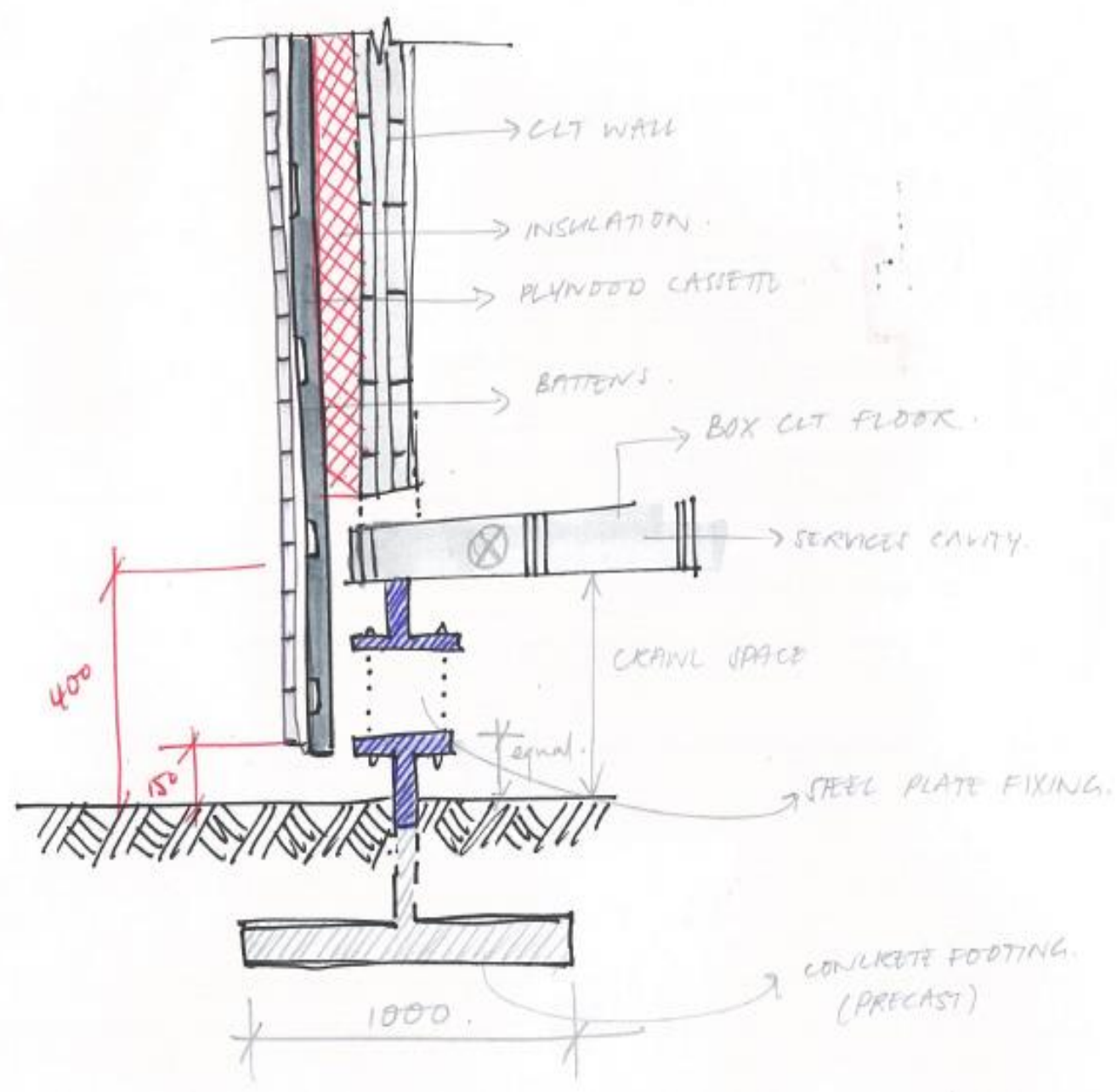

Figure 6.1.10 Floor to foundation junction. Either concrete pads or screw piles used for minimal impact on the site. Metal plates screw together to hold modules in place and cater for varying site levels as the connecting rod can be extended or shortened. $400 \mathrm{~mm}$ crawl space to access services in CLT box flooring. Façade panel extends below this level to conceal crawl space. 


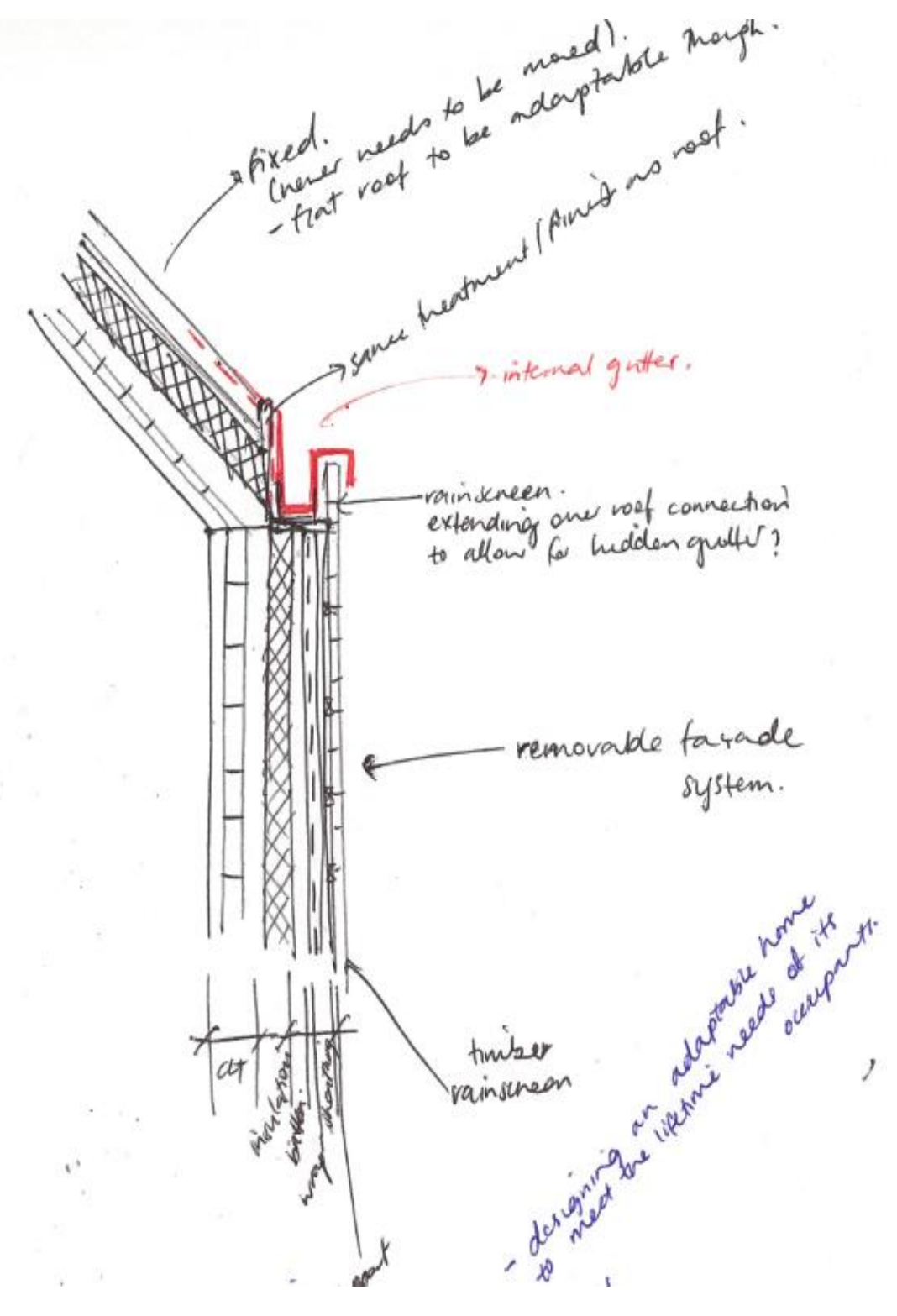

Figure 6.1.11: Wall to roof junction for pitched roofs. Internal gutter concealed behind removable façade panel. 

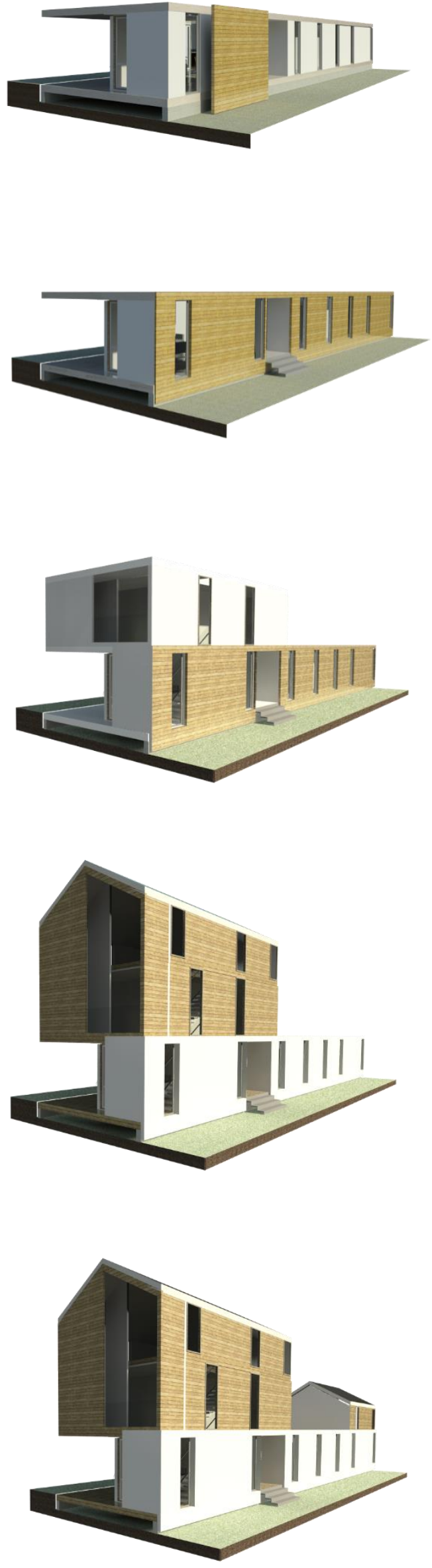

Figure 6.1.12: Base modules arrive on site, attached to screw piles, facades clipped into place.

Figure 6.1.13: Base modules completed and habitable. All homes include a combined service module including kitchen, laundry and bathroom.

Figure 6.1.14: Home is able to grow to the rear or up to the second and third floors.

Figure 6.1.15: Home grows to accommodate growing family or multigenerational living. The façade panels can be replaced with different materials to distinguish ownership and identity when there are two separate residences within the same building. For example, a retired couple may change ownership of their upper modules. This sees their needs met by shrinking the home without having to move, living all on one level for safety and support provided through multigenerational living.

Figure 6.1.16: The home is able to accommodate most circumstances. This example of growth sees a family reside in the ground, first and second floors to the front of the property. Towards the rear, one ground floor module is for the upper residence leading to their first floor studio apartment. This scenario would be suitable for a young single or couple looking to enter the property market. 

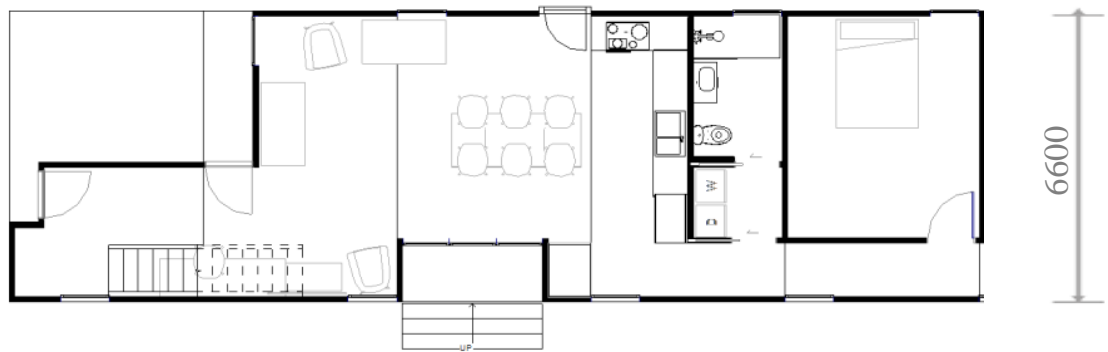

Figure 6.1.17: The plan of the home offers a high level of residential amenity even in the smallest possible configurations of the home. Access to private outdoor space, sunlight, ventilation, privacy and accessible rooms are not compromised in any layout of the home.

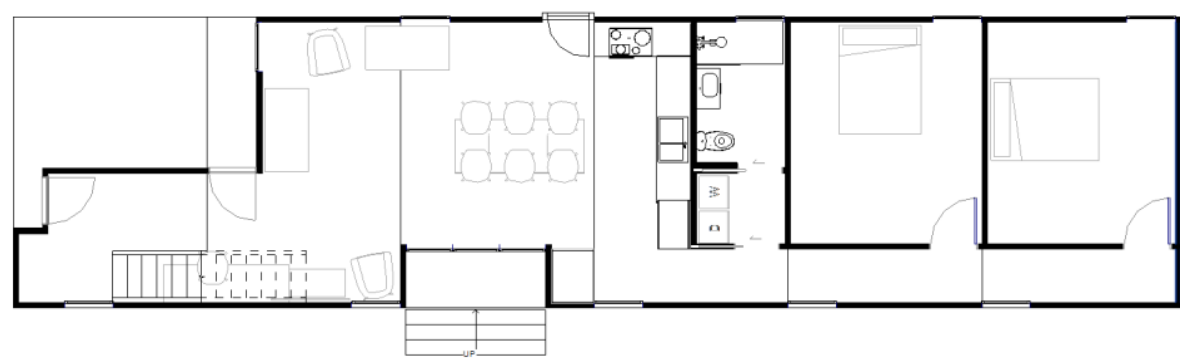

Figure 6.1.18: The home is able to grow through the use of standardisation at a regulated point of each module. The hallway acts as a central spine not only to offer wheelchair accessibility measuring 1000mm, but also an interchangeable opening, window, door or wall panel to suit the needs of residents.

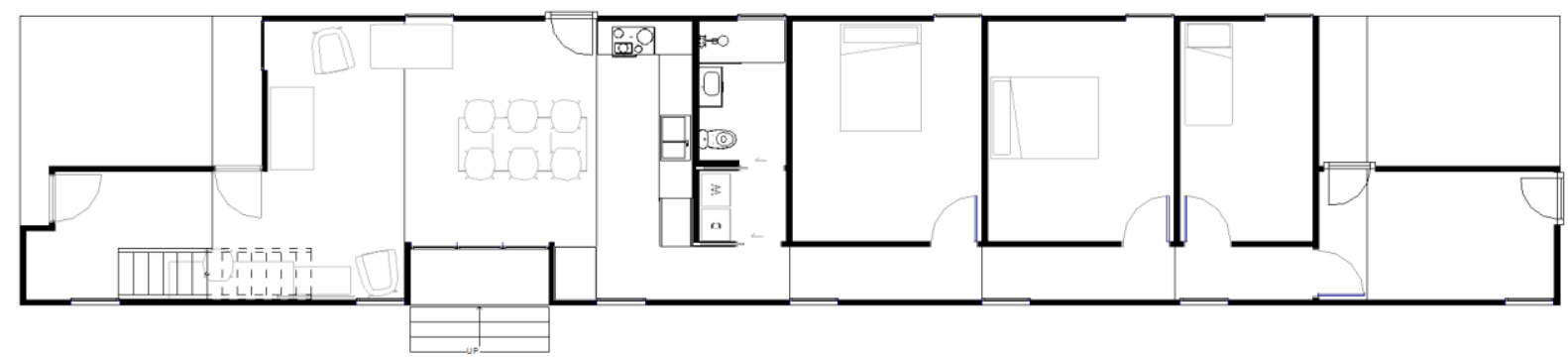

Figure 6.1.19: The maximum bedrooms at the ground floor is 4, with a maximum number of eight modules connected on their longest edge. The home is able to adapt through the standardised hallway openings to see ownership of these rooms change if the upper floor is to expand to different owners.

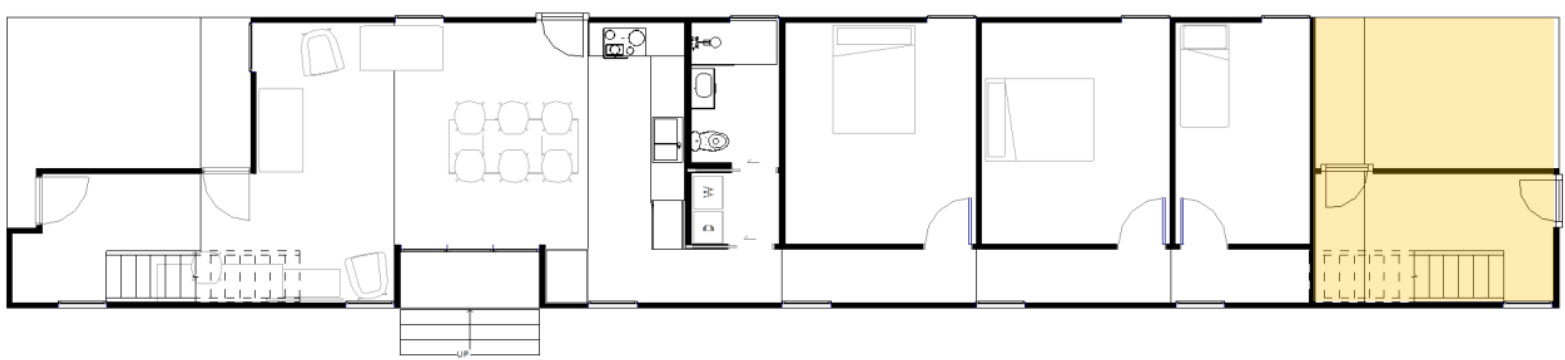

Figure 6.1.20: The end module is able to change ownership to become the access to the upper floor to create a new home within the MDH complex. The use of dual access roads within the development enables this separation of residences at either end of the section. The end module also includes carport parking. 


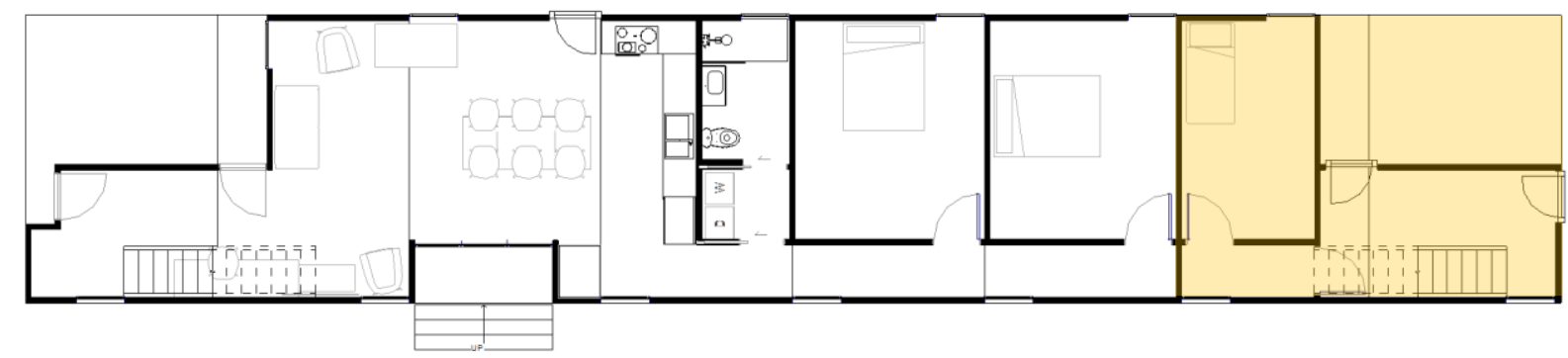

Figure 6.1.21: The ownership of other downstairs modules can also be allocated to upper floors if the dominant downstairs home wishes to downsize. An infill wall panel is inserted into the hallway to divide the two homes.

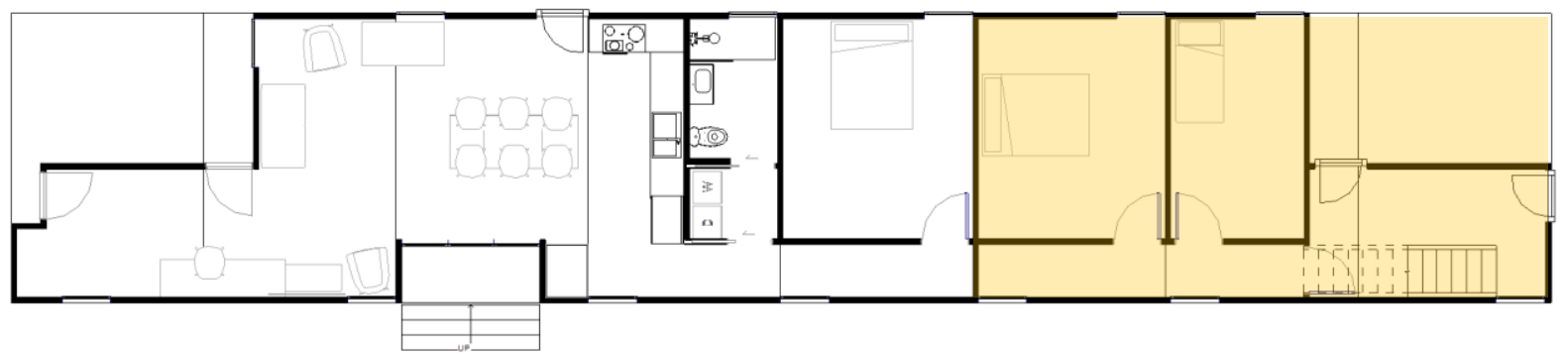

Figure 6.1.22: Ideal for multigenerational living, the home is able to shrink back down to its ground floor and remove all stairs to live safely on one level. Other requests of the elderly population are also considered with the addition of a hobby space near the entrance, small sections for maintenance and a low maintenance home.
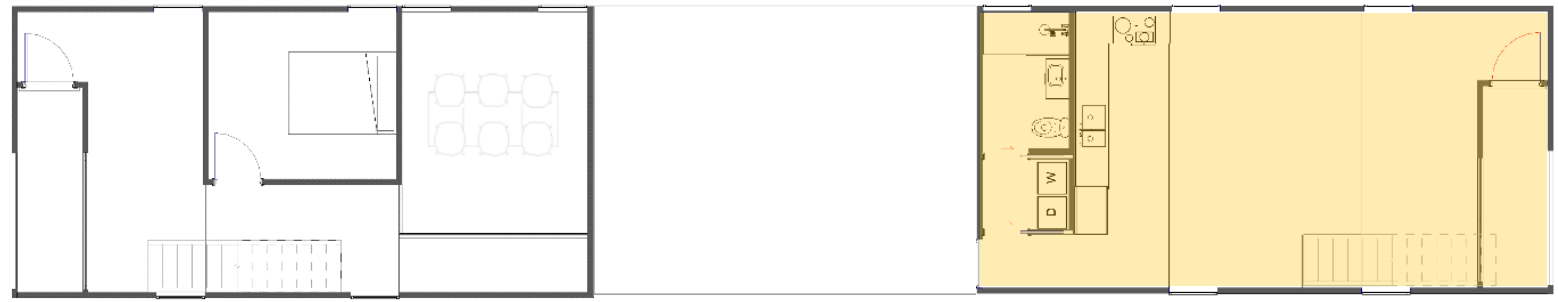

Figure 6.1.23: The upper floors can easily accommodate for larger families or studio living as indicated on the right-hand side of the first floor. In the centre there is room for expansion of rooms to the studio apartment.

All modules include floor to ceiling windows to allow for plenty of natural light and ventilation while still offering privacy with window treatments such as tinting or blinds. The bathroom is also wheelchair accessible with CLT walls providing enough strength for support rails throughout the home should they be required in future. There are also provisions in place for a stair lift should this also be necessary.

Ultimately, the home provides plenty of choice for all households as well as having the ability to adapt embedded within the design of the home. 


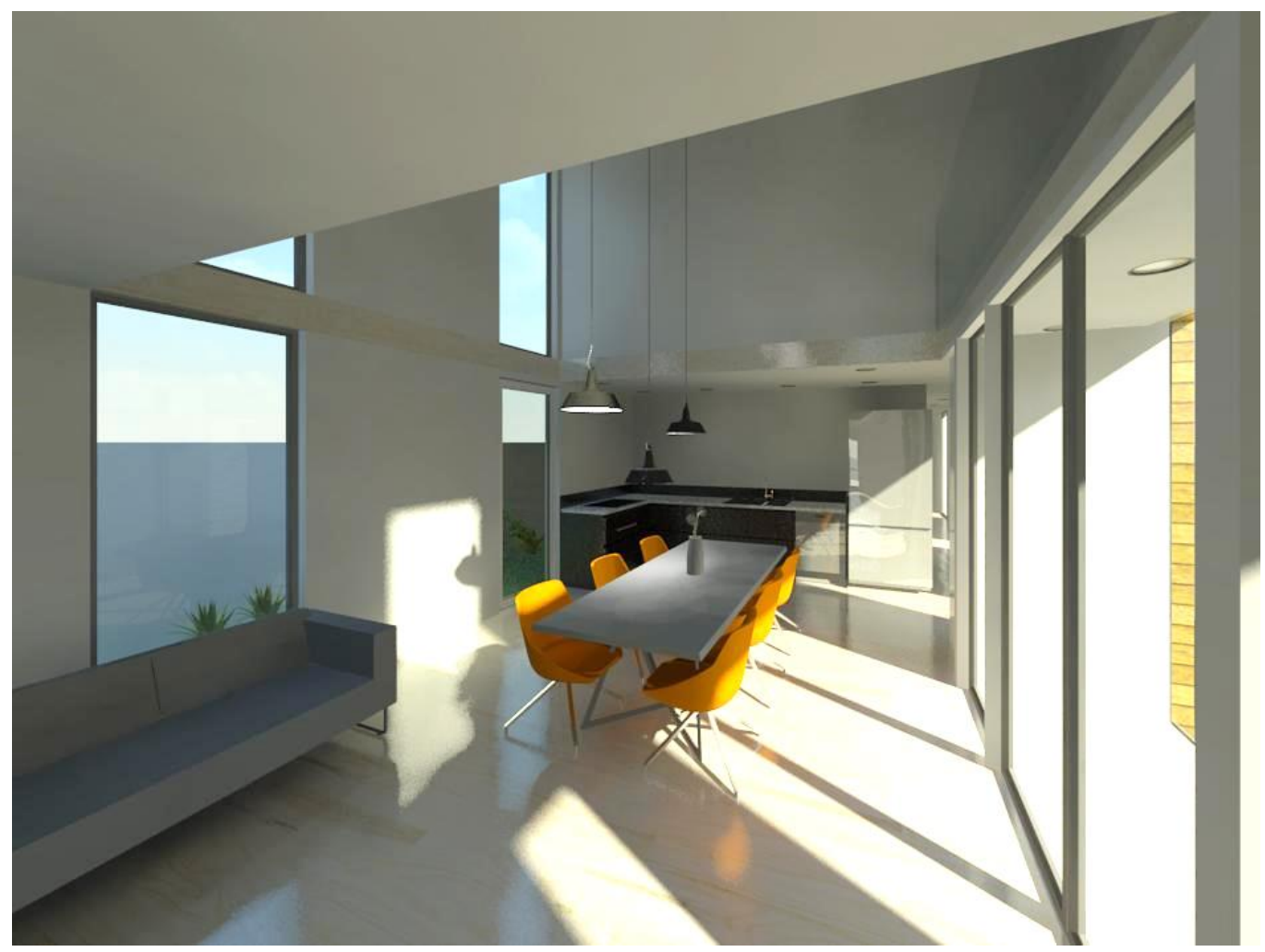

Figure 6.2.1: Ideal for all ages, the modular home provides enough space for children to play, family and friends to gather and allows for wheelchair accessibility. Double height spaces in the living areas give an architectural edge not often found in compact homes. 


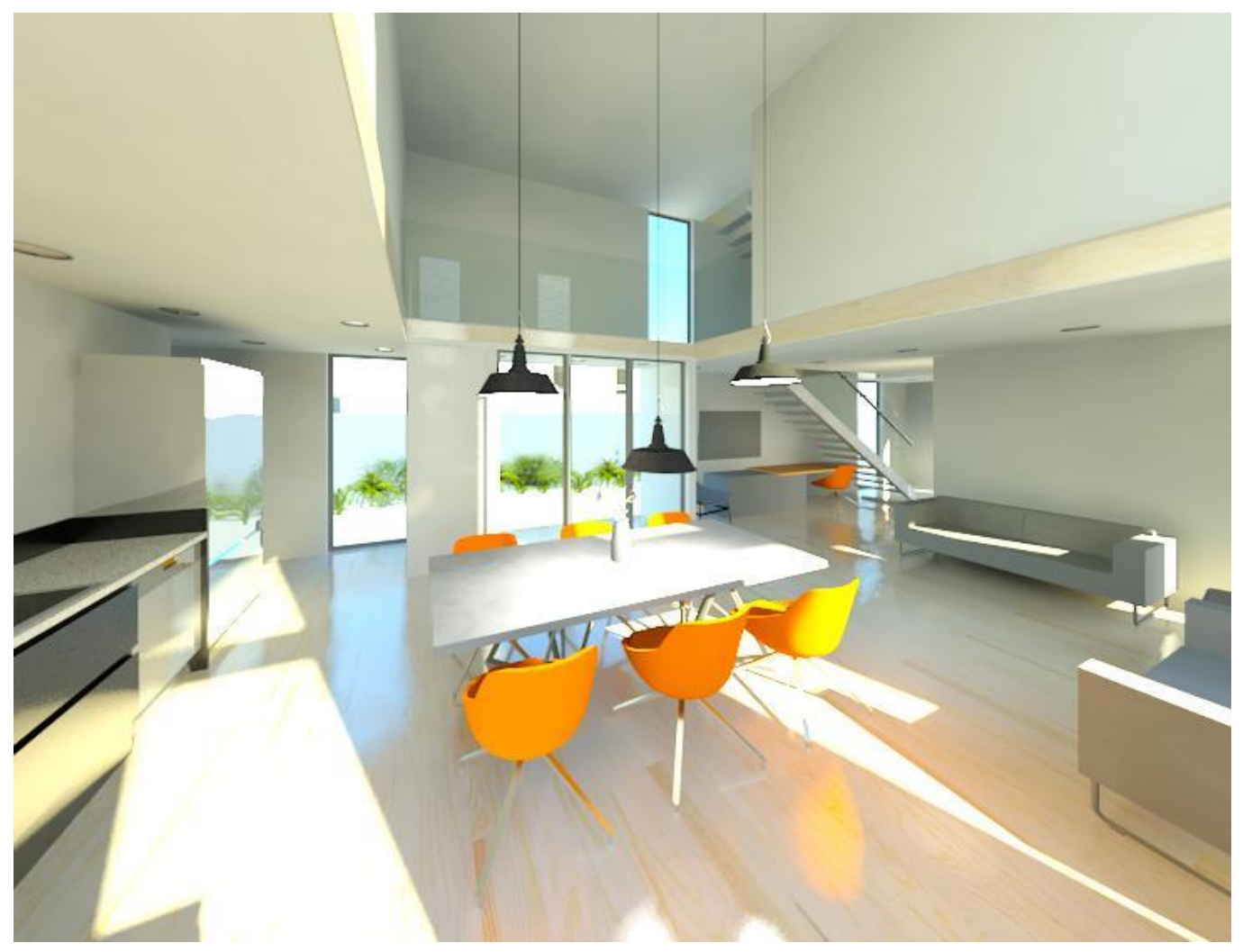

Figure 6.2.2: The interior perspective illustrates the home when the upper modules belong to the main ground floor modules. There is a hallway mezzanine connecting the upstairs bedrooms, which is easily interchanged with a full-length wall panel to separate areas of the home as shown below. 


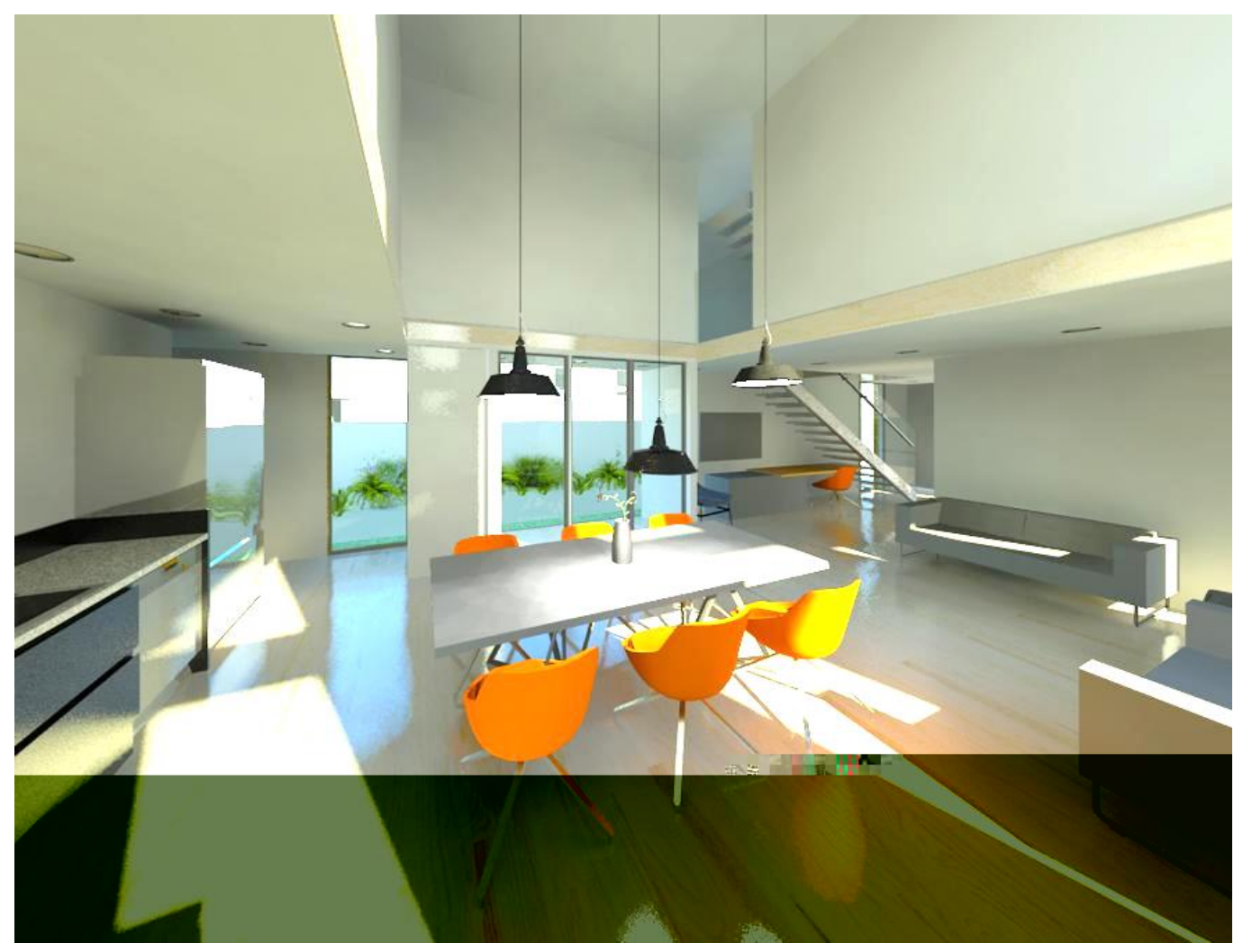

Figure 6.2.3: The full-length wall panel in place of the balustrade allows for a separation within the home. A door to this now enclosed hallway is ideal in situations of multigenerational living, where internal access between residences is required. The remaining balustrade can also be replaced with an infill wall panel to remove any overlook to the living area for separate residences upstairs. This would also see the removal of the staircase and an infill panel in the floor opening. 


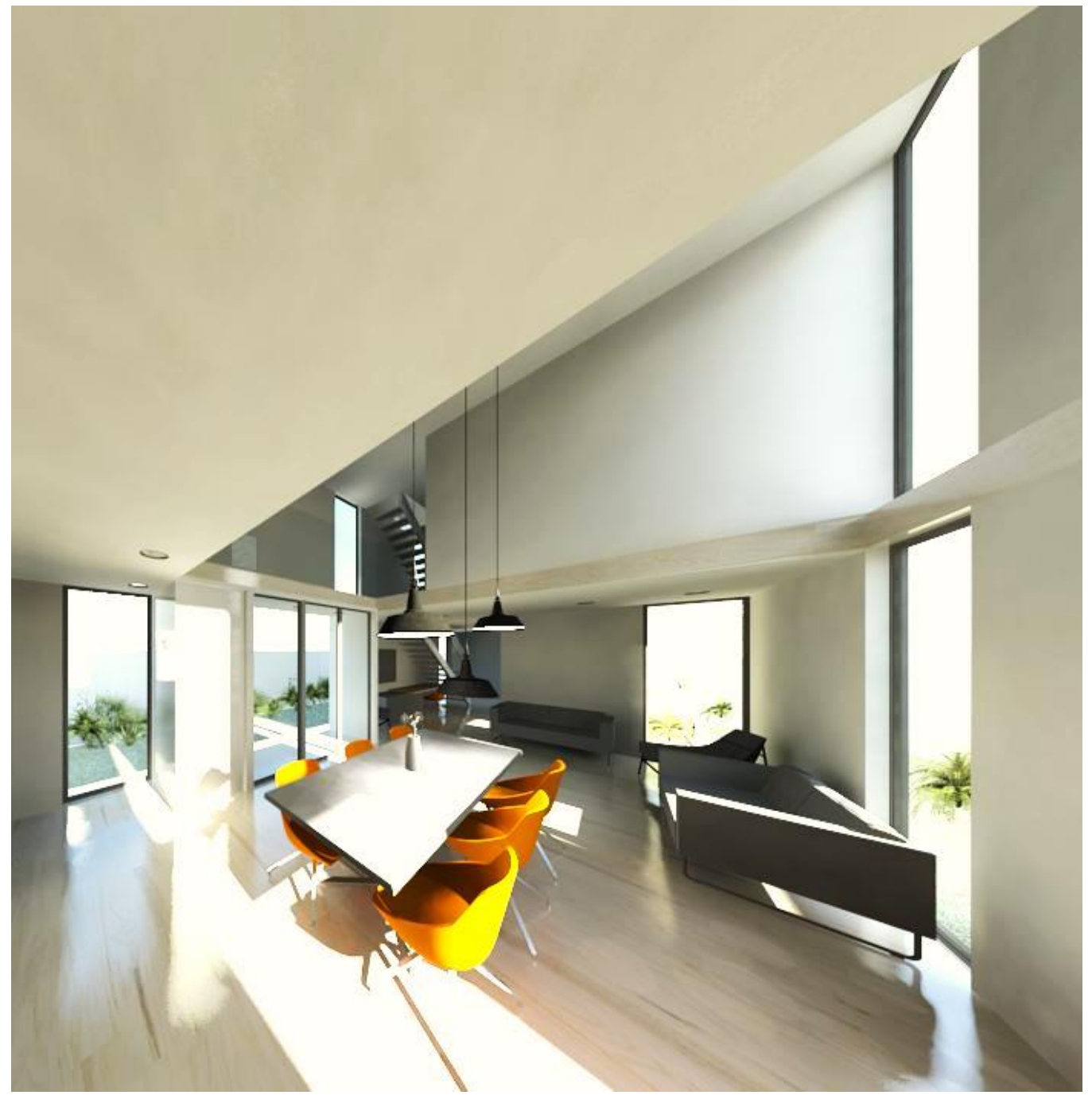

Figure 6.2.4: This perspective from the living area also highlights the ability for the home to expand to the maximum height of three storeys. A pleasant outlook is achieved in the private outdoor spaces and out over communal spaces as the design guidelines of Marcus and Sarkissian recommend. 


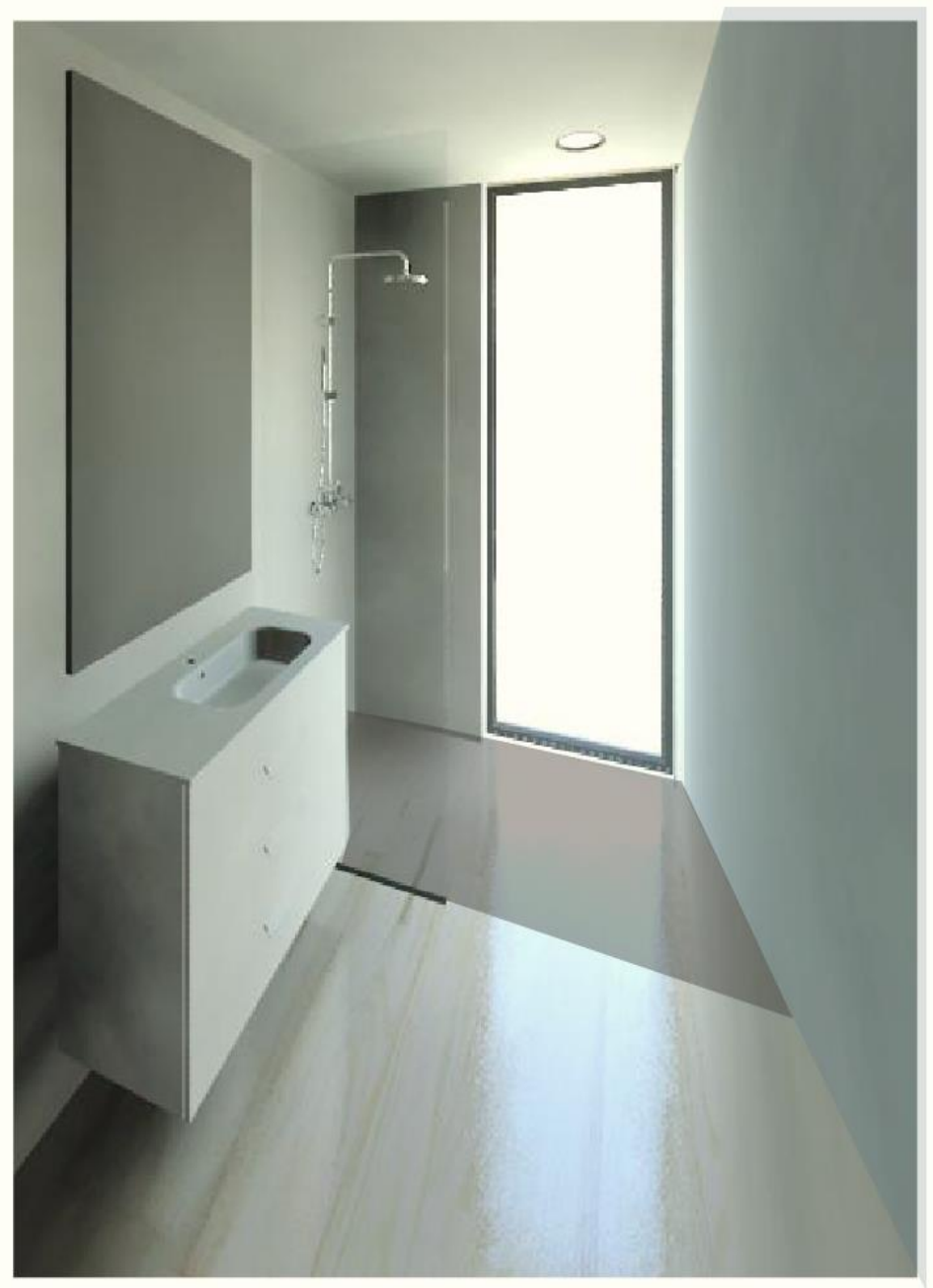

Figure 6.2.5: The bathroom is included within the central service module that accommodates all services for the kitchen, laundry and bathroom. These spaces are also built to wheelchair accessible requirements to ensure the home meets the lifetime requirements of occupants. 


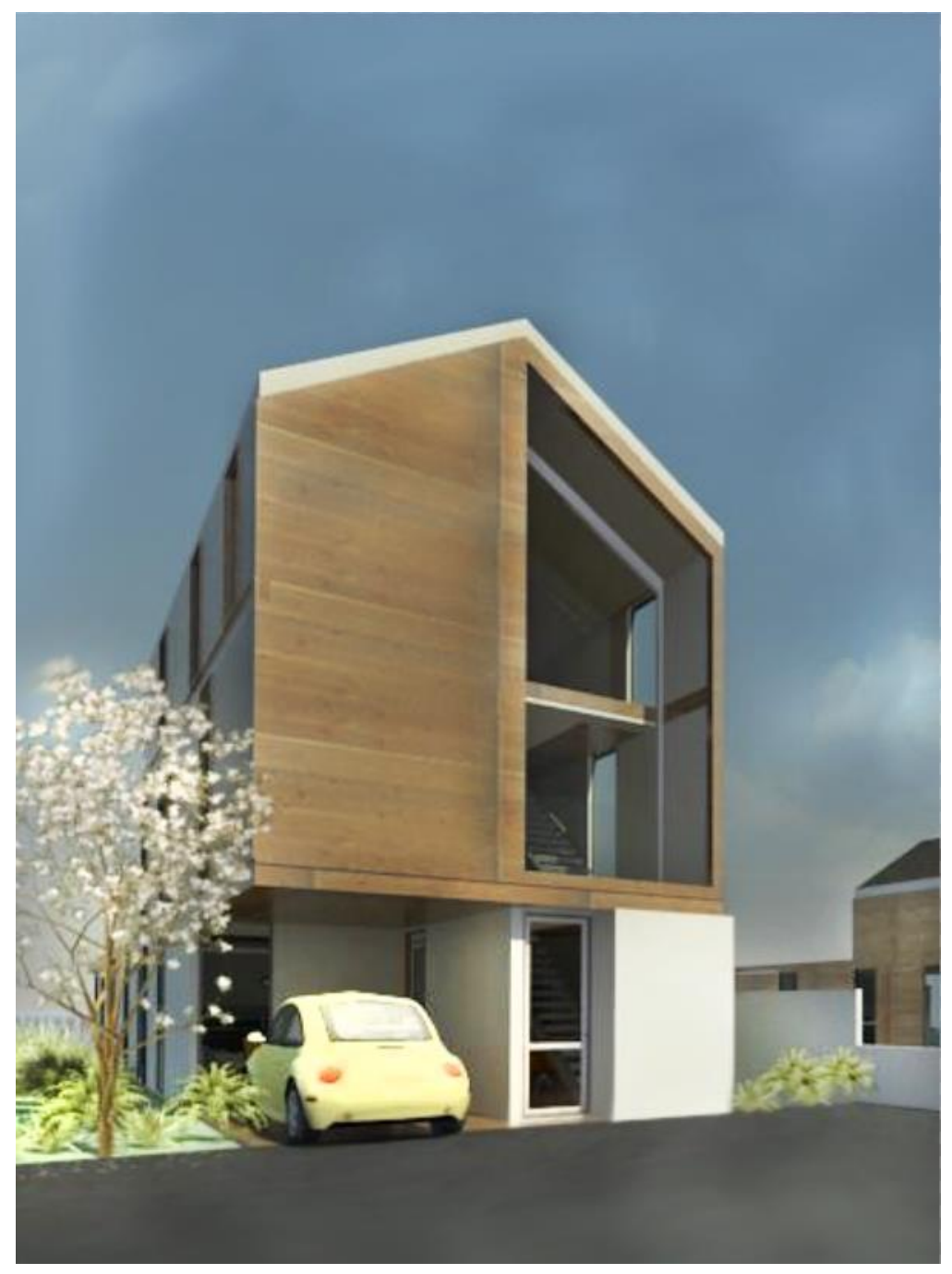

Figure 6.2.6: An external perspective of the home. Most fundamentals of residential amenity are achieved within this design with the following considerations met:

- $\quad$ Sheltered carparking

- Overhang from rain at the front door

- $\quad$ Setback from the street for safety and security

- Upper levels provide private outdoor space on deck for pleasant outlook and surveillance of communal spaces

- Large windows in all modules for natural daylight and ventilation.

- Wheelchair accessibility within the home, with bathrooms, hallways and doorways all accommodating this

- Provisions in place for stair lift should it be required in future

- Private outdoor space for children to play

- $4 \mathrm{~m}$ between neighbouring houses for privacy and avoid shading of the home.

- Ability to age in place with the earlier requirements of elderly, highlighted by Davey, all met within the developed design of the home. 


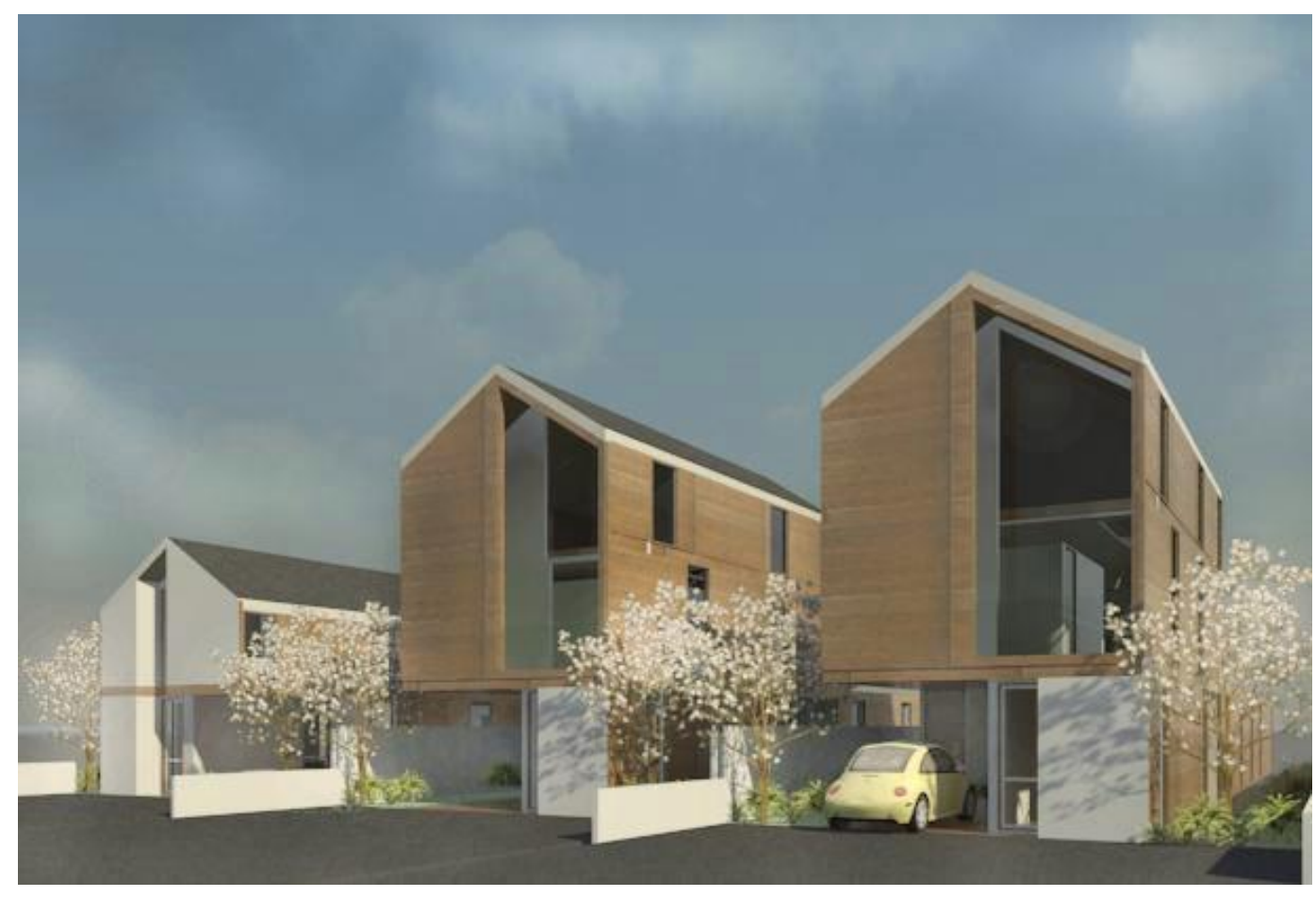

Figure 6.2.7: Exterior perspective of the home in context, overlooking public shared space to the centre of the development. 
The limitations of this developed design include the issue of needing to expand a module where The design outcome is an adaptable home designed to meet the lifetime needs of its occupants. The prefabrication of modular units allows for a universal design with standardised openings. These specifically located openings, windows or doors create potential to expand or contract the home as circumstances change in the future. Prefabrication of standardised façade panels also facilitates the aim of an adaptable home, making the addition of units possible without the need to waste materials take cater for a new addition.

This research has proposed an alternative housing solution that considers the occupants' wellbeing over their lifetime. The design ensures the wellbeing of occupants by addressing all fundamentals of residential amenity. Public amenity within the development and the wider context of Karori, sees this adaptable medium density housing solution improve the current standards. Exceeding current considerations of health and wellbeing through residential amenity, it is possible to reduce the ill effects of poor housing to reduce the strain on public healthcare and facilities as the population, especially that of the elderly, continues to rise. 


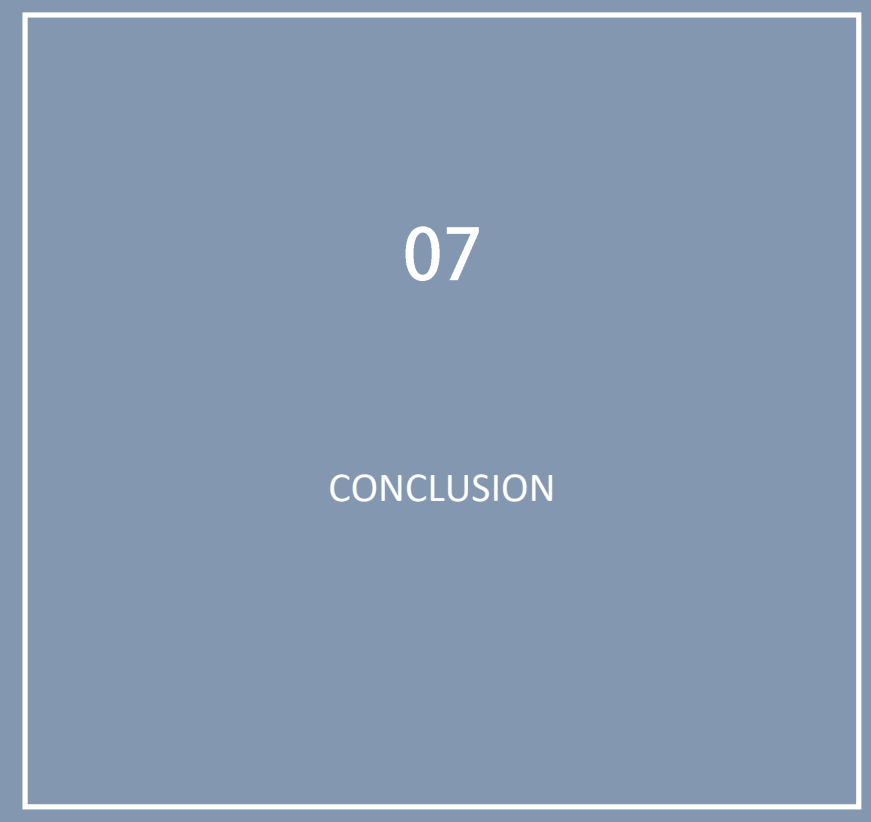




\section{CONCLUSION}

\section{0}

This research aims to challenge the status quo, specifically questioning, 'how can the home be redefined to adapt to the changing needs of its occupants?'

The aim of this design-led research was to explore an adaptable home designed to meet the lifetime needs of its occupants. The need for a change in housing stock has become more prevalent in recent years as housing affordability lessens, population increases and current housing fails to reflect the evolving dynamic of the household. Due to the housing shortage, hasty attempts to deliver medium density housing have neglected the fundamentals of residential amenity, resulting in poor living conditions that are detrimental to the health of the dweller.

The need to research alternate housing solutions through design is not only relevant but extremely necessary in relieving the pressures of the housing crisis. Adaptability is an important feature of future housing as change is inevitable. Today's homeowner is forced into the cyclical motion that sees the home become unsuitable as needs change, resulting in relocation only for the home to be rendered unsuitable as needs change again in future.
The needs of the occupants are the met in the developed design by addressing the fundamentals of residential amenity to aid good health and wellbeing of residents of all ages. The adaptability of the home is met by the prefabrication of modular units which also offer a universal design, employing standardised openings to offer greater flexibility within the home.

The developed design sees the question addressed alongside the aims and objectives of the research to produce a home that considers the pressing needs within the housing market. The expected population boom calls for a need to increase density. However, intensifying results in multi-level living which consequently impedes accessibility. This creates an issue for the increasing population of elderly, who are expected to make up more than a quarter of the NZ population by 2050.

Through the literature review it was found that the elderly requires choices around housing. The want to age in place can be facilitated by the design of the home to ensure safety and security in a familiar environment that has come to be recognised as home. The requirements of the home requested by elderly were subsequently used as the basis of the design experiments to see the home facilitate ageing in place within a medium density context. 
The needs of the elderly are similar to that of younger generations. Drawing upon the design guidelines of Clare Cooper Marcus and Wendy Sarkissian, the fundamentals of residential amenity have been addressed throughout design experiments to assess the suitability of the home in terms of achieving the overarching aims and objectives. Choice is offered in the adaptable nature of the home, made possible using prefabrication as a construction method.

The resulting design framework from the literature review was vital in realising the developed design solution, to assess the strengths and weaknesses of the preliminary design stages. A strength of the modular design is that despite the transport restrictions impacting the exterior dimensions of the modules, the interior layout has still been designed as a functional, accessible space within these parameters.

Throughout the project review it was found that adaptable housing is often approached using prefabricated modular units to minimise disruption on site. While it is recognised that there are benefits to panelised prefabrication, it was intentionally veered away from due to its on-site demands. The scope of the research could be expanded in future to test the feasibility of panelised prefabrication. This would ultimately change the nature of the design as transport restrictions would not directly influence the dimensions and subsequent form of the home, as has occurred in the modular design.
To further this research, the construction of the module could be resolved to create a cost planning analysis to contribute to the validity of this argument. Extending the scope of the research to providing a cost comparison with existing new builds would strengthen the argument of affordability to see the introduction of adaptable medium density housing in New Zealand.

The case studies surrounding adaptable housing are drawn upon from overseas examples. While there is still relevance to the NZ market, prefabrication and adaptability of the home have not advanced at the same rate as other countries. The adaptable home, comprised of prefabricated modules could be beneficial in areas suffering land shortages and unusual sized plots of land to apply the findings of this research as infill housing.

This design research experiment offers an alternative to the current housing in New Zealand. Designed to adapt to meet the needs of an increased population, to consider the good health and wellbeing of occupants through residential amenity and assist ageing in place, it is understood that this housing solution may not benefit everyone. This solution intends to offer one alternative to a myriad of issues within the housing sector by critically examining how the home can be designed to hold the ability to change on demand and expect the unexpected. 


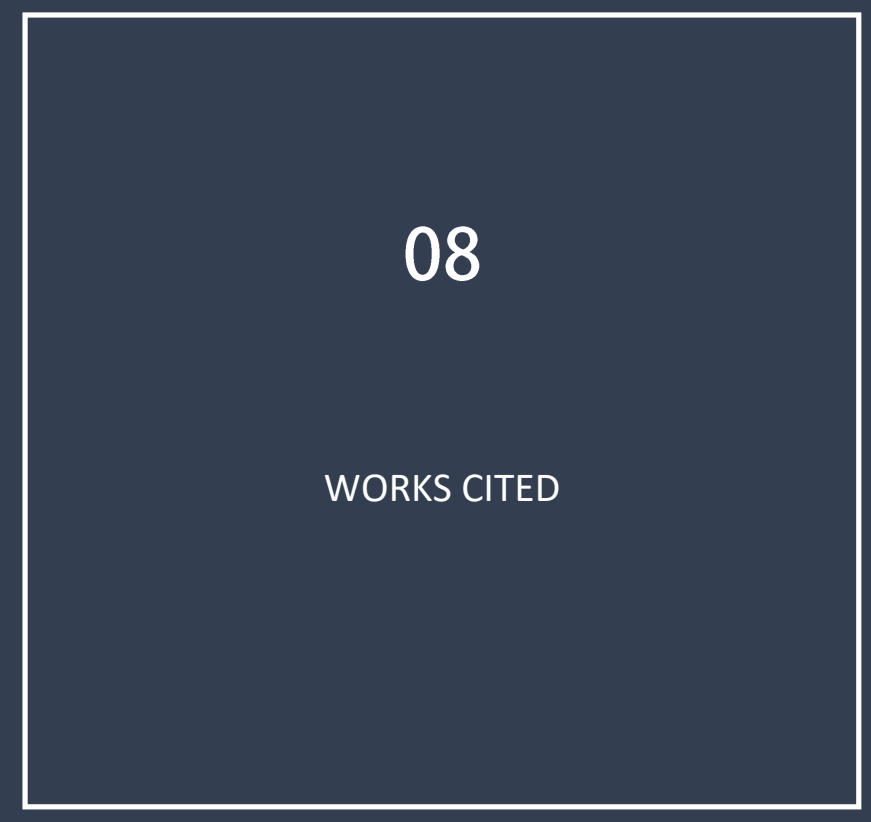




\section{WORKS CITED}

8.0

Bassett, Michael, and Luke Malpass. Priced Out: How New Zealand Lost Its Housing Affordability. Wellington City: The New Zealand Initiative, 2013.

$<$ <ttps://nzinitiative.org.nz/. Web.>

Bulleyment, Alan. Homes Without Barriers: A Guide to Accessible Houses. Porirua: BRANZ, 2001. Print.

$<$ <http://www.branz.co.nz/cms show download.php?id=f67d42b2b445fc3b2e2404c3e2539d90b76c97f1>

Davey, Judith. "'Ageing in place': the views of older homeowners on maintenance, renovation and adaptation." Social Policy Journal of New Zealand 27 (2006): 128+. Academic OneFile. Web. 20 June 2016.

<http://go.galegroup.com.helicon.vuw.ac.nz/ps/i.do?id=GALE\%7CA146354001\&v=2.1\&u=vuw\&it=r\&p=AONE\&s $\underline{w=w \& a s i d=e b 83 a f 01 f d 5985392 d d d a 327195231 d e>}$

Habitat 67. "Montreal - Canada." Habitat 67. 2010. Web. 20 Nov. 2016. <http://www.habitat67.com/en/>.

Hansen, Eigil B., and Georg Gottschalk. "What Makes Older People Consider Moving House and What Makes Them Move?" Housing, Theory and Society 23.1 (2006): 34-54. Print.

$<$ http://www.tandfonline.com/doi/pdf/10.1080/14036090600587521>

Howden Chapman, Philippa. "BOOK EXTRACT: Home Truths - Confronting New Zealand's Housing Crisis." The National Business Review. Bridget Williams Books, Wellington, 2016. Web. 6 May 2016.

<http://www.nbr.co.nz/article/book-extract-home-truths-\%E2\%80\%93-confronting-new-zealand\%E2\%80\%99shousing-crisis-183320>.

MacPherson, Liz. National Family and Household Projections: 2013(base)-2038. Wellington City: Statistics New Zealand, 2015. Web. 10 Apr. 2016.

<http://www.stats.govt.nz/browse_for_stats/population/estimates_and_projections/NationalFamilyAndHouseh oldProjections_HOTP2013base.aspx>.

Marcus, Clare C, and Wendy Sarkissian. Housing As If People Mattered: Site Design Guidelines for MediumDensity Family Housing. Berkeley: U of California P, 1986. Print.

McNeill, Mark. "Watch Why Am I? - Episode 4." TVNZ OnDemand. June 2016. Web. 16 June 2016. <https://www.tvnz.co.nz/ondemand/why-am-i/23-05-2016/series-2015-episode-4>. 
Meinhold, Bridgette. "Casa Garoza: Spanish Prefab Prototype is Designed to Grow Over Time I Inhabitat - Green Design, Innovation, Architecture, Green Building." Inhabitat / Design For a Better World! 5 Oct. 2011. Web. 25 Mar. 2016. <http://inhabitat.com/casa-garoza-spanish-prefab-prototype-is-designed-to-grow-over-time/>.

NZ Transport Agency. "Driving Overdimension Vehicles | NZ Transport Agency." Home / NZ Transport Agency. New Zealand Government, 2017. Web. 24 June. 2017. <https://www.nzta.govt.nz/commercialdriving/permits/overweight-overdimension-permit/driving-overdimension-vehicles/>.

"Projects - Karori As a Medium-density Housing Area - Wellington City Council." Wellington City Council. 2015. Web. 20 Mar. 2016. <http://wellington.govt.nz/your-council/projects/housing-choice-and-supply/karori/karorias-a-medium-density-area>.

Schneider, Tatjana, and Jeremy Till. Flexible Housing: The Means to the End. Cambridge UP, 2005. PDF.

Vale, B. and Khajehzadeh, I. (2016) Time-use and resource use in private open space in New Zealand, The $9^{\text {th }}$ Australasian Housing Researchers Conference, Auckland, 1-14.

Wellington City Council. "Karori: Medium-density Housing: Draft District Plan Change." Wellington City Council. Nov. 2015. Web. 12 Apr. 2016. <http://wellington.govt.nz/ /media/have-your-say/publicinput/files/consultations/2015/11-karori-housing/housing-affordability-choice-karori-fact-sheet.pdf?la=en>.

Wellington City Council. "Projects - Housing Choice \& Town Centre Planning - Wellington City Council." Wellington City Council: Housing choice \& town centre planning. 2016. Web. 10 Apr. 2016. <http://wellington.govt.nz/your-council/projects/housing-choice-and-supply>.

Wiles, J. L., A. Leibing, N. Guberman, J. Reeve, and R. E. Allen. "The Meaning of "Aging in Place" to Older People." The Gerontologist 52.3 (2011): 357-366. Print. <https://www.researchgate.net/publication/51702716_The_Meaning_of_Aging_in_Place_to_Older_People> Wraight+ Associates Limited. "Karori Character Assessment." Wellington City Council. 30 Oct. 2015. Web. 12 Apr. 2016. <http://wellington.govt.nz/ /media/your-council/projects/files/housing-choice-supply/mediumdensity-housing/karori-character-assessment.pdf>.

Xie, Jenny. "Prefab Housing Customized by Residents Sprouts Up in the U.K." Curbed. Vox Media, 9 Mar. 2016. Web. 18 Aug. 2016. <http://www.curbed.com/2016/3/9/11187742/prefab-housing-custom-design>. 


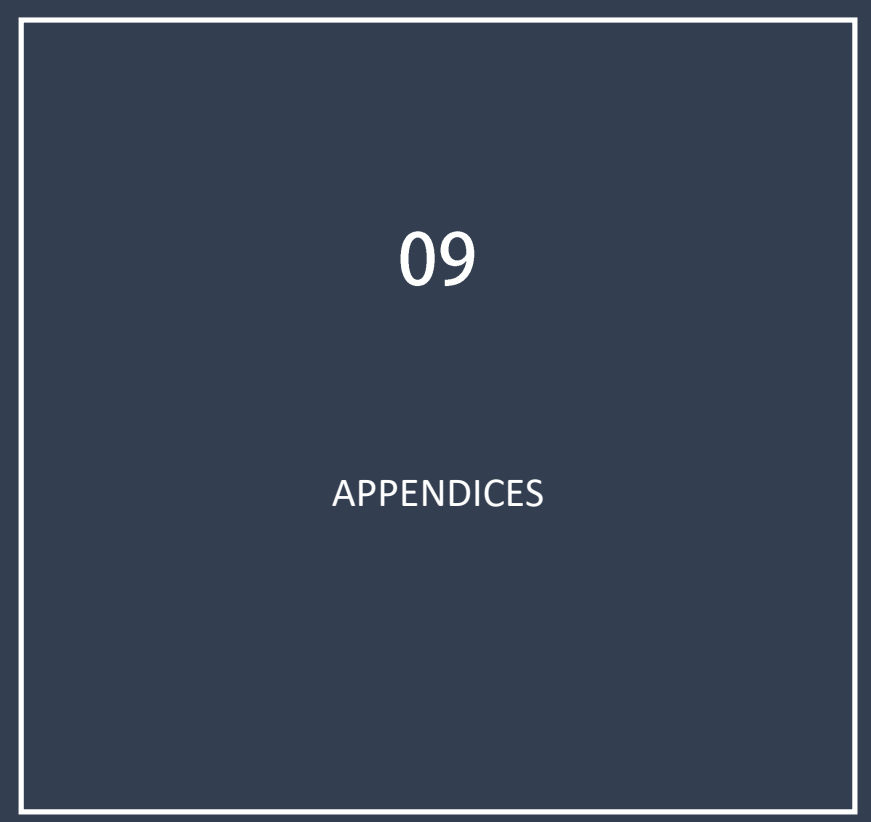


APPENDIX A: Design Guidelines from Housing as ilf People Mattered, Clare Cooper Marcus and Wendy Sarkissian, 1986.

\section{LIST OF DESIGN GUIDELINES}

II. Landscape quality

Landscaping and site layout contribute highly to resident satisfaction.

12. View from the window Most people base their notions of attractiveness on what they can see from their windows.

13. House on its own land The ideal of most families is to live in a house with some land around it; therefore, when a higher density or different form must be used, try to give residents as many of the advantages of house dwell. ing as possible.

14. Popular forms

To minimize the likelihood of jealousy among neighbors, avoid a mixing of housing forms that have differing degrees of

5. Conforming image

Most residents appreciate an image that reflects local prevailing middle-class norms.

16. Unobtrusive image Low-income residents prefer housing schemes that do not stand out in the neighborhood.

17. Locally acceptable materials In rental housing select building materials of comparable quality and image to those used in local owner-occupied housing to minimize the likelihood of stigma.
CHAPTER 3

Basic Considerations of the

Design Program

I. Density and form

There is no simple relationship between density and satisfaction; other significant variables combining with density affect perceived density and influence satisfaction.

a. Overall size

b. Spacing of units

c. Visual and functional access to open space from the dwelling

d. Protection of privacy

e. Division into small clusters

f. Variety in facade design

g. Access to buildings

h. Minimum of noise intrusion

i. Well-sited community facilities

j. Parking

k. Adequate private open space

2. Project size A multifamily housing development should be small enough to avoid the appearance of a "project," but large enough to provide adequate space for children's activities

3. Children safe from cars Families with children under ten value highly residential environments where pedestrians are segregated from or have precedence over vehicles.

4. Space hierarchy Clearly delineate public space (streets)

(1)

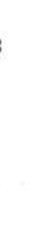

8

20. Color External color schemes should be care- 56 fully considered to reflect residents' tastes.

21. Subunit identity Each subunit of a scheme should have some elements of uniqueness to create a sense of place and identity.

22. Edge treatment Residents are particularly sensitive to conflicts that occur at the edge of a development.

23. Site map

When the design of a development does not follow the normal street pattern, orientation maps should be placed at major entry points.

24. Name sign

If a development is generally known by its name, this should be prominently displayed at frequently used entry points.

25. Street names To assist in finding addresses, name all internal streets, courtyards, and other identifiable common areas.
CHAPTER 4

Image, Building Form, and Orientation

10. Pleasing milieu satisfaction.

DESIGN GUIDELINES: HOW TO USE THIS BOOK

community space (shared open space, play areas, communal laundries, and so
forth), and private space (dwellings and private open spaces).

. Community identity A sense of community and security is ikely to be enhanced when access to the

A degree of homogeneity is necessary be fore residents will develop a feeling of community.

7. Life cycle clusters 42 the same stage in the life cycle.

8. Ground-floor households In multistory schemes preference for ground-floor units should be given to holds, and physically disabled persons.

9. Dwelling mix

Provide a variety of dwelling sizes so that ouseholds can move within the same neighborhood or development as their space needs change.

26. Dwelling addresses

The street number and address of every dwelling unit should be clearly identified.

27. Conforming signs

Site signs and numbering should conform as much as possible to that used in the surrounding neighborhood.

28. Visible dwelling numbers Visitors approaching by car st to read the numbers by should be able dwellings at night.

CHAPTER 5

\section{Personalization}

29. Territorial expression Provide opportunities for residents to experience or express a sense of territory around their dwellings.

30. Added privacy Give residents the option of increasing the sense of privacy around their homes.

31. Articulated facade

The more articulated the facade, the more likely are residents to add their own touches to the design.

32. Personal additions Use permeable cladding to facilitate the addition of personal touches to house exteriors.

33. Component replacement Use standard-sized doors, windows, and 
balconies so that residents may replace or modify these if they wish.

34. Entry personalization Allow for personalization of the front entry.

\section{CHAPTER 6}

\section{Access to Dwellings}

35. Private entry

Provide as many dwellings as possible with a private entrance at ground level.

36. Visible entry

Ensure that the main entry to the dwell is clearly visible from the nearest public circulation path.

37. Private front path Avoid sharing private, ground-level front paths.

\section{Entry path location} Ensure that the positioning of the front path does not violate interior privacy.

39. Transitional filters

Provide a series of transitional filters for pedestrians passing from public spaces to the private domain of the dwelling.

40. Front porch Provide a porch or porchlike space at every front entry.

41. Back and front entries

Back and front entrances to the dwelling should be clearly identified and distinguished from each other.

42. Neighborly surveillance

A delicate balance must be struck be tween designing for ease of surveillance and designing for privacy.

43. Accessibility Dwellings should be accessible to physically disabled people.

44. Shared entry

Where one building entry serves a group of dwellings, the number sharing should be between three and eight households.

45. Outdoor gallery access Be cautious in providing access via long. shared-access galleries.

46. Deck connection Be cautious about providing aboveground deck connections to adjacent neighborhoods.

47. Quality detailing

In linear-access schemes provide highquality design details, finishes, and lighting and stipulate maintenance responsibilities.

48. Street activities off the ground 90 Design off-ground linear access ways to accommodate-as many activities as possible that would normally occur on the street, sidewalk, front porch, or path.

49. Corridor access Avoid corridor-access buildings for households with children
50. Ramps and elevators Provide ramps or elevators for people un able to use stairs.

51. Entry storage Provide storage spaces for strollers, bicycles, shopping carts, and so forth close to the main entries of dwellings or groups of dwellings

52. Furniture moving Access ways should be designed to facilitate moving furniture.

CHAPTER 7

\section{Private Open Space}

53. Yard amenities

Provide a private garden, yard patio, or balcony for every unit, appropriately furnished with amenities to facilitate its use.

54. Access to private open space The private open space of all units should be visually and functionally accessible from inside the dwelling

55. Yard linked to common space 96

The needs of children - and their parents- will be best served if there is direct, level access from a fenced yard to a safe communal play area.

56. "Front" and "back" customs 97

Design and delimit front and back yards according to locally accepted norms of "front" and "back" behavior.
57. Privacy screening scrive activities are likely to occur and to delimit private from communal open space.

58. Overlooking

Arrange dwellings so that windows of neighboring units do not overlook private open spaces likely to be used for private activities

59. Orientation to sun

People will use only private outdoor spaces that are oriented for a comfortable daytime temperature.

60. Square back yards To facilitate use, make private open space approximately square.

61. Yard size Where minimally sized yards are inevitable, compensate residents with access to communal space.

62. Display garden

Provide residents with the opportunity of maintaining a semipublic (or display) garden around the front entry.

63. Front of modest size Front-entry yards should be deep enough for privacy but not so large as to inhibit personalization.

64. Above-ground balconies 105 Units above ground level should have access to private balconies of usable dimensions.
65. Balcony off living room Where possible, locate the balcony adja cent to the living room.

66. Balcony drainage Ensure that balconies are adequately drained

\section{CHAPTER 8}

\section{Common Open Space and the}

\section{Needs of Children}

67. Pedestrian precinct

Within reasonable bounds provide as ex tensive a traffic-free area as possible.

68. Traffic management Reduce the speed and volume of traffc on residential streets.

69. Sidewalk activities Design sidewalks as part of community space.

70. Woonerfs

Consider the controlled mixing of pedestrians and vehicles by means of woonerfs or mixer courts.

71. Adjacent public facilities In designing or rehabilitating a site of limited dimensions, make maximum use of existing adjacent public space or unused public facilities.
72. Group territory

Recognition o the undisputable territory of a group of dwellings provides, for many residents and their children, a needed sense of place and belonging.

73. Interesting landscaped spaces 120 Children will be attracted to safe, interio landscaped areas only if they find them more interesting play spaces than the sur rounding roads or parking areas.

74. Comfortable space dimensions 121 The design of comfortable landscaped spaces requires attention to locally accepted notions of size, dimension, and height/width ratios.

75. Varying spaces

A series of connected, medium-sized spaces of varying shape and appearance is more suitable than one large or several identical spaces.

76. Common space at the back 125 Care should be taken in connecting dwelling entries with communal open space.

77. Common space boundary 127 Ensure that the boundaries between private and communal outdoor spaces are clearly defined.

78. Street linkage Design the linkage between common open space and adjacent public street with care. 
79. Playing everywhere

Children tend to play anywhere and everywhere, and not just in designated play spaces.

80. Children on the move Moving around the neighborhood is children's most frequent outdoor activity.

81. Children's spaces in settings that are varied and full of surprises.

82. Hard-surface play choice between the two.

83. Leftover spaces . leftover spaces, leave part of the site undeveloped.

84. Unrestricted setting

Create an environment that channels children's play without the need for rules and regulations.

85. Children's rights

A resident's manual or lease-sales agreement should make clear that communal open spaces are intended primarily for children's play.

86. Open space maintenance

Maintenance of communal onen snace is strongly linked to overall resident satisfaction. Children need to play and move around

\section{CHAPTER}

Purpose-Built Play Areas for Children

Play Areas for Preschool Children

(Ages Two to Five)

87. Yard play Yards should meet the needs of children under five.

88. Balcony play Where families must be housed off the ground, provide a safe and usable balcony for children's play.

89. Doorstep play Design dwelling entries to accommodate doorstep play.

90. Tot lot location

Provide purpose-built play areas for c dren under five within sight and calling distance of home.

91. Tot lot catchment A tot lot, or play space for preschool children, should be located in every court or subspace of a family housing development.

92. Hazard-free play Play areas for young children should be physically separated from potentia hazards.

93. Tot lot design

Design tot lots with careful consideration for children's needs.
94. Supervising adults Provide seating areas for adults supervising children's play.

95. Sand play 148 Provide sand beneath all play equipment.

96. Water play Provide opportunities for children to play in or with water.

97. Established play areas Basic play equipment should be on site and ready to use when the first residents move in.

Equipped Play Areas for Children

Five to Twelve Years Old

98. Middle-childhood users

The whole site must be designed with

high priority to the needs of five- to

twelve-year-olds, who will be the predominant user group.

99. Children as planners

Children need to be included in the process of designing areas they will use.

100. Equal play opportunities 154 The outdoor environment close to home must provide equally for boys and girls.

10I. Play on site Neighborhood play provision should never be regarded as a substitute for play space within the housing development for this age group.

102. Walk to play

Provide on-site, well-equipped, and challenging play areas for school-age childre within five minutes' walk from home.

103. Complementary play Locate play equipment areas for schoolage children near other play opportunities.

104. Sibling play

Play areas for different age groups should be separated for safety reasons, but not necessarily segregated.

105. Safe play The whole environment should be designed with the safety needs of children in mind.

Provide play equipment for a variety of experiences.

107. Children's preferences Play equipment should be selected 164 children's preferences in mind.

108. Tarzan swings Children enjoy testing their skills and 168 age in daring experiences.

109. Children's lookouts Children like to climb up high and gain a sense of mastery by looking out over the environment.

110. Flow of play

Link activities in play equipment area so that there is an obvious flow of play options.
III. Attractive play materials Although play facilities should be built of sturdy materials, they should also fulfill children's and adults' aesthetic needs.

112. Supervised play As more and more parents work, access to supervised after-school and summer play becomes essential.

113. Adventure playground Provide an adventure playground on site or nearby.

114. Loose parts playing with maniput the opportunity of

115. Children's gardens Children need to relate to the natural world and to have opportunities to care for growing things.

116. Play nests

Children need to withdraw, to play a or in small groups in sheltered, enclosed spaces

117. Children's seating Provide places for school-age children to sit.

118. Children's toilets Provide accessible toilets near major play areas.

119. Undercover play rovide a facility for sheltered phy weather.
178

vide a location that can easily be converted to an ice

121. Snow play

Where snow clearance routinely occurs in roadways and parking lots, take account of where children will slide on deposited snow piles.

122. Winter playgrounds In cold winter regions play areas should be designed for winter as well as summer use.

Recreation Opportunities for Teenagers

123. Ball games

On larger developments space should be provided for informal ball games.

124. Teenage hangouts Teenagers need informal gathering pla

125. Teen center enough, indoor socia delopment is large provided for teenagers.

126. Teen entertainment Provide challenging and interesting activi ties for teenagers to minimize the like lihood of boredom.

127. Off-site facilities

Where sports facilities on site are seen as uninecessary because of the proximity to sports or leisure centers, ensure that the 
center is really available to teenage

residents.

CHAPTER 10

\section{On-site Facilities for Adults}

Casual Social Needs
128. Home turf
Provide opportunities for residents to
watch the world go by from their own
"turf."
129. Casual meetings
Many adults appreciate opportunities for
casual outdoor encounters around the
home.
130. Meeting neighbors
Dwellings should be arranged so that it is
possible for neighbors to meet one an-
other, but not so that neighbor contact is
forced.
131. Friendly encounters
Sharing a common pedestrian open space
enhances the potential for neighborly so-
cial contact.
132. Dwelling cluster
The number of dwellings grouped around
a common landscaped space should be
somewhere between twenty and one
hundred.
133. Courtyard width
The distance between units facing each
other across a communal landscaped

space should not be less than about 30 feet $(9.14 \mathrm{~m})$.

Communal Focilities

134. Small meeting room

However desirable.

135. Sharing work Provide for the possibility of neighbors collaborating on tasks that have traditionally been undertaken individually in private dwellings.

136. Day-care center Provide accessibility to day care.

137. Laundry facilities Provide easily accessible communal laundry facilities.

138. Outdoor drying Provide opportunities for outdoor drying

139. Workshops tool loan services.

140. Supervised facilities Indoor recreation facilities should be provided only if supervision by salaried personnel is possible.

141. Community garden Provide residents with opportunities to have a plot in a communal vegetable garden. ple meeting or multipurpose room is Provide community workshop space and

142. Access to facilities 198 Easy access to adequate commercial and community facilities is especially needed by less-mobile population groups.

143. Local services 199

The more traumatic the breaks with old neighborhoods experienced by residents of a new site, the more crucial is the local provision of adequate social and community services for them.

144. Multiservice centers 201 In large, subsidized developments provide facilities for a multiservice or advice center

145. Adult sports 202 Provide facilities for adult outdoor leisure and sports.

146. Swimming pool 203 Where the budget permits, provide a swimming pool.

147. Facility size 203 The quantity and size of community facilities should be commensurate with user demand.

\section{CHAPTER I।}

\section{Parking}

148. Vehicular segregation 207

Vehicle access and parking arrangements should respect the need for an uninterrupted network of safe landscaped spaces for children and adults.

DESIGN GUIDELINES: HOW TO USE THIS BOOK

27

157. Assigned parking

49. Vehicle speeds

Vehicular flow should be controlled by signs, changes in roadway texture, and speed bumps.

150. Locked garages

Where possible, provide each dwelling with its own locked garage.

151. Convenient parking Where private garages are not feasible, a carport or driveway space is a preferable alternative.

152. Small parking lots 210 Open parking lots should be relatively small and within view of some of the dwellings.

153. Grouped carports Parking spaces in grouped parking areas and be clearly marked.

158. Visitor parking Visitor parking should be sensitively located and clearly identified.

159. Car maintenance Provide one or a number of hardsurfaced spaces with water and electrical connections.

160. Cold-weather parking 217 In cold or wet regions make special provisions in parking design.

161. Hot-weather parking In very hot climates residents should be provided with shaded parking to protect the paint finish of their vehicles.

162. Recreational vehicle parking 218 Consider providing parking for boats, recreational vehicles, and other occasionally used vehicles.

CHAPTER 12

Landscaping, Footpaths, and Site Furniture

Landscaping and Planting they are secure, pleasant, well lit, and wel ventilated.

156. Accurate parking provision

163. Landscaping importance Landscaping should be treated as an intrinsic part of site design.
164. User-oriented landscaping 222 Landscaping should be planned with resident satisfaction as its chief concern.

165. Children in the landscape Use of the site by children is a critical consideration in landscape design.

166. Ground shaping 224 Ground shaping and grading should be used to create interest on flat sites.

167. Paved areas Avoid large, empty paved areas.

168. Functional spaces 224 In selecting plant materials keep the actual use of every section of the site in mind.

169. Grassed areas 226 When considering the inclusion of a grassed area, the designer must decide whether its purpose is mainly for appearance or also for children's use.

170. Trees 226 Employ trees as softening, spacelevel.

171. Native species 228 Plant native species and retain existing trees.

172. Tree maintenance Choose trees so as to minimize maintenance. enhancing, and shading elements at eye 
173. Microclimate

mate and to act as a passive method of climate control for dwellings.

174. "Keep off" planting

Ground cover and shrub plantings should be used only where there is a logical reason to prevent use of a space.

175. Shrubs for play

Where shrubs are to be planted for largely aesthetic purposes, consider using species that will also enhance children's need for hiding spaces.

176. Privacy planting Use planting to enhance the privacy of ground-level dwellings.

177. Snowmelt Ensure that planting in areas with cold mates does not impede the melting of snow and ice.

178. Planting edges All planted areas (other than lawns) next to hard surfaces should have wooden edges, raised borders, or retaining walls.

179. Landscape installation and modification

Although major items of landscaping need to be carefully installed and established before occupancy, residents must have the opportunity to make later modifications.

180. Personalized landscape Provide planting spaces where individuat 231

(1)

2

187
186. Leisure walking 239 Provide pathways for strolling or leisure walking.

187. Pedestrians passing by When planning circulation routes, ensure that no population group will have to violate another's temporary territory while moving around the site.

188. Footpath privacy Locate footpaths so that pedestrians 24 not violate the privacy of nearby dwellings or yards.

add to the general land-

of the development.

Ownership and maintenance arrangements will affect what can be planned.

ootpaths and pedestrian circulation

Footpath systems should accommodate predictable patterns of pedestrian circulation.

3. Footpath design Design footpaths to facilitate use and maintenance.

Footpaths should be designed with the

238 Provide sidewalks along all streets in resiProvide sidewa

189. Footpath play 242 列 modate children's play.

190. Footpath security Design paths to enhance security.

191. Footpath lighting Design footpath lighting with care Site Furniture

192. Outdoor seating 244 A variety of pleasant outdoor seating locations will meet different needs.

193. Sunny/shaded seating 245 In locating sitting areas be conscious of the local microclimate.

194. Seating variety 246 Provide a variety of sitting area designs.

195. Seating environment 247 Pay close attention to the detailed design of seating areas.

196. On-site picnic Provide picnic tables and barbecues. 248

197. Child table 249 Provide a child-sized table and benches.

198. Drinking fountains in regions with hot summers provide drinking fountains.

199. Public phones Public phones are a high priority.

200. Litter receptacles On-site litter receptacles are a high priority.

DESIGN GUIDELINES: HOW TO USE THIS DOOK 249 250

210. Secure garages Provide all garages with security and high visibility.

211. Secure storage Provide strong and securable storage rooms for use by personnel.

212. Utility meters Protect utility facilities and meters in highcrime areas.

Territoriality

213. Territorial zones Subdivide residential environments into specific territorial zones.

214. Entrance group Limit the number of households sharing an entrance.

Opportunities for Surveillance

215. Superblocks Consider the security risks of traffic-free superblocks.

216. Incorporating the street incorporate local streets into the site plans of new developments.

217. Direct access Provide direct access to buildings from parking lots, public transit, and city streets.

218. Resident allocation Allocation policies can promote or dis courage informal surveillance.
219. Informal surveillance

Place windows and orient entries to maximize natural surveillance of the site.

220. Yard surveillance

The enclosure of private open space should not prevent surveillance.

221. Evening use 272 Encourage casual use of the environment during evening hours.

222. Lighting for safety 272 Well-used public access ways require bright, even, and vandal-proof lighting.

223. Management office 273 Locate the management office at a central visible point.

224. Safe meeting places Locate social rooms close to other heavily used areas.

225. Safe laundry rooms 273 Minimize opportunities for vandalism of laundry rooms.

226. Alarm systems

In vulnerable locations or in existing developments where the original layout provides little natural surveillance, electronic alarm systems may be appropriate.

Ambiguity

227. User group territories 276

Ensure that each identified user group has a place on the site for its preferred outdoor activities. 
228. Buffer zone

Create a buffer between dwellings and communal open space.

Resident Conflicts

229. Running the gauntlet Ensure that no resident group, while goin about its daily business on the site, will have to "run the gauntlet" through an area dominated by others.

230. Conflicting uses

Ensure that potentially conflicting activities are not placed next to each other.

Vandalism

231. Child density 280 Design with particular care where child densities are high.

232. Taking risks If adequate facilities for adventurous play are not provided, children and teenagers are likely to take risks in and on buildings.

233. Vulnerable materials Avoid the use of highly vulnerable materials.

234. Attractive materials Although robust materials are caution, do not use them at the expense of appearance.

235. Prompt repairs Maintenance staffing and budgeting must allow for the prompt repair of damage.
236. Mailboxes possibility of vandalism and theft.

Management

237. Managing security Employ effective management techniques to minimize crime.

\section{CHAPTER 14}

Management, Maintenance, and Refuse Disposal

Manogement and Maintenance

238. Good management Design can facilitate or inhibit good management.

239. Maintenance policies Physical design should take account of projected management, maintenance, and repair policies.

240. Maintenance responsibilities Management and resident responsibilities on site should be clearly spelled out.

241. Resident's manual Designers and management should prepare a resident's manual.

242. On-site office Where possible, provide a management office on site.
243. Resident caretaker Resident or full-time caretakers are essential to successful management.

244. Tenant involvement 29 Consider increasing the amount of tenant participation in management.

245. Resident responsibilities 292 The greater the level of responsibility accorded to each resident, the easier will be the task of management.

246. Domestic animals

Housing developments should be designed to allow residents to keep domestic animals, within certain limits.

247. Play equipment upkeep Play equipment should be inspected and repaired regularly,

Refuse Disposa

248. Garbage disposa

If possible, provide garbage areas close to kitchen entrances.

249. Bulky refuse

Provide for the disposal of bulky items that cannot be handled in the normal way.

250. Garbage chutes Where garbage chutes are provided, particular care should be taken in their design and location.

251. Dumpster location

Where garbage is handled by communa dumpsters, each disposal point should

94

serve a specific number of units and be clearly accessible to them

252. Dumpster collection

Locate dumpsters with consideration for collection (and lack of obstruction of other functions)

253. Dumpster screening Screen garbage dumpsters from view.

254. Dumpster selection

Select refuse dumpsters for ease of use.

.

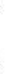
94 
APPENDIX B: CLT Construction

XLAM NZ Ltd. "Cross Laminated Timber Design Guide." 2013.
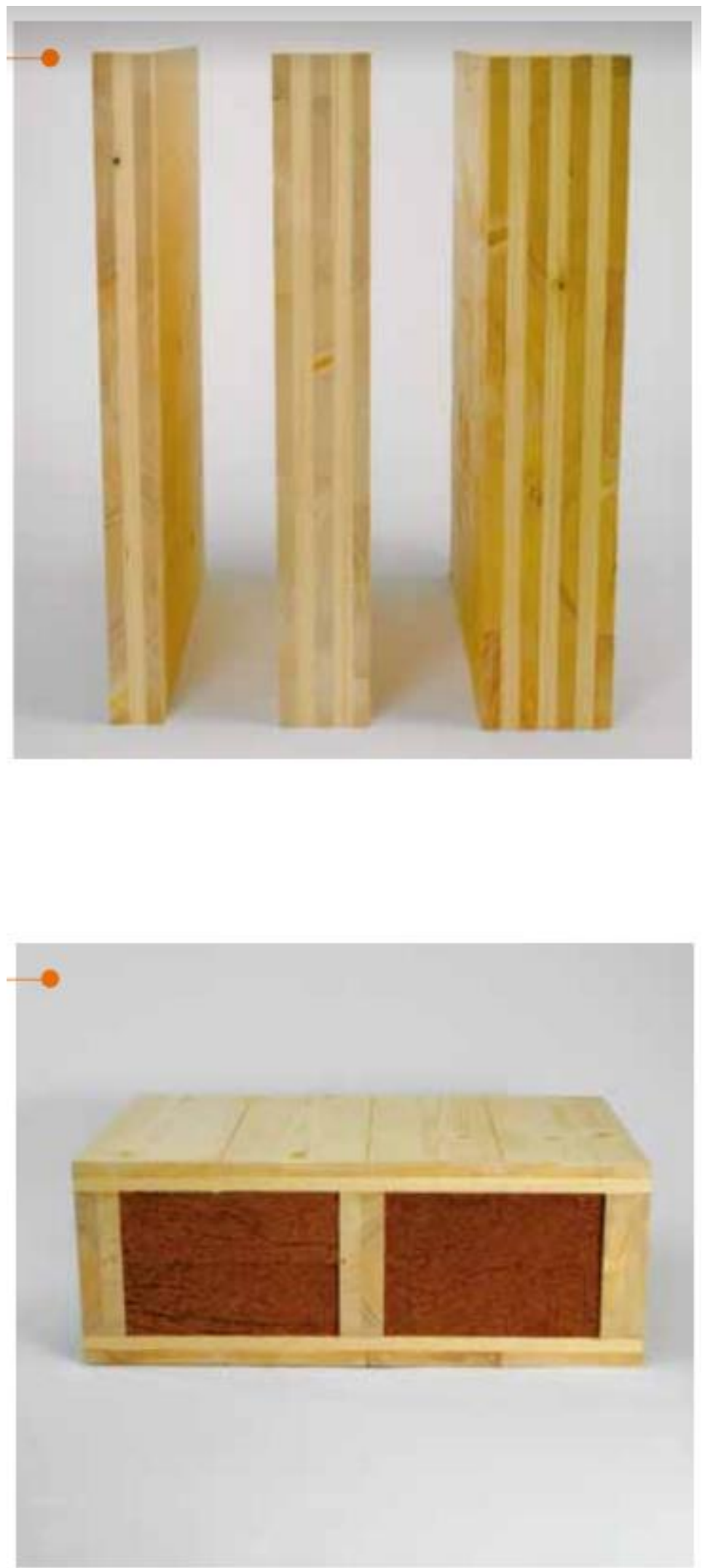


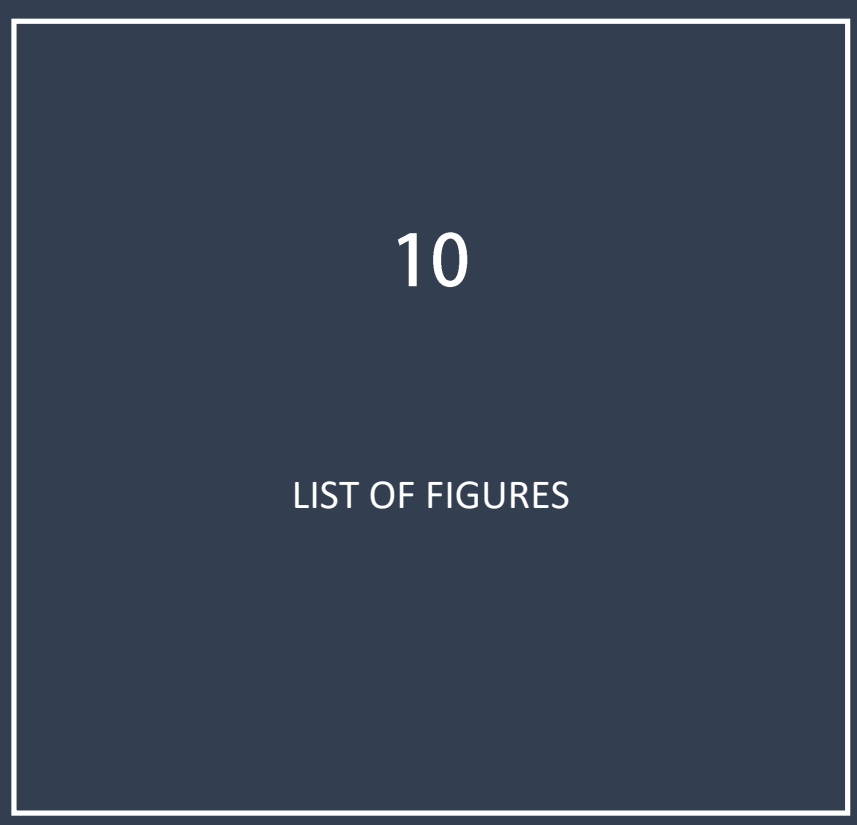




\section{LIST OF FIGURES}

\section{Chapter 1 | Introduction}

Figure 1.4.1: Methodology diagram. Author's own image, 2016.

\section{Chapter 2 | Context Analysis}

Figure 2.1.1: Map of greater Wellington. Author's own image, 2016.

Figure 2.1.2: Map of Karori. Author's own image, 2016.

Figure 2.1.3: Map of MDRA zone. Author's own image, 2016.

Figure 2.1.4: Selected site map, 300-318 Karori Road, Karori, Wellington. Author's own image, 2016.

Figure Series 2.2.1: Photographs of poor housing currently on site. Author's own image, 2016.

Figure Series 2.2.2: Solar studies of existing site. Author's own image, 2016.

Figure 2.3.1: Wraight+ Associates Limited. Karori Character Assessment: MDRA zone. Wellington. Digital image.

Wellington City Council. 30 Oct. 2015. Web. 12 Apr. 2016. <http://wellington.govt.nz/ /media/yourcouncil/projects/files/housing-choice-supply/medium-density-housing/karori-character-assessment.pdf>.

Figure 2.3.2: Wraight+ Associates Limited. Karori Character Assessment: Walking zones. Wellington. Digital image. Wellington City Council. 30 Oct. 2015. Web. 12 Apr. 2016. <http://wellington.govt.nz/ /media/yourcouncil/projects/files/housing-choice-supply/medium-density-housing/karori-character-assessment.pdf>.

Figure 2.3.4: Perspective of existing site during summer solstice. Author's own image, 2016.

Figure 2.3.5: Perspective of existing site during winter solstice. Author's own image, 2016.

Figure 2.4.1: Site perspective with dimensions. Author's own image, 2016.

Figure 2.4.2: Sketch exploration of site layout. Author's own image, 2016.

Figure 2.4.3: Site sketch exploration to increase density. Author's own image, 2016.

Figure 2.4.4: Site layout to determine sections and orientation. Author's own image, 2016.

Figure 2.4.5: Site layout to determine access routes. Author's own image, 2016.

Figure Series 2.4.6: Solar studies of existing site. Author's own image, 2016.

Figure 2.5.1: Site layout exploration one. Author's own image, 2016.

Figure 2.5.2: Site layout exploration two. Author's own image, 2016. 
Figure 2.5.3: Site layout exploration three. Author's own image, 2016.

Figure 2.5.4: Site layout exploration four. Author's own image, 2016.

Figure 2.5.5: Final site layout perspective. Author's own image, 2016.

\section{Chapter 3 | Literature Review}

Figure 3.2.1: Graph of reasons why elderly consider moving. Author's own image, 2016.

Figure 3.5.1: Framework for MDH in an environment susceptible to change. Author's own image, 2016.

\section{Chapter 4 | Project Review}

Figure 4.1.1: Safdie, Moshe. Habitat 67: Brutalist housing complex, 1967. Montreal, Canada. Digital image. 20 Nov. 2016. Web. <http://www.habitat67.com>

Figure 4.1.2: Safdie, Moshe. Habitat 67: Brutalist housing complex, 1967. Montreal, Canada. Digital image. 20 Nov. 2016. Web. <http://www.habitat67.com>

Figure 4.1.3: Safdie, Moshe. Habitat 67: Brutalist housing complex, 1967. Montreal, Canada. Digital image. 20 Nov. 2016. Web. <http://www.habitat67.com>

Figure 4.2.1: Xie, Jenny. Shedkm Architects: Medium Density Housing. New Islington, Manchester, UK. Digital image. Curbed.com. Urban Splash, 9 Mar. 2016. Web. 20 Nov. 2016.

<http://www.curbed.com/2016/3/9/11187742/prefab-housing-custom-design>.

Figure 4.2.2: Xie, Jenny. Shedkm Architects: Medium Density Housing. New Islington, Manchester, UK. Digital image. Curbed.com. Urban Splash, 9 Mar. 2016. Web. 20 Nov. 2016.

<http://www.curbed.com/2016/3/9/11187742/prefab-housing-custom-design>.

Figure 4.2.3: Xie, Jenny. Shedkm Architects: Medium Density Housing. New Islington, Manchester, UK. Digital image. Curbed.com. Urban Splash, 9 Mar. 2016. Web. 20 Nov. 2016.

<http://www.curbed.com/2016/3/9/11187742/prefab-housing-custom-design>.

Figure 4.2.4: Xie, Jenny. Shedkm Architects: Medium Density Housing. New Islington, Manchester, UK. Digital image. Curbed.com. Urban Splash, 9 Mar. 2016. Web. 20 Nov. 2016.

<http://www.curbed.com/2016/3/9/11187742/prefab-housing-custom-design>.

Figure 4.3.1: Callejas, Javier (Herreros Arquitectos), and Bridgette Meinhold. Prefabrication of modular home within factory controlled environment. Digital image. http://inhabitat.com. 05 Mar. 2011. Web. 25 Mar. 2016. <http://inhabitat.com/casa-garoza-spanish-prefab-prototype-is-designed-to-grow-over-time/>. 
Figure 4.3.2: Callejas, Javier (Herreros Arquitectos), and Bridgette Meinhold. On site completion. Digital image. http://inhabitat.com. 05 Mar. 2011. Web. 25 Mar. 2016. <http://inhabitat.com/casa-garoza-spanishprefab-prototype-is-designed-to-grow-over-time/>.

Figure 4.3.3: Callejas, Javier (Herreros Arquitectos), and Bridgette Meinhold. Core of the home uses standardised openings to expand. Digital image. http://inhabitat.com. 05 Mar. 2011. Web. 25 Mar. 2016. <http://inhabitat.com/casa-garoza-spanish-prefab-prototype-is-designed-to-grow-over-time/>.

Figure 4.3.4: Callejas, Javier (Herreros Arquitectos), and Bridgette Meinhold. Diagram of expansion off the main service module. Digital image. http://inhabitat.com. 05 Mar. 2011. Web. 25 Mar. 2016.

<http://inhabitat.com/casa-garoza-spanish-prefab-prototype-is-designed-to-grow-over-time/>.

\section{Chapter 5 | Preliminary Design}

Figure Series 5.1.1: Design exploration of modules to achieve practical dimensions for both interior configurations and transportability. Author's own image, 2016.

Figure Series 5.1.2: The initial home layout looks to comprise of the following modules: living, kitchen, bathroom, laundry and bedroom. Author's own image, 2016.

Figure Series 5.1.3: Design exploration to see growth of home accommodate multigenerational living. Author's own image, 2016.

Figure Series 5.1.4: Design exploration of how site impacts the layout of the site to achieve the best possible level of residential amenity for all properties. Author's own image, 2016.

Figure Series 5.1.5: Design exploration of home the width of two modules, each at $4 \mathrm{~m}$, resulting in the site adopting long narrow sections to achieve medium density. Author's own image, 2016.

Figure 5.1.6: Design exploration to achieve medium density. Author's own image, 2016.

Figure 5.1.7: The plan view illustrates the new road access through the site to allow for maximum intensification. Author's own image, 2016.

Figure Series 5.1.8: Perspective views of the site accommodating 60 homes. Author's own image, 2016.

Figure Series 5.1.9: The plan view illustrates initial modules of the home positioned at equal set back distances from the centre of the development. Author's own image, 2016.

Figure 5.2.1: Physical model to realise linear growth of the home. Author's own image, 2016.

Figure Series 5.2.2: Consideration: The need for standardisation on the $\mathrm{x}$ axis for lineal growth. Author's own image, 2016.

Figure 5.2.3: The home adds modules to the rear of the home to allow for growth. Author's own image, 2016.

Figure 5.2.4: Design exploration conveying the temporality of the home. Author's own image, 2016. 
Figure 5.2.5: Design exploration conveying the temporality of the home. Author's own image, 2016.

Figure Series 5.3.1: A range of modules available for mass customization of the home to express individuality within the complex. Author's own image, 2016.

Figure Series 5.3.2: Sees the modules group together in different formations. Author's own image, 2016.

Figure Series 5.4.1: Physical models demonstrating the growth of the home, made possible through aligning standardised openings. Author's own image, 2016.

Figure Series 5.5.1: Computer iterations for standardising openings. Author's own image, 2016.

Figure 5.6.1: The physical models illustrate how the home would grow over time. Author's own image, 2016.

Figure 5.6.2: Modules translated into computer model to generate floor plans.

Figure 5.6.3: The selection of modules available to configure the home. Author's own image, 2016.

Figure 5.7.1: First iteration of the home. Author's own image, 2016.

Figure 5.7.2: Second iteration of the home. Author's own image, 2016.

Figure 5.7.3: Third iteration of the home. Author's own image, 2016.

Figure 5.7.4: Fourth iteration of the home. Author's own image, 2016.

Figure 5.7.5: Fifth iteration of the home. Author's own image, 2016.

Figure 5.7.6: Exterior perspectives of the development. Author's own image, 2016.

Figure 5.8.1: Exploded perspective of modules creating the adaptable home. Author's own image, 2016.

Figure 5.8.2: Floor plan of modules available for customisation of the home. Author's own image, 2016.

Figure 5.8.3: Section perspective of the home. Author's own image, 2016.

Figure Series 5.8.4: Perspective renders of interior of the home. Author's own image, 2016.

\section{Chapter 6 | Developed Design}

Figure Series 6.1.1: Exploration of removable façade panels. Author's own image, 2016.

Figure 6.1.2: Removable façade panel clips into CLT wall to finish the exterior of the home. Author's own image, 2016.

Figure 6.1.3: Removable façade panel facilitating growth of home. Author's own image, 2016.

Figure 6.1.4: Composition of the façade panel allows for customization of exterior cladding. Author's own image, 2016. 
Figure Series 6.1.5: Understanding CLT as a self-supporting material. Author's own image, 2016.

Figure 6.1.6: The home expands on upper levels. Author's own image, 2016.

Figure 6.1.7: Understanding the connection of new modules. Author's own image, 2016.

Figure 6.1.8: Site foundations. Author's own image, 2016.

Figure 6.1.9 Wall to roof junction detail. Author's own image, 2016.

Figure 6.1.10 Floor to foundation junction. Author's own image, 2016.

Figure 6.1.11: Wall to roof junction for pitched roofs. Author's own image, 2016.

Figure 6.1.12: First iteration of home. Author's own image, 2016.

Figure 6.1.13: Base modules completed and habitable. Author's own image, 2016.

Figure 6.1.14: Home grows to the rear and the second and third floors. Author's own image, 2016.

Figure 6.1.15: Home for multigenerational living. Author's own image, 2016.

Figure 6.1.16: The home is adaptable to most circumstances. Author's own image, 2016.

Figure 6.1.17: The plan of the home in its smallest form. Author's own image, 2016.

Figure 6.1.18: The home expands. Author's own image, 2016.

Figure 6.1.19: The home expands. Author's own image, 2016.

Figure 6.1.20: Plan of change in ownership of ground floor modules. The home expands. Author's own image, 2016.

Figure 6.1.21: Plan of ownership change at ground floor. The home expands. Author's own image, 2016.

Figure 6.1.22: Plan demonstrating multigenerational living. Author's own image, 2016.

Figure 6.1.23: Plan of upper flows of family home or studio living. Author's own image, 2016.

Figure 6.2.1: Interior perspective of living space. Author's own image, 2016.

Figure 6.2.2: The interior perspective. Author's own image, 2016.

Figure 6.2.3: The interior perspective of separation of ownership. Author's own image, 2016.

Figure 6.2.4: Perspective from the living area highlighting expansion to third floor. Author's own image, 2016.

Figure 6.2.5: Perspective of bathroom: included within the central service module for kitchen, laundry and bathroom. Author's own image, 2016.

Figure 6.2.6: An external perspective of the home. Author's own image, 2016. 
Figure 6.2.7: External perspective in context. Author's own image, 2016. 
